UNIVERSIDADE DE SÃO PAULO

FACULDADE DE ZOOTECNIA E ENGENHARIA DE ALIMENTOS

AMANDA MURAROLLI RIBEIRO

Detecção de mixosporídeos por PCR em Tempo Real e PCR Convencional em amostras de água de pisciculturas 
Detecção de mixosporídeos por PCR em Tempo Real e PCR Convencional em amostras de água de pisciculturas

\section{Versão Corrigida}

Dissertação apresentada ao Programa de PósGraduação em Zootecnia da Faculdade de Zootecnia e Engenharia de Alimentos da Universidade de São Paulo, como parte dos requisitos para a obtenção de título de Mestra em Ciências.

Área de Concentração: Qualidade e Produtividade Animal

Orientador: Prof. Dr. Antonio Augusto Mendes Maia 
Ficha catalográfica elaborada pelo

Serviço de Biblioteca e Informações, FZEA/USP, com os dados fornecidos pelo(a) autor(a)

\begin{tabular}{|c|c|}
\hline R484d & $\begin{array}{l}\text { Ribeiro, Amanda Murarolli } \\
\text { Detecção de mixosporídeos por PCR em Tempo Real e } \\
\text { PCR Convencional em amostras de água de } \\
\text { pisciculturas / Amanda Murarolli Ribeiro ; } \\
\text { orientador Professor Dr. Antonio Augusto Mendes } \\
\text { Maia. -- Pirassununga, } 2020 \text {. } \\
\quad 89 \text { f. } \\
\text { Dissertação (Mestrado - Programa de Pós-Graduação } \\
\text { em Zootecnia) -- Faculdade de Zootecnia e } \\
\text { Engenharia de Alimentos, Universidade de São Paulo. } \\
\text { 1. Myxozoa. 2. eDNA. 3. Peixes. 4. SSrDNA. 5. } \\
\text { Diagnóstico. I. Maia, Professor Dr. Antonio Augusto } \\
\text { Mendes, orient. II. Título. }\end{array}$ \\
\hline
\end{tabular}

Permitida a cópia total ou parcial deste documento, desde que citada a fonte - o autor 


\title{
Detecção de mixosporídeos por PCR em Tempo Real e PCR Convencional em amostras de água de pisciculturas
}

\author{
Dissertação apresentada ao Programa de Pós- \\ Graduação em Zootecnia da Faculdade de Zootecnia e \\ Engenharia de Alimentos da Universidade de São \\ Paulo, como parte dos requisitos para a obtenção de \\ título de Mestra em Ciências. \\ Área de Concentração: Qualidade e Produtividade \\ Animal
}

Orientador: Prof. Dr. Antonio Augusto Mendes Maia

Data da Defesa: $17 / 02 / 2020$

\section{Banca Examinadora:}

Prof. Dr.: Antonio Augusto Mendes Maia

Instituição: Faculdade de Zootecnia e engenharia de Alimentos - FZEA/USP

\section{Presidente da Comissão Julgadora}

Dr.: Paulo Sérgio Monzani

Instituição: Centro de Pesquisa e Conservação da Biodiversidade Aquática Continental CEPTA/ICMBio

Dr.: Kassia Roberta Hygino Capodifoglio

Instituição: Faculdade de Zootecnia e engenharia de Alimentos - FZEA/USP

Prof. Dra.: Juliana Naldoni

Instituição: Universidade Federal de São Paulo - UNIFESP 


\section{Dedicatória}

Dedico este trabatho a todos os meus familiares, em especial a minha mãe, Lucilena, a meu paí Odercino, responsáveís pela minha formação como pessoa e pelos inúmeros incentivos na busca dos meus objetivos. $\mathcal{A}$ meu amado fitho Matheus Kauã pela compreensão e apoío. 


\section{Agradecimentos}

Agradeço a Deus por tudo, pela presença onipotente em todos os momentos da minha vida, principalmente pela família que me destes e pela realização dos meus sonhos. Agradeço a Ele e Nossa Senhora Aparecida por todas as vitórias e conquistas alcançadas durante a minha vida;

Ao meu orientador Prof. Dr. Antônio Augusto Mendes Maia, pela orientação, por compartilhar seu conhecimento, contribuído desta forma para meu crescimento científico e intelectual;

Ao Dr. Tiago Milanin, agradeço por estar presente desde minha iniciação científica, me acompanhando em todos os procedimentos laboratoriais e pelos valiosos ensinamentos. Mesmo quando estávamos 10.596 km de distância você esteve disponível para sanar minhas dúvidas, ajudar, debater e me incentivar, contribuindo fortemente para a realização deste projeto;

À Dra. Márcia Ramos Monteiro da Silva, especialista do Laboratório de Parasitologia do Departamento de Medicina Veterinária da FZEA, pelo incentivo e principalmente pela ajuda, atuando como pesquisadora e uma grande amiga;

Ao Dr. Mateus Carriero, pela ajuda na execução e sugestões a respeito dos procedimentos do qPCR presentes nessa dissertação;

A todos os que tive e tenho o privilégio de trabalhar no laboratório de Parasitologia da FZEA-USP, com quem pude aprender, com aqueles que tiveram paciência em me ensinar e aturar os meus erros. Sou muito grata por toda a experiência que adquiri com cada um de vocês;

A minha amada família que sempre me amparou em todos os momentos da minha vida, e pelos sacrifícios que vocês fizeram em razão da minha educação; 
Ao meu irmão Gabriel Murarolli Ribeiro, pelo incentivo e por toda amizade que construímos;

Ao meu esposo Fábio Marinho, sempre me ajudando nos momentos de dificuldades e pelo companheirismo e compreensão;

A meu amado filho Matheus Kauã, compreendendo muitas vezes minha ausência para realização deste trabalho. Obrigado meu amado por tudo o que você transformou na minha vida. Essa conquista também é sua.

À Faculdade de Zootecnia e Engenharia de Alimentos, pela oportunidade de realização do curso de mestrado;

À Coordenação de Aperfeiçoamento de Pessoal de Nível Superior (CAPES) pela bolsa de estudos de mestrado para a realização desta pesquisa. 
RIBEIRO, A. M. Detecção de mixosporídeos por PCR em Tempo Real e PCR Convencional em amostras de água de pisciculturas. 2020. Dissertação (Mestrado) Faculdade de Zootecnia e Engenharia de Alimentos, Universidade de São Paulo, Pirassununga, 2020.

\section{RESUMO}

Mixosporídeos são cnidários cosmopolitas e endoparasitas obrigatórios, com cerca de 2.600 espécies descritas. Possuem um complexo ciclo biológico, caracterizado pela transmissão via esporos multicelulares. Podem ser encontrados em vários tecidos e órgãos de vertebrados, principalmente peixes, mas também em anfíbios, répteis, aves e mamíferos. Esses cnidários também são encontrados em invertebrados aquáticos (oligoquetas), estes atuam como hospedeiro definitivo e os vertebrados atuam como hospedeiros intermediário. Uma variada gama de espécies de mixosporídeos são importantes patógenos de peixes, e apresentam grande impacto econômico na aquicultura e na pesca extrativista, no mundo inteiro. No Brasil são descritas aproximadamente 140 espécies de mixosporídeos e algumas dessas em peixes nativos e de sistemas de criação têm se mostrado patogênicas ou com grande potencial para causar danos em seus hospedeiros, ocasionando impactos e prejuízos econômicos tanto na pesca quanto na aquicultura. Os métodos tradicionais de detecção desses parasitas em peixes e oligoquetas necessitam da captura dos hospedeiros, para a obtenção de cistos ou esporos e normalmente estes métodos demandam muito trabalho envolvendo uma série de etapas, e a necessidade de vários equipamentos. Ainda quando não há a presença visível de infecções ou altas taxas de mortalidades de peixes, a detecção dos parasitas pode ser dificultada. Este estudo teve como objetivo otimizar métodos para detectar a presença de DNA de mixosporídeos através da análise do SSrDNA em amostras ambientais através das técnicas de PCR Convencional (cPCR) e PCR em Tempo Real (qPCR), oferecendo métodos simples de detecção precoce, e que podem avaliar e quantificar a presença de mixosporídeos na água de pisciculturas. Foram coletadas 48 amostras de água de duas pisciculturas do interior do estado de São Paulo. As amostras contendo cada um 1 litro de água foram armazenadas em gelo e conduzidas para o laboratório. Posteriormente, as amostras foram processadas seguindo as etapas: filtração à vácuo em membrana de nitrato de celulose; extração de DNA de esporos reditos na membrana; Reação de cPCR e qPCR com primers descritos na literatura, e primers construídos para esse estudo. A metodologia utilizada para a filtração e extração de DNA mostraram-se eficientes para a obtenção de DNA de esporos de mixosporídeos presentes na água e as concentrações de DNA variaram entre 1,6 ng a 53,2 ng. A cPCR foi capaz de detectar até $0,1 \times 10^{-3} \mathrm{ng}$ de DNA e identificar 24 amostras positivas (50\%). A qPCR detectou concentrações de até $0,1 \times 10^{-4} \mathrm{ng}$ de DNA de mixosporideos e 40 amostras coletadas $(83 \%)$ foram positivas. Os resultados desse trabalho, mostraram que a qPCR é mais sensível que a cPCR sendo capaz de detectar a presença do SSrDNA de mixosporídeos em um número maior de amostras.

Palavras chaves: Myxozoa, eDNA, Peixes, SSrDNA, Diagnóstico. 
RIBEIRO, A. M. Detecção de mixosporídeos por PCR em Tempo Real e PCR Convencional em amostras de água de pisciculturas. 2020. Dissertação (Mestrado) Faculdade de Zootecnia e Engenharia de Alimentos, Universidade de São Paulo, Pirassununga, 2020.

\begin{abstract}
Myxosporeans are cnidarians, mandatory cosmopotian, endoparasites, with about 2.600 species listed. They have a complex biological cycle, characterized by transmission via multicellular spores. Myxosporeans infect a variety of tissues and vertebrate organs, mainly fish, but also amphibians, reptiles, birds and mammals. Annelids serve as the invertebrate hosts in the complex life cycle of myxosporeans. The latter are invertebrate hosts. A wide range of myxosporeans species are important fish pathogens, and present a great economic impact in aquaculture and commercial fishing worldwide. In Brazil, 140 myxosporeans species were registered. Some listed in native fish and fish farming have been shown to be pathogenic or in great potential to cause damage to their hosts, causing impacts and economic losses in both fishing and aquaculture. The current methods of detecting these parasites require the capture of hosts to obtain samples, which is toilful and time consuming. Even when there is no visible infection or high fish mortality rates, the detection of parasites can be challenging. This present study aimed to optimize methods to detect the presence of myxosporeans DNA in environmental samples using conventional PCR (cPCR) and Real-Time PCR (qPCR) techniques, offering simple methods of early detection, which can evaluate and quantify the presence of myxosporeans in fish farms water. 48 water samples were collected from two fish farms in the countryside of São Paulo state. They were stored in ice and transported to the laboratory. After, the samples were processed according to the following steps: filtration, vacuum on cellulose nitrate membrane; DNA extraction from the membrane; Reaction of Conventional PCR and Real-Time PCR with primers described in the literature, and primers built for this study. The methodology used for DNA filtration and extraction proved to be efficient for obtaining DNA from myxosporeans present in water and the DNA concentrations varied from $1.6 \mathrm{ng}$ to $53,2 \mathrm{ng}$. The cPCR was able to detect up to $0.1 \mathrm{x} \mathrm{10-3} \mathrm{ng}$ of DNA and identify 24 positive samples (50\%). The qPCR detected concentrations up to $0,1 \times 10-4 \mathrm{ng}$ of myxosporeans DNA and 40 samples collected (83\%) were positive. The results of this work showing to be more sensitive qPCR than cPCR able to detect the presence of myxosporid SSrDNA in a larger number of samples.
\end{abstract}

Keywords: Myxozoa, eDNA, Fish, SSrDNA, Diagnostic. 


\section{SUMÁRIO}

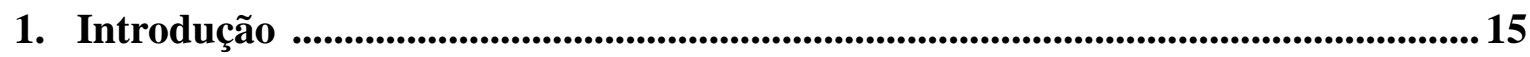

1.1 Panorama da aquicultura no Brasil ................................................................................. 16

1.2 Filo Cnidaria, Subfilo Myxozoa ........................................................................... 17

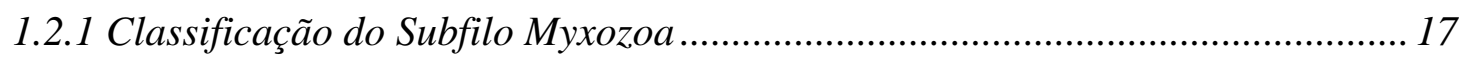

1.3 Ciclo de vida dos mixosporídeos ............................................................................................ 22

1.3.1 Hospedeiro Invertebrado - estágio actinosporo ................................................. 22

1.3.2 Hospedeiro Vertebrado - estágio mixosporo ..................................................... 23

1.4 Estudo da classe Myxosporea no Brasil ................................................................................ 23

1.5 Detecção de mixosporídeos............................................................................................................. 25

1.6 Diagnóstico de mixosporídeos a partir da água

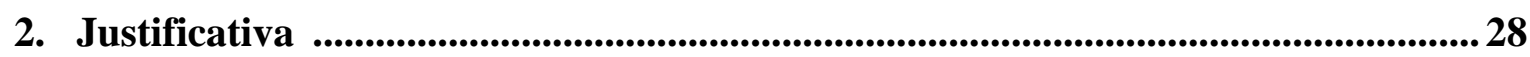

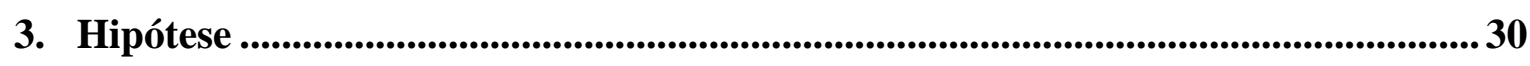

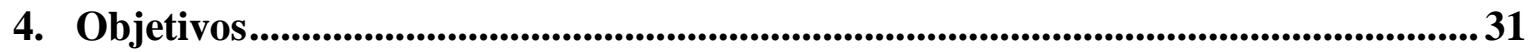

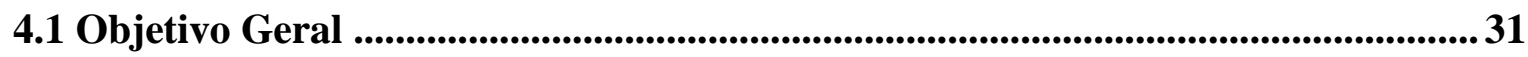

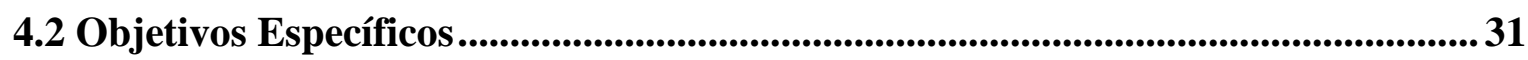

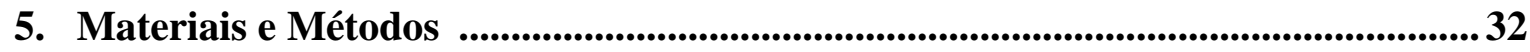

5.1 Coleta de amostras de água suspeitas em pisciculturas para análise de DNA ..... 32

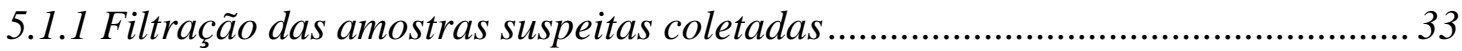

5.1.2 Extração de DNA das membranas de nitrato de celulose ................................... 34

5.2 Validação das etapas de filtração e extração de DNA com amostras-controle..... 35

5.2.1 Realização da PCR Convencional com as amostras-controle ............................ 36

5.3 Realização da PCR Convencional em amostras suspeitas.......................................... 37

5.3.1 PCR Convencional com os primers MX5 e MX3............................................. 37

5.3.1.1 Escolha dos primers para reação de PCR Convencional para amplificação de DNA das amostras suspeitas...................................................................... 37

5.3.1.2 Curva padrão para a definição do limiar de detecção de DNA com os

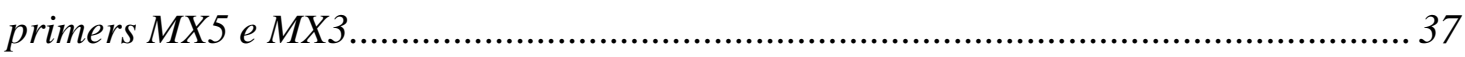

5.3.1.3 PCR Convencional com DNA das amostras suspeitas com os primers

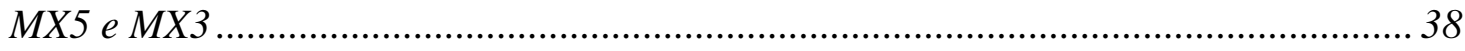

5.3.2 PCR Convencional com os primers HpelF e HpelR ......................................... 38

5.3.2.1 Escolha dos primers para reação de PCR Convencional para amplificação de DNA das amostras suspeitas....................................................................... 38 
5.3.2.2 Curva padrão para a definição do limiar de detecção de DNA com os primers HpelF e HpelR.

5.3.2.3 Especificidade dos primers HpelF e HpelR para detecção de DNA de Henneguya pellucida 39

5.3.2.4 PCR Convencional com DNA obtidos das amostras suspeitas com os primers HpelF e HpelR 39

5.4 Realização da PCR em Tempo Real em amostras suspeitas 40

5.4.1 Sistema TaqMan® 40

5.4.1.1 Curva de eficiência da reação com os primers MilF, MilR e a probe AMARO. 41

5.4.1.2 Curva padrão para definição do limiar de detecção de DNA com os primers MilF, MilR e a probe AMARO.

5.4.1.3 Realização da PCR em Tempo Real com DNA obtidos das amostras suspeitas com os primers MilF e MilR2 e a probe AMARO.

5.4.1.4 Sequenciamento de DNA das amostras suspeitas. 42

5.4.1.5 Análises das sequências obtidas 42

5.4.1.6 Estimativa do número de cópias do SSrDNA 42

5.4.2 Sistema SYBR Green ${ }^{\circledR}$ 43

5.4.2.1 Curva de eficiência da reação com os primers HpelF e HpelR 44

5.5 Primers utilizados nas reações de PCR Convencional e PCR em Tempo Real..... 44

6. Resultados 46

6.1 Coleta de amostras suspeitas, filtração e extração de DNA 46

6.2. Validação das etapas de filtração e extração de DNA com as amostras-controle 47

6.2.1 Realização da PCR Convencional com as amostras-controle ..... 47

6.2.2 Sequenciamento e análise das sequências obtidas das amostras-controle .......... 47

6.3. Realização da PCR Convencional em amostras suspeitas ..................................... 48

6.3.1 PCR Convencional com os primers MX5 e MX3. 48

6.3.1.1 Curva padrão para a definição do limiar de detecção de DNA com os primers $M X 5$ e $M X 3$...

6.3.1.2 PCR Convencional com DNA das amostras suspeitas com os primers MX5 e MX3 49 
6.3.2.1 Curva padrão para a definição do limiar de detecção de DNA com os

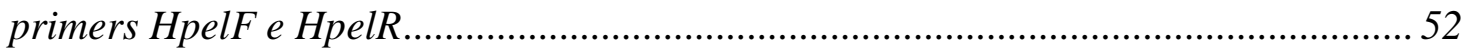

6.3.2.2 Especificidade dos primers HpelF e HpelR para detecção de DNA de Henneguya pellucida

6.3.2.3 PCR Convencional com DNA das amostras suspeitas com os primers

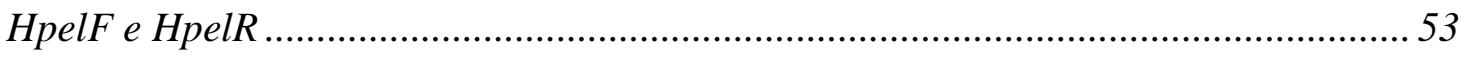

6.4 Realização da PCR em Tempo Real em amostras suspeitas .................................... 55

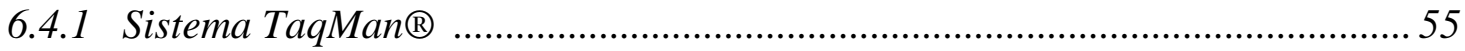

6.4.1.1 Curva de eficiência da reação com os primers MilF, MilR e a probe

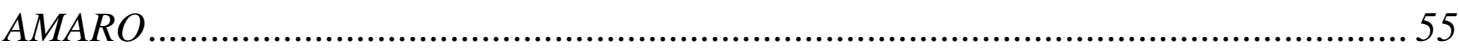

6.4.1.2 Curva padrão para definição do limiar de detecção de DNA com os primers MilF, MilR e a probe AMARO ....................................................................... 57

6.4.1.3 Realização da PCR em Tempo Real com DNA obtidos das amostras suspeitas com os primers MilF e MilR2 e a probe AMARO....................................... 58

6.4.1.3.1 Amostras suspeitas coletas no CEPTA na cidade de Pirassununga, SP, Brasil............................................................................................ 58

6.4.1.3.2 Amostras suspeitas coletas na psicultura da cidade de Porto

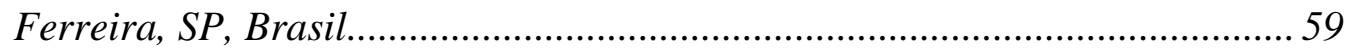

6.4.1.4 Sequenciamento e análise das sequências obtidas de DNA das amostras suspeitas.

6.4.1.5 Estimativa do número de cópias do SSrDNA .................................... 62

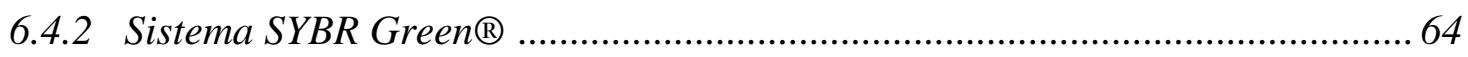

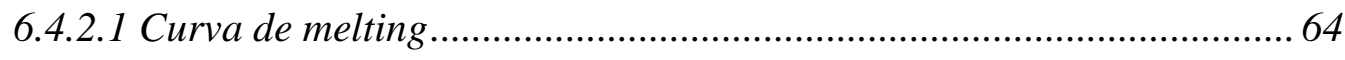

6.4.2.1 Curva de eficiência da reação com os primers HpelF e HpelR ........... 65

6.4 Comparação entre as técnicas de PCR Convencional e PCR em Tempo rela para detecção de DNA de mixosporídeos em amostras de água suspeitas coletadas em

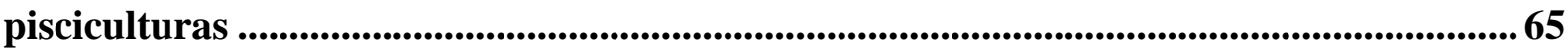

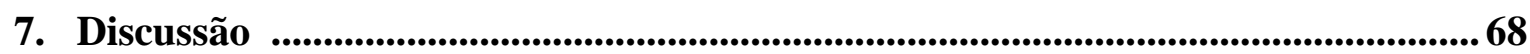

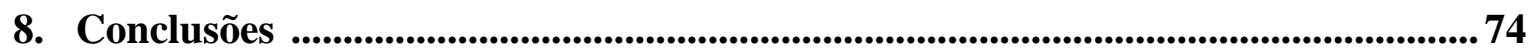

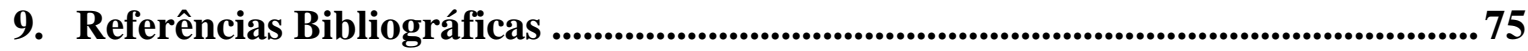




\section{LISTA DE FIGURAS}

Figura 1. Representações esquemáticas de parasitas da Classe Myxosporea "estágio mixosporo". A. Myxobolus muelleri B. Henneguya psorospermica e "estágio actinosporo" C. Hexactinomyxon D. Raabeia. Editado a partir de Lom \& Dyková, 2006. yxosporea "estágio mixosporo". A. Myxobolus muelleri, Bütschli, 1882; B. Henneguya psorospermica, Thélohan, 1892; "estágio actinosporo" C. Hexactinomyxon (tipo psammoryctis Štolc, 1899) D. Raabeia (tipo magna Janiszewska, 1957). Editado a partir de Lom \& Dyková, 2006).

Figura 2. Ciclo de vida dos mixosporídeos A. Peixe infectado (hospedeiro vertebrado) B. Mixosporo liberado na água pelo peixe. C. Oligoqueta (hospedeiro invertebrado) D. Actinosporo liberado na água pelo oligoqueta. Editado a partir de ATKINSON, 2011.

Figura 3. Coleta de amostras de água em um sistema de criação de peixes no município de

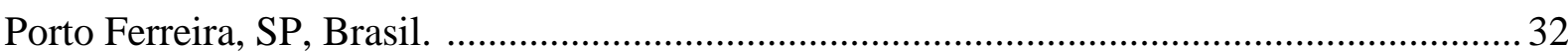

Figura 4. Sistema completo de filtração à vácuo de $500 \mathrm{~mL}$

Figura 5. Representação esquematizada da localização dos primers e probe utilizados para amplificação e sequenciamento do SSrDNA na cPCR e qPCR.

Figura 6. Eletroforese em gel de agarose 1,5\% corado com SyBr Safe A. Marcador de Peso Molecular $1 K b$. (1100 pares de bases); B. Produto de PCR do controle 1; C. Produto de PCR do controle 2; D. Controle Negativo.

Figura 7. Pesquisa BLASTn com a sequência obtida para a amostra-controle 1 48

Figura 8. Eletroforese em gel de agarose 1,5\% corado com SyBr Safe; A. Marcador de Peso Molecular $1 K b$.; 1. ao 6. Pontos da curva padrão da cPCR com os primers MX5 e MX3 em diluições de DNA controle variando de $1 \mathrm{ng}$ a $0,1 \times 10^{-4} \mathrm{ng} ; \mathbf{1} .1 \mathrm{ng}$ de DNA de H. pellucida; 2. $0,1 \mathrm{ng}$ de DNA de $H$. pellucida; 3. $0,1 \times 10^{-1} \mathrm{ng}$ de DNA de $H$. pellucida; 4. $0,1 \times 10^{-2} \mathrm{ng}$ de DNA de $H$. pellucida; 5. $0,1 \times 10^{-3} \mathrm{ng}$ de DNA de $H$. pellucida; 6. $0,1 \times 10^{-4} \mathrm{ng}$ de DNA de $H$. pellucida; B. Contorole Negativo

Figura 9. Eletroforese em gel de agarose 1,5\% corado com $\mathrm{SyBr}$ Safe do produto de cPCR das amostras suspeitas coletadas no CEPTA com os primers MX5 e MX3; A. Marcador de Peso Molecular $1 K b$.; 1. a 12. Produto de PCR com DNA das amostras água suspeitas coletadas no CEPTA; B. Controle Negativo

Figura 10. Eletroforese em gel de agarose 1,5\% corado com SyBr Safe do produto de cPCR das amostras suspeitas coletadas no CEPTA com os primers MX5 e MX3; A. Marcador de Peso Molecular $1 K b$; 13. a 24. Produto de PCR com DNA das amostras água suspeitas coletadas no CEPTA; B. Controle Negativo 50

Figura 11. Eletroforese em gel de agarose 1,5\% corado com $\mathrm{SyBr}$ Safe, do produto de cPCR das amostras suspeitas coletadas na piscicultura de Porto Ferreira com os primers MX5 e MX3; A. Marcador de Peso Molecular $1 K b$.; 1. a 12. Produto de PCR com DNA das amostras água suspeitas coletadas na piscicultura da cidade de Porto Ferreira; B. Controle Negativo. 
Figura 12. Eletroforese em gel de agarose 1,5\% corado com $\mathrm{SyBr}$ Safe, do produto de cPCR das amostras suspeitas coletadas na piscicultura de Porto Ferreira com os primers MX5 e MX3; A. Marcador de Peso Molecular $1 K b . ; 13$. a 24. Produto de PCR com DNA das amostras água suspeitas coletadas na piscicultura da cidade de Porto Ferreira; B. Controle Negativo.

Figura 13. Eletroforese em gel de agarose 1,5\% corado com SyBr Safe; A. Marcador de Peso Molecular $1 K b$.; 1. ao 6. Pontos da curva padrão da cPCR com os primers HpelF e HpelR em diluições de DNA controle variando de $1 \mathrm{ng}$ a $0,1 \times 10^{-4} \mathrm{ng} ; \mathbf{1} .1 \mathrm{ng}$ de DNA de H. pellucida; 2. $0,1 \mathrm{ng}$ de DNA de H. pellucida; 3. $0,1 \times 10^{-1} \mathrm{ng}$ de DNA de H. pellucida; 4. $0,1 \times 10^{-2} \mathrm{ng}$ de DNA de $H$. pellucida; 5. $0,1 \times 10^{-3} \mathrm{ng}$ de DNA de $H$. pellucida; 6. $0,1 \times 10^{-4} \mathrm{ng}$ de DNA de $H$. pellucida; B. Contorole Negativo.

Figura 14. Gel de agarose 1,5\% corado com SyBr Safe; A. Marcador de Peso Molecular $1 \mathrm{~Kb}$.; B. Produto de PCR com DNA de actinosporo (Aurantiacnomyxon tipo 1); C. Produto de PCR com DNA de mixosporo (Myxobolus macroplasmodialis); D. Controle Negativo; E. Produto de PCR com DNA de $H$. pellucida.

Figura 15. Eletroforese em gel de agarose 1,5\% na presença de $\mathrm{SyBr}$ Safe, do produto de cPCR das amostras suspeitas do CEPTA com os primers HpelF e HpelR; A. Marcador de Peso Molecular $1 K b$; 1. a 12. Produto de PCR com DNA das amostras água suspeitas coletadas no CEPTA; B. Controle Negativo.

Figura 16. Gráfico da curva padrão de eficiência da reação com os primers MilF, MilR2 e probe AMARO, na qPCR utilizando como alvo DNA de actinosporos em diluições de 3,8 a 3,8 x $10^{-5}$ cópias de DNA

Figura 17. Gráfico da curva padrão para definição do limiar de detecção de DNA de mixosporídeos com os primers MilF e MilR2 com a probe AMARO, utilizando como alvo DNA de Henneguya pellucida em diluições de 0,1 a $0,1^{\times} 10^{-5}$ ng de DNA...... 58

Figura 18. Comparação da sequência da amostra CE 9, através do algoritmo Basic Local Alignment Search Tool Nucleotide (BLASTn), com outras sequências depositadas no GenBank

Figura 19. Comparação da sequência da amostra CE 10, através do algoritmo Basic Local Alignment Search Tool Nucleotide (BLASTn), com outras sequências depositadas no GenBank

Figura 20. Comparação da sequência da amostra CE 13, através do algoritmo Basic Local Alignment Search Tool Nucleotide (BLASTn), com outras sequências depositadas no GenBank

Figura 21. Comparação da sequência da amostra CE 21, através do algoritmo Basic Local Alignment Search Tool Nucleotide (BLASTn), com outras sequências depositadas no GenBank

Figura 22. Gráfico da análise da curva de melting os primers HpelF e HpelR utilizando como alvo DNA de Hennuguya pellucida.

Figura 23. Gráfico da curva padrão de eficiência da reação com os primers HpelF e HpelR, utilizando como alvo DNA de Henneguya pellucida em diluições de 0,1 a $0,1^{\text {× }} 10^{-5}$ ng de DNA 


\section{LISTA DE TABELAS}

Tabela 1. Estimativa para a produção de peixes, projeção de crescimento de 2016 para 2030. (http://www.fao.org/3/I9540EN/i9540en.pdf).

Tabela 2. Sequência de primers e probe utilizados para amplificação e sequenciamento do SSrDNA na cPCR e qPCR deste estudo.

Tabela 3. Concentração de DNA extraído das amostras de água coletadas das pisciculturas do CEPTA (CE) e de Porto Ferreira (PF) em ng/ $\mu \mathrm{L}$

Tabela 4. Resultados das cPCR com os conjuntos de primers MX5 - MX3 e HpelF - HpelR das 48 amostras suspeitas de DNA coletadas nas pisciculturas do CEPTA (CE) e Porto Ferreira (PF)

Tabela 5. Resultado da eficiência da reação com os primers MilF, MilR2 e probe AMARO, na qPCR utilizando como alvo DNA de actinosporos (pool de 150 actinosporos) em diluições de 3,8 a $3,8^{\times} 10^{-5}$ ng de DNA

Tabela 6. Curva padrão para definição do limiar de detecção de DNA de mixosporídeos com os primers MilF, MilR2 e a probe AMARO, utilizando como alvo DNA de Henneguya pellucida em diluições de 0,1 a $0,1^{\times} 10^{-5} \mathrm{ng}$ de DNA

Tabela 7. Resultados das reações de PCR em Tempo Real com os primers MilF, MilR2 e a probe AMARO, utilizando o DNA das amostras suspeitas coletadas no CEPTA (CE): Ct médio das duplicatas; números de cópias do SSrDNA; diagnóstico final

Tabela 8. Resultados das reações de qPCR com os primers MilF, MilR2 e a probe AMARO, utilizando o DNA das amostras suspeitas coletadas em Porto Ferreira (PF): Ct médio das duplicatas, números de cópias do SSrDNA, diagnóstico final

Tabela 9. Resultados do valor total em ng de DNA das amostras suspeitas e a estimativa do número de cópias do SSrDNA presentes em cada litro de água suspeita coletada nas pisciculturas

Tabela 10. Comparação dos resultados da PCR Convencional e a PCR em Tempo Real com todas as 48 amostras de DNA coletadas nas psiculturas 66 


\section{Introdução}

A aquicultura é um dos sistemas de produção de alimentos de origem animal que mais vem se expandido mundialmente. Para a Organização das Nações Unidas para a Agricultura e Alimentação - FAO, a aquicultura é a atividade que envolve o cultivo de organismos aquáticos, incluindo peixes, moluscos, crustáceos e plantas (FAO, 1997). Conforme o tipo de organismo envolvido, a aquicultura recebe diferentes denominações, como piscicultura (criação de peixes), carcinicultura (criação de camarões), ranicultura (criação de rãs) e malacocultura (criação de moluscos) (SCORVO FILHO, 2009).

A pesca é uma atividade baseada no extrativismo e no uso dos recursos naturais, enquanto a aquicultura é a atividade controlada pelo homem com o objetivo de exploração produtiva econômica e financeira. A produção de pescado, que por muitos anos teve sua origem da pesca extrativista, vem, nas últimas décadas, passando por uma estagnação, sobretudo pela explotação dos estoques pesqueiros. Com a queda do setor pesqueiro extrativo, o rápido crescimento da aquicultura tem sido a forma de acompanhar a alta demanda do consumo de pescado mundial (SEBRAE, 2008).

A piscicultura é o setor da aquicultura de maior importância econômica. Segundo o Sebrae (2015), a piscicultura envolve, comercialmente, a criação de peixes em tanques, lagoas, lagos, rios e oceanos, geralmente destinados a alimentação.

Nas últimas décadas, a demanda por pescado tem crescido significativamente como consequência do crescimento populacional e do aumento da procura por proteína de alto valor nutricional (BRABO et al., 2016; FAO, 2014; MERINO et al., 2012). Os peixes são uma excelente fonte de proteína animal e de outros nutrientes essenciais, contribuindo para a segurança alimentar em numerosas regiões. Em termos per capita, o consumo de peixe comestível global aumentou de 9,0 kg em 1961 para 20,2 kg em 2015, uma taxa média de aproximadamente 1,5\% ao ano. Novos avanços ocorreram nos anos de 2016 e 2017, aumentando o consumo mundial para $20,3 \mathrm{~kg}$ e 20,5 kg, respectivamente (FAO, 2016).

Estima-se que, em 2030, a aquicultura atingirá 109 milhões de toneladas. Espera-se que o maior crescimento na produção de alimentos será originário da aquicultura. Desta forma, provavelmente, a atividade dominará a futura oferta global de pescado (SCHULTER \& VIEIRA FILHO, 2017). Nesse contexto, quando comparados com outras partes do mundo, 
a América Latina e o Caribe estarão entre as regiões com maior crescimento da aquicultura, $24,2 \%$ entre 2016 e 2030. A estimativa de crescimento da aquicultura neste mesmo período para o Brasil será de 89\%, ou seja, 1097 toneladas em 2030 (Tabela 1).

Tabela 1. Estimativa para a produção de peixes, projeção de crescimento de 2016 para 2030. (http://www.fao.org/3/I9540EN/i9540en.pdf).

\begin{tabular}{|c|c|c|c|c|c|c|}
\hline \multirow{3}{*}{ Region/country } & \multicolumn{3}{|c|}{ Fisheries and aquaculture } & \multicolumn{3}{|c|}{ Aquaculture } \\
\hline & \multicolumn{2}{|c|}{$\begin{array}{c}\text { Production } \\
\text { (1 } 000 \text { tonnes) }\end{array}$} & \multirow{2}{*}{$\begin{array}{c}\text { Growth, } \\
2016 \text { to } \\
2030 \\
(\%)\end{array}$} & \multicolumn{2}{|c|}{$\begin{array}{l}\text { Production } \\
\text { (1 } 000 \text { fonnes) }\end{array}$} & \multirow{2}{*}{$\begin{array}{c}\text { Growth, } \\
2016 \text { to } \\
2030 \\
(\%)\end{array}$} \\
\hline & 2016 & 2030 & & 2016 & 2030 & \\
\hline Asia & 121776 & 144666 & 18.8 & 71546 & 97165 & 35.8 \\
\hline China & 66808 & 79134 & 18.4 & 49244 & 64572 & 31.1 \\
\hline India & 10762 & 13407 & 24.6 & 5700 & 8212 & 44.1 \\
\hline Indonesia & 11492 & 15158 & 31.9 & 4950 & 8253 & 66.7 \\
\hline Japan & 3872 & 3427 & -11.5 & 677 & 745 & 10.1 \\
\hline Philippines & 2821 & 3229 & 14.4 & 796 & 1085 & 36.3 \\
\hline Republic of Korea & 1894 & 1831 & -3.3 & 508 & 632 & 24.4 \\
\hline Thailand & 2493 & 2757 & 10.6 & 963 & 1305 & 35.6 \\
\hline Viet Nam & 6410 & 8087 & 26.1 & 3625 & 5085 & 40.3 \\
\hline Africa & 11260 & 13556 & 20.4 & 1982 & 3195 & 61.2 \\
\hline Egypt & 1706 & 2657 & 55.7 & 1371 & 2302 & 68.0 \\
\hline Morocco & 1448 & 1712 & 18.2 & 1 & 2 & 33.3 \\
\hline Nigeria & 1041 & 1231 & 18.2 & 307 & 418 & 36.2 \\
\hline South Africa & 618 & 590 & -4.5 & 5 & 6 & 1.9 \\
\hline Europe & 16644 & 17954 & 7.9 & 2945 & 3953 & 34.2 \\
\hline European Union & 6463 & 7025 & 8.7 & 1292 & 1664 & 28.8 \\
\hline Norway & 3360 & 3909 & 16.3 & 1326 & 1719 & 29.6 \\
\hline Russian Federation & 4932 & 5244 & 6.3 & 173 & 291 & 67.9 \\
\hline North America & 6703 & 6470 & -3.5 & 645 & 744 & 15.4 \\
\hline Canada & 1063 & 1099 & 3.5 & 201 & 249 & 24.2 \\
\hline United States of America & 5364 & 5371 & 0.1 & 444 & 495 & 11.4 \\
\hline Latin America and Caribbean & 12911 & 16035 & 24.2 & 2703 & 4033 & 49.2 \\
\hline Argentina & 759 & 853 & 12.4 & 4 & 4 & 3.4 \\
\hline Brazil & 1286 & 1885 & 46.6 & 581 & 1097 & 89.0 \\
\hline Chile & 2535 & 3665 & 44.6 & 1035 & 1309 & 26.4 \\
\hline Mexico & 1732 & 1993 & 15.1 & 221 & 316 & 42.6 \\
\hline Peru & 3897 & 4450 & 14.2 & 100 & 221 & 120.9 \\
\hline Oceania & 1640 & 1973 & 20.3 & 210 & 299 & 42.1 \\
\hline Australia & 269 & 289 & 7.3 & 97 & 151 & 55.7 \\
\hline New Zealand & 532 & 560 & 5.3 & 109 & 143 & 31.0 \\
\hline World & 170941 & 200955 & 17.6 & 80031 & 109391 & 36.7 \\
\hline Developed countries & 28050 & 28720 & 2.4 & 4498 & 5762 & 28.1 \\
\hline Developing countries & 142885 & 172235 & 20.5 & 75532 & 103630 & 37.2 \\
\hline Least developed countries & 12978 & 14434 & 11.2 & 3749 & 5487 & 46.3 \\
\hline
\end{tabular}

\subsection{Panorama da aquicultura no Brasil}

Dentre os países que se destacam como grandes produtores, o Brasil vem mostrando grande notoriedade, pois apresenta condições excepcionais para o desenvolvimento das mais diversas modalidades aquícolas, destacando-se dentre os países da América do Sul, visto que o país conta com características favoráveis ao desenvolvimento da aquicultura. São mais de 8,4 mil 
quilômetros de costa marítima, 5,5 milhões de hectares de reservatórios de água doce em reservatórios naturais e artificiais, aproximadamente $12 \%$ da água doce disponível no planeta, clima favorável (quente o ano todo) na maior parte do país, vasta extensão territorial, mão de obra relativamente abundante, além de um crescente mercado interno e grande diversidade de espécies de peixes nativas com potencial para serem criadas em cativeiros (CASTAGNOLLI, 1992; HALWART et al., 2007; ONO \& KUBITZA, 1999). Esses atributos, juntamente com a meta do Ministério da Pesca e Aquicultura, de incentivar a produção nacional para se tornar um dos maiores produtores do mundo, credenciam o Brasil a ser um dos poucos a alargar a demanda na produção mundial de pescado (FAO, 2016; MPA, 2012).

No entanto, o aumento significativo das atividades relacionadas à aquicultura, expande também as preocupações com a sanidade dos peixes, problemas causados por organismos patógenos podem causar amplos prejuízos econômicos para a atividade aquícola (ANTONELLI, 2010). A sanidade é um dos aspectos mais relevantes para a criação comercial de qualquer espécie de peixe, altas densidades de estocagens, problemas de manejo, má qualidade da água, questões nutricionais entre outros fatores podem refletir na homeostasia dos organismos aquáticos, predispondo-os ao ataque de organismos patogênicos (KUBTIZA, 2000; RÜCKERT et al., 2008).

Os peixes podem ser acometidos por uma variedade de agentes patogênicos, como vírus, bactérias, fungos e parasitas de diversos grupos taxonômicos (AUSTIN \& NEWAJ-FYZUL, 2017; LUQUE, 2004), infectando a superfície externa e/ou interna dos hospedeiros, podendo afetar o seu desenvolvimento tanto em ambientes naturais como em sistemas de criação.

Neste contexto, os parasitas são frequentemente reportados como sérias ameaças à aquicultura, pois são as maiores causas de perdas econômicas em peixes, podendo desencadear surtos epizoóticos graves e dizimar criações inteiras (COMBES, 1990; EIRAS et al., 2004; JOHNSON et al., 2004; ROBERTS, 2012).

Dentre os parasitas de organismos aquáticos, os mixosporídeos (subfilo Myxozoa) se destacam, não apenas pelas espécies patogênicas, mas também pela diversidade de espécies, complexo ciclo biológico e pela sua controversa história taxonômica e evolutiva (OKAMURA et al., 2015a).

\subsection{Filo Cnidaria, Subfilo Myxozoa}

\subsubsection{Classificação do Subfilo Myxozoa}


Cnidários são invertebrados amplamente reconhecidos por sua importância ecológica e econômica, contribuindo para a qualidade de vida, além de serem representantes típicos de ambientes marinhos e de água doce. Até recentemente, todos os cnidários eram considerados animais de vida livre, no entanto, agora está claro, que um clado de cnidários divergiu nos tempos antigos para se tornarem endoparasitas que hoje compõem o Subfilo Myxozoa parasitas comuns e ocasionalmente altamente problemáticos de peixes conhecidos desde o século XIX (OKAMURA et al., 2015). O Subfilo Myxozoa engloba duas classes de parasitas, a Classe Myxosporea (mixosporídeos) e a Classe Malacosporea (malacosporídeos), e atualmente compõem cerca de $18 \%$ da diversidade de espécies cnidárias.

A Classe Malacosporea alberga apenas uma pequena fração da diversidade de Myxozoa existentes, que, atualmente, conta com cinco espécies descritas (OKAMURA et al., 2015b). A espécie Tetracapsuloides bryosalmona Canning, Curry, Feist, Longshaw e Okamura, 1999, destaca-se pelo seu potencial patogênico, causando uma doença renal proliferativa generalizada e altas taxas de mortalidade induzida em salmonídeos do continente europeu (OKAMURA et al., 2011).

A Classe Myxosporea, por outro lado, compreende a vasta maioria das espécies de Myxozoa atualmente conhecidas (BARTOŠOVA-SOJKOVA et al., 2014), e seus membros infectam vários tecidos e órgãos de vertebrados, principalmente os peixes, mas também outros vertebrados, como anfíbios, répteis, aves e mamíferos (BARTHOLOMEW et al., 2008; FEIST \& LONGSHAW 2006; MORRIS 2012; PRUNESCU et al., 2007). Várias espécies de mixosporídeos são importantes patógenos de peixes e apresentam grande impacto econômico na aquicultura e na pesca comercial (FEIST \& LONGSHAW, 2006; OKAMURA et al., 2015b).

O primeiro registro de Myxozoa foi no início do século XIX, quando Jurine Müller, em 1838, encontrou cistos na musculatura de Coregonus fera, e, desde sua descoberta, há mais de 180 anos, os mixosporídeos têm sido frequentemente comparados aos cnidários. Apesar dessas observações, estes inicialmente foram classificados por muito tempo entre táxons protistas (OKAMURA et al., 2015a). Inúmeros avanços ocorreram para a compreensão fundamental dos aspectos da história de vida dos mixosporídeos e foram alcançados ao longo dos anos. Atualmente, os mixosporídeos pertencem a um amplo grupo de endoparasitas obrigatórios microscópicos que foram recentemente reconhecidos como um grupo irmão dos medusozoários no Filo Cnidaria (CHANG et al., 2015; JIMENEZ-GURI et al., 2007). Estima-se que os mixosporídeos tenham divergido dos cnidários de vida livre durante a era cambriana (KODÁDKOVÁ et al., 2015) e hoje estão entre os parasitas de peixes mais comuns. 
Várias espécies de mixosporídeos são importantes patógenos da ictiofauna, dentre as quais incluem-se endoparasitas caracterizados por um ciclo de vida envolvendo obrigatoriamente dois hospedeiros: Os vertebrados (principalmente peixes) atuam como hospedeiros intermediários; e organismos invertebrados (principalmente anelídeos) como hospedeiros definitivos. Os parasitas desse subfilo são microscópicos, multicelulares, formadores de esporos e encontrados tanto em ambientes marinhos como de água doce (LOM \& DYKOVÁ, 2006; OKAMURA et al., 2015a). Possuem como caráter morfológico diferencial a presença de cápsulas polares, que são estruturas análogas aos nematocistos dos cnidários (ATKINSON, 2011). Estas estruturas contêm filamentos polares usados para invasão do hospedeiro (BEMDAVID et al., 2016; FENG et al., 2014). A seguir encontra-se a atual classificação do Subfilo Myxozoa proposta por Okamura et al., 2015b:

\section{Filo: Cnidaria}

Subfilo: Myxozoa

Classe: Myxosporea

Ordem: Bivalvulida

Subordem: Variisporina

Família Sphaeromyxidae: Sphaeromyxa

Família Myxidiidae: Myxidium, Zschokkella, Enteromyxum, Sigmomyxa, Soricimyxum, Cistodiscus

Família Ortholineidae: Ortholinea, Neomyxobolus, Cardimyobolus, Triangula, Kentmoseria Família Sinuolineidae: Sinuolinea, Myxodaviísia, Myxoproteus, Bipteria, Bipteria, Paramyxoproteus, Neobipteria, Schulmania Noblea, Latypora

Família Fabesporidae: Fabespora

Família Ceratomyxidae: Ceratomyxa, Meglitschia, Ellipsomyxa, Ceratonova

Família Sphaesporidae: Sphaerospora, Wardia, Palliatus

Família Myxobilatidae: Myxobilatus, Acauda, Hoferellus

Família Chloromyxidae: Chloromyxum, Caudomyxum, Agarella

Família Coccomyxidae: Coccomyxa, Auerbachia, Globospora

Família Alatosporidae: Alatospora, Pseudalatospora, Renispora

Família Parvicapsulidae: Parvicapsula, Neoparvicapsula, Gadimyxa

Subordem Platysporina 
Família Myxobolidae: Myxobolus, Spirosuturia, Unicauda, Dicauda, Phlogospora, Laterocaudata, Henneguya, Hennegoides, Tetrauronema, Thelohanellus, Neothelohanellus, Neohenneguya, Trigonosporus

Ordem Multivalvulida

Família Trilosporidae: Trilospora, Unicapsula

Família Kudoidae: Kudoa

Família Spinavaculidae: Octospina Incertae sedis em Multivalvulida: Trilosporoides

Consideráveis avanços foram alcançados para a compreensão fundamental dos aspectos da história de vida dos mixosporídeos. Historicamente, os parasitas encontrados em oligoquetas, eram incluídos na Classe Actinosporea, e aqueles encontrados em peixes, eram pertencentes a Classe Myxosporea. Wolf e Markiw, ao estudarem o mecanismo de transmissão de Myxobolus cerebralis Hofer, 1903, que é a espécie mundialmente mais conhecida, mostraram que o parasita alterna entre o hospedeiro vertebrado, salmonídeos e um hospedeiro invertebrado, o oligoqueta Tubifex tubifex Müller, 1774 e a partir deste estudo inicial e de outros estudos realizados posteriormente, constatou que os parasitas das classes Myxosporea e Actinosporea representavam, na realidade, estágios distintos do ciclo de vida do mesmo parasita (MARKIW \& WOLF, 1983; WOLF E MARKIW, 1984).

Sendo assim, a Classe Actinosporea foi extinta, e, com a finalidade de facilitar a compreensão entre aqueles que estudam os parasitas da Classe Myxosporea, acordou-se em usar os termos "estágio actinosporo" para as formas encontradas nos hospedeiros invertebrados e "estágio mixosporo" para as formas encontradas no hospedeiro vertebrado (FEIST \& LONGSHAW, 2006) (Figura 1). 
Figura 1. Representações esquemáticas de parasitas da Classe Myxosporea "estágio mixosporo". A. Myxobolus muelleri B. Henneguya psorospermica e "estágio actinosporo" C. Hexactinomyxon D. Raabeia. Editado a partir de Lom \& Dyková, 2006.

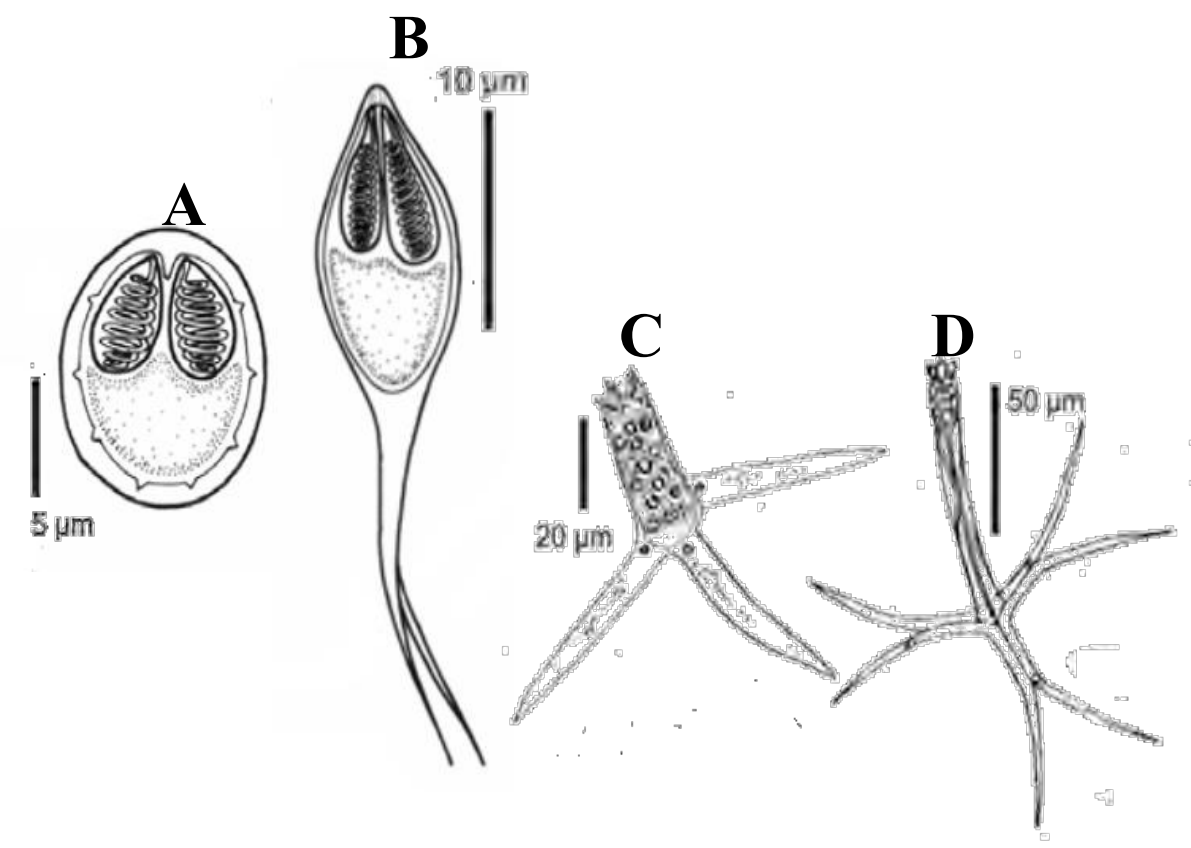

Desenvolvimentos em biologia molecular forneceram novas provas evidenciando que os Myxozoa pertencem ao Filo Cnidaria (JIMÉNEZ-GURI et al., 2007). No novo contexto da organização do Filo Cnidaria, os endoparasitas do subfilo Myxozoa correspondem a cerca de $18 \%$ do total de espécies, com diversidade superior àquela observada em Cubozoa e Scyphozoa juntos (OKAMURA et al., 2015b). Fortes afinidades estruturais de longa data e dados genômicos levaram ao reconhecimento de que os Myxozoa são um subfilo dentro do Filo Cnidaria (EVANS et al., 2008; NESNIDAL et al., 2013; OKAMURA et al., 2015a).

Atualmente, são conhecidas aproximadamente 2.600 espécies de mixosporídeos, (OKAMURA et al., 2018), distribuídas em 60 gêneros, que infectam a ictiofauna em ecossistemas marinhos e dulciaquícolas em todos os continentes. Dentre os principais gêneros, pode-se destacar Hennneguya Thélohan, 1892 e Myxobolus Butschli, 1882 (BARTOSOVÁSOJKOVÁ et al., 2014; FIALA et al., 2015; OKAMURA et al., 2015a; WHIPPS, 2015).

Embora muitos mixosporídeos tenham estabelecido relações benignas e assintomáticas com seus hospedeiros, algumas espécies causam doenças devastadoras nas populações de peixes de ambientes naturais e de criação. São considerados uma ameaça emergente para as populações de peixes, pois infectam uma grande variedade de espécies economicamente importantes (FEIST \& LONGSHAW, 2006), incluindo o salmão (HALLETT \& BARTHOLOMEW 2012), 
trutas (LONGSHAW et al., 2002), peixe-gato (POTE et al., 2000), maruca (FLEURANCE et al., 2008) e a carpa (YOKOYAMA, 1997).

A espécie mais popular é Myxobolus cerebralis conhecido por ser o agente etiológico da "doença do rodopio", uma patologia geralmente fatal que acomete jovens salmonídeos, provocando altas taxas de mortalidade (FEIST \& LONGSHAW, 2006). Além de M. cerebralis, várias outras espécies de mixosporídeos foram relatadas causando importantes danos a diversas espécies de peixes: Ceratomyxa shasta Noble, 1950, que é um parasita comum em salmonídeos da América do Norte, responsável por alta taxa de mortalidade em salmões juvenis nos estados da Califórnia e do Oregon (ATKINSON, 2011; BARTHOLOMEW \& LOTAN, 2010). A espécie Henneguya ictaluri Pote, Hanson e Shivaji, 2000, causa a doença proliferativa das brânquias em Ictalurus punctatus Rafinesque, 1818, e é considerada a mais importante doença para o catfish, resultando em altas taxas de mortalidade em exemplares jovens em sistemas de criação no Sul dos Estados Unidos (FEIST \& LONGSHAW, 2006; GRIFFIN et al., 2008). A espécie Parvicapsula sp. infecta as brânquias, fígado e rins de salmão do atlântico Salmo salar Linnaeus, 1758. A espécie Enteromyxum scophthalmi Palenzuela, Redondo e Alvarez-Pellitero, 2002, infecta o trato digestivo, estômago e reto de Psetta maxima Linnaeus, 1758, em pisciculturas do noroeste da Espanha, induzindo a alta resposta inflamatória e causando necrose tecidual, com elevada mortandade (BERMÚDEZ et al., 2010).

\subsection{Ciclo de vida dos mixosporídeos}

O ciclo de vida dos mixosporídeos é complexo e envolve alternância entre hospedeiros vertebrados e invertebrados (ATKINSON, 2011; FIALA et al., 2015). A transmissão entre hospedeiros ocorre através de dois estágios morfologicamente distintos: O estágio mixosporo em hospedeiros vertebrados e o estágio actinosporo em hospedeiros invertebrados (Figura 2).

\subsubsection{Hospedeiro Invertebrado - estágio actinosporo}

O desenvolvimento do parasita mixosporídeo no hospedeiro invertebrado inicia-se pela ingestão de mixosporos livres no meio aquático. O mixosporo ingerido pelo oligoqueta libera filamentos polares que, quando em contato com o epitélio intestinal, ancoram-se para maior fixação. As valvas dos mixósporos se abrem, liberando o esporoplasma, que penetram nas células epiteliais do intestino do anelídeo. Após a liberação do esporoplasma, ocorrem divisões celulares para a formação de novos parasitas. Este processo é considerado a fase sexual do ciclo biológico do parasita dentro do hospedeiro invertebrado. Este estágio serve de fonte de infecção para peixes, dando continuidade ao ciclo biológico (MILANIN, 2015b). 


\subsubsection{Hospedeiro vertebrado - estágio mixosporo}

Os actinosporos livres na água entram em contato com a superfície do hospedeiro vertebrado. O parasita no hospedeiro vertebrado está sujeito a seguir vários caminhos, como pela circulação ou migração intercelular, até atingir o tecido alvo; este caminho é dependente da espécie do parasita. No momento em que o parasita alcança o tecido alvo, ocorre o seu desenvolvimento, iniciando-se divisões celulares originando a formação de plasmódios, que contêm em seu interior os mixosporos. Os mixosporos desenvolvidos no hospedeiro vertebrado apresentam morfologia distinta dos actinosporos que se desenvolvem no hospedeiro invertebrado. Os mixosporos maduros após o rompimento do plasmódio, com a morte do hospedeiro, são liberados na água, iniciando-se, assim, um novo ciclo biológico (MILANIN, 2015b).

Figura 2. Ciclo de vida dos mixosporídeos A. Peixe infectado (hospedeiro vertebrado) B. Mixosporo liberado na água pelo peixe. C. Oligoqueta (hospedeiro invertebrado) D. Actinosporo liberado na água pelo oligoqueta. Editado a partir de ATKINSON, 2011.

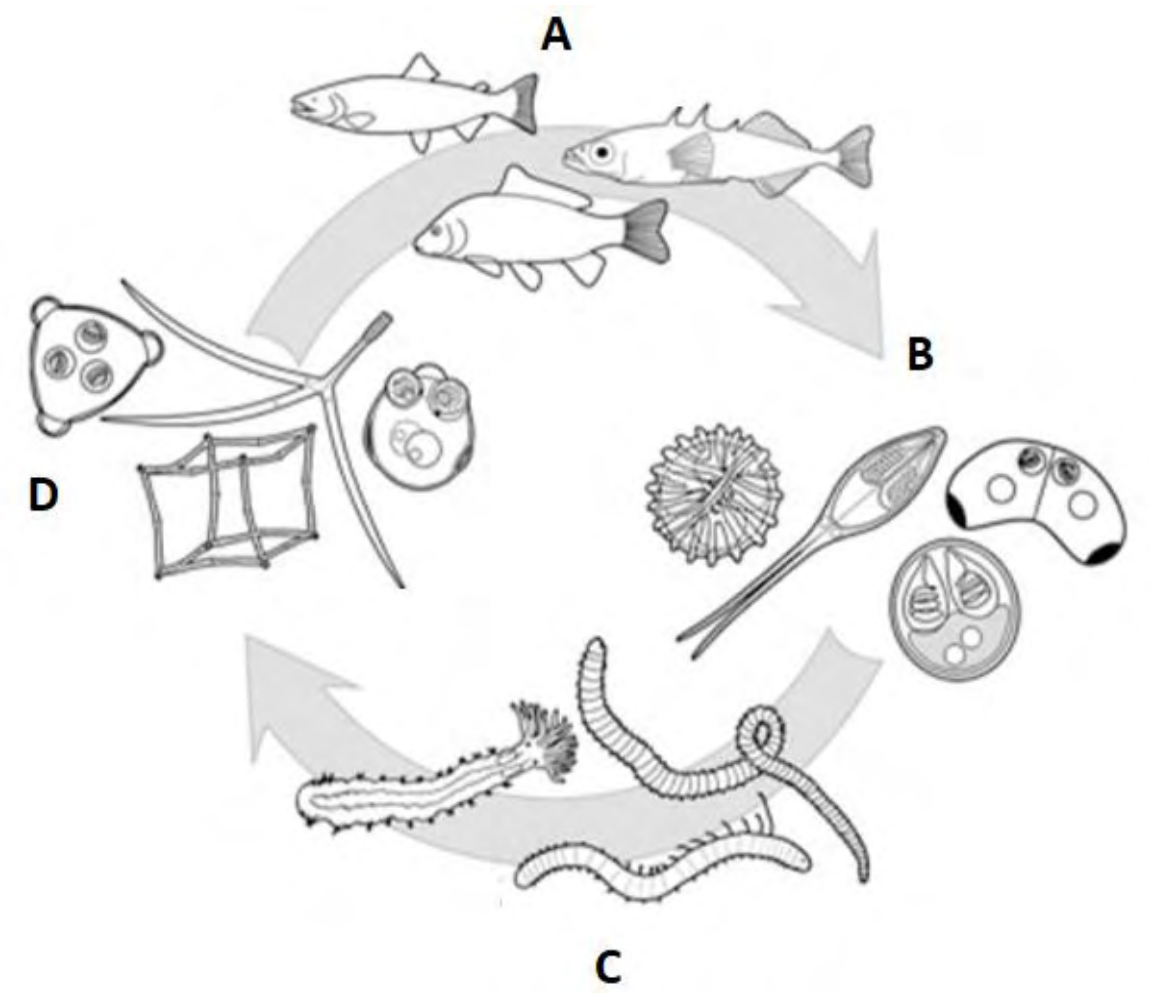

\subsection{Estudos da Classe Myxosporea no Brasil}

Os parasitas são as maiores causas de perdas econômicas em peixes de criação. Por consequência do desenvolvimento da piscicultura brasileira, observa-se um crescente interesse 
dos pesquisadores e criadores, no que se refere aos prejuízos causados por mortalidade e problemas na produção de peixes (SCHALCH, 2011). Esforços têm sido feitos nas últimas décadas para expandir o conhecimento da diversidade de mixosporídeos, principalmente em peixes de importância comercial, o que tem possibilitado um forte progresso no conhecimento da diversidade destes parasitas e estudos dos danos causados em seus hospedeiros.

Até o momento, foram descritas 140 de espécies de mixosporídeos, conhecidas por parasitarem peixes de água doce brasileiras de diferentes bacias hidrográficas (ADRIANO \& OLIVEIRA, 2018; OKAMURA et al., 2018) e algumas, infectando peixes nativos amplamente cultivados em pisciculturas (ADRIANO et al., 2005a, 2005b; 2006; 2009a; 2009b; 2012; EIRAS et al., 2009; MARTINS \& SOUZA, 1997; MARTINS, 1997; NALDONI et al., 2009; 2011). Muitas destas descrições foram realizadas por pesquisas desenvolvidas no Laboratório de Imunologia de Parasitas da FZEA-USP (ADRIANO et al., 2005a, 2005b, 2006, 2009, 2012; CAPODIFOGLIO et al.,2015, 2016 e 2019; CARRIERO 2013; MILANIN et al., 2010, 2015a; 2015b; 2017; 2018a; 2018b; MOREIRA et al., 2014; NALDONI et al., 2011, 2014, 2015; 2018; 2019).

Algumas espécies de mixosporídeos descritas em peixes nativos do Brasil têm se mostrado patogênicas ou com grande potencial para causar danos em seus hospedeiros (ADRIANO et al. 2012), ocasionando impactos e prejuízos econômicos tanto na pesca quanto na aquicultura, como é o caso de Henneguya multiplasmodialis Adriano, Carriero, Maia, Silva, Naldoni, Ceccarelli e Arana, 2012, que infecta as brânquias, formando grandes plasmódios acobertando totalmente os filamentos e o arco branquial do pintado e da cachara (Pseudoplatystoma spp.) de ambiente natural no Pantanal Mato-Grossense, e a Henneguya Pseudoplatystoma Naldoni, Arana, Maia, Ceccarelli, Tavares, Borges, Pozo, Adriano, 2009, relatado causador de uma importante redução da função branquial no pintado de pisciculturas dos estados de São Paulo e Mato Grosso do Sul, apresentando intensa infecção com a ocorrência de vários plasmódios no filamento branquial dos peixes.

De uma maneira geral, os estudos envolvendo a diversidade desses parasitas, bem como os possíveis danos que podem causar em seus hospedeiros, ainda são escassos na América do Sul, em comparação com a diversidade de peixes de água doce dessa região, que é a mais rica do planeta (BUCKUP et al., 2007). De acordo com os estudos de Naldoni et al., (2011), se cada espécie de peixe pode ser acometida por no mínimo duas espécies de mixosporídeos, a estimativa da diversidade desses parasitas na América do Sul pode alcançar até 16.000 espécies, o que significa que estamos muito aquém de conhecer a diversidade desses organismos na região. 


\subsection{Detecção de mixosporídeos}

Nas últimas décadas, as técnicas de biologia molecular vêm sendo empregadas em diversos estudos envolvendo ictioparasitologia e têm sido importantes aliados na taxonomia e no diagnóstico de doenças (CRISCIONE et al., 2005; FIGUEIREDO \& LEAL, 2008). No estudo de mixosporídeos, as análises moleculares contribuem notoriamente na sistemática, auxiliando na identificação de novas espécies e na compreensão das relações evolutivas destes organismos (OKAMURA et al., 2015a).

Os métodos moleculares receberam grande impulso com o desenvolvimento da técnica conhecida como Reação em Cadeia da Polimerase (PCR). Atualmente é considerada uma técnica de biologia molecular revolucionária, que permitiu o rápido desenvolvimento do estudo de sequências de ácidos nucléicos (MOLINA \& TOBO, 2004). Essa técnica descrita por Saiki et al., (1985), permite amplificar pequenos e específicos segmentos do genoma, permitindo a obtenção de várias cópias de determinada região do DNA.

Atualmente, a pequena subunidade do DNA ribossomal Small Subunit Ribosomal DNA (SSrDNA) é o principal marcador molecular utilizado nos estudos taxonômicos e filogenéticos de Myxozoa (ADRIANO \& OKAMURA, 2017; CARRIERO et al., 2013; FIALA, 2006; FIALA \& BARTOŠOVÁ-SOJKOVÁ, 2010; ZATTI et al., 2017a, 2017b), e, por ser heterogêneo, ou seja, possuir regiões mais variáveis e outras conservadas, facilitando a discriminação de táxons em diferentes níveis (HILLIS \& DIXON, 1991).

Devido à capacidade das técnicas de PCR em detectar agentes infecciosos com alta sensibilidade e especificidade (HOFMANN et al., 2008), sem necessidade de se encontrar microrganismos viáveis na amostra biológica, a PCR tornou-se uma ferramenta de diagnóstico valiosa e muito confiável para o diagnóstico e monitoramento de doenças dos animais. A partir da PCR, é possível avaliar a presença de pequenas quantidades de DNA do patógeno em diferentes amostras (HASS \& TORRES, 2016).

Nos últimos anos, a PCR é amplamente aplicada e considerada como o método de escolha no diagnóstico e caracterização molecular de diversos agentes patogênicos. Duas versões do método da PCR são bem conhecidas e utilizadas nos estudos: a PCR Convencional (cPCR) e a PCR em Tempo Real (qPCR), uma modificação da tradicional, e, é representada como outro salto tecnológico.

A reação de qPCR acontece da mesma forma que a cPCR, exceto pelo fato de que a reação é monitorada em tempo real e identifica o DNA alvo com maior sensibilidade, uma vez que a detecção da amplificação é feita através da captação de fluorescência. É uma das técnicas 
mais precisas para quantificar e obter resultados rápidos e reprodutíveis (NOVAIS \& PIRESALVES, 2004; COELHO, 2013). Essa técnica monitora o progresso da PCR enquanto ela progride (ou seja, em tempo real). Os dados são, desta forma, coletados ao longo da PCR, ao invés de serem apenas no final da reação, como ocorre na PCR Convencional.

Existem diversas abordagens para a realização da qPCR. O composto fluorescente utilizado na reação pode ter dois comportamentos distintos, dando origem às duas mais utilizadas tecnologias: SYBR® Green e TaqMan®.

O sistema SYBR Green®, o fluorocromo não é específico para uma determinada sequência de DNA, detectando e ligando-se a qualquer produto de cadeia dupla da PCR, sendo a especificidade da detecção e quantificação devida, unicamente, à especificidade dos primers. Já o sistema TaqMan® apresenta maior especificidade devido à utilização de uma sonda específica, probe para o fragmento alvo na reação.

Nas reações de qPCR, a amplificação e a detecção do DNA são realizadas simultaneamente em um sistema fechado, dispensando procedimentos adicionais como a corrida eletroforética dos produtos em gel de agarose e fotodocumentação. Com a eliminação destas etapas, os resultados são obtidos mais precocemente pela PCR em Tempo Real quando comparada à PCR Convencional (ALONSO et al., 2003; NICKLAS \& BUEL, 2003).

Por serem técnicas altamente utilizadas nas análises moleculares e ser possível avaliar a presença de pequenas quantidades de DNA do patógeno em diferentes amostras, este estudo propôs utilizar essas técnicas, cPCR e qPCR, para a detecção de parasitas em amostras de água coletadas de psiculturas do interior do estado de São de Paulo, Brasil.

\subsection{Diagnóstico de mixosporídeos a partir da água}

O DNA ambiental, conhecido também como eDNA, é definido como uma mistura complexa de DNA genômico oriundo de organismos inteiros ou partes de deles, presentes em amostras ambientais. Essas amostras podem ser, por exemplo, solo, água, sedimentos, fezes ou neve (THOMSEN \& WILLERSLEV, 2015). É considerada uma nova ferramenta molecular que tem o potencial de alterar a maneira como a detecção e o monitoramento de doenças ocorrem na aquicultura, podendo ser um poderoso indicador de presença de organismos dos quais a observação direta é impossível (BASS et al., 2015; FICETOLA et al., 2008; GOLDBERG et al., 2015).

A primeira abordagem do eDNA ocorreu em 1987 por Ogram et al. com o objetivo de entender comunidades microbianas em sedimentos. No entanto, a técnica começou a crescer 
em popularidade como uma ferramenta para detectar a biodiversidade de sistemas aquáticos recentemente (FICETOLA et al., 2008).

Sabe-se que as metodologias empregadas em estudos de amostras ambientais possuem potencial para melhorar os sistemas de monitoramento da saúde animal na aquicultura, já que muitos patógenos são microscópicos, difíceis de detectar e os sinais clínicos de doenças são frequentemente observados em estágios avançados de infecção. Desta forma, a técnica de uso de amostras ambientais oferece uma abordagem alternativa a métodos tradicionais que ocorrem a captura física dos indivíduos ((BASS et al., 2015; FICETOLA et al., 2008; TABERLET et al., 2012).

O aperfeiçoamento das metodologias de $e D N A$ podem oferecer técnicas simples de detecção que avaliem o risco de doenças antes do aparecimento de altas taxas de mortalidades ou surtos.

Detectar infecções na ausência de doença e mortalidade pode ser desafiador e problemático (FONTES et al., 2016). Os parasitas de organismos aquáticos emergentes representam ameaças à biodiversidade, conservação e uso sustentável de água doce (OKAMURA \& FEIST 2011). Como uma alternativa de abordagem e uma ferramenta complementar, a detecção de DNA do parasita em amostras ambientais é cada vez mais empregada em água doce e marinha (AUDEMARD et al., 2006; HUNG \& REMAIS 2008; STRAND et al., 2014).

A detecção e quantificação de agentes de doenças em amostras ambientais oferecem um potencial único para informar sobre a ecologia e epidemiologia das interações parasita hospedeiro ao contornar abordagens parasitológicas tradicionais (FONTES et al., 2016). A promessa do uso do DNA ambiental em detectar espécies aquáticas foi identificada como uma das 15 perspectivas da conservação a nível global no relatório anual de 2013 da Trends in Ecology and Evolution (SUTHERLAND et al., 2013).

Alguns testes de PCR em tempo real (qPCR) para detectar e quantificar outros mixosporídeos em amostras de água foram desenvolvidos para especies como: Ceratonova (anteriormente Ceratomyxa shasta) (HALLETT \& BARTHOLOMEW 2006), Parvicapsula mini bicornis (FOOTT et al., 2007), Henneguya ictaluri (GRIF FIN et al., 2009), Ceratomyxa puntazzi (ALAMA BERMEJO et al., 2013) e Kudoa yasunagai (ISHIMARU et al., 2014). Porém nenhum teste foi ainda realizado na busca de mixosporídeos a partir da água em pisciculturas do Brasil. 


\section{Justificativa}

Os peixes, tanto de ambiente natural quanto de sistemas de criação, podem ser acometidos por uma variedade de agentes patogênicos, como vírus, bactérias, fungos e parasitas de diversos grupos taxonômicos (AUSTIN \& NEWAJ-FYZUL, 2017; LUQUE, 2004). Neste contexto, os parasitas são frequentemente reportados como sérias ameaças à aquicultura, e em alguns casos, podem também afetar as populações de estoques selvagens devido as patologias severas e as elevadas taxas de mortalidades causadas por algumas espécies (AUSTIN \& NEWAJ-FYZUL, 2017; ROBERTS, 2012). A América do Sul é o continente com a mais alta diversidade de peixes de água doce (SCHAEFER, 1998). Muitas destas espécies, além de importantes na pesca extrativista, têm também sido introduzidas com sucesso na piscicultura visando suprir o mercado de alimentos e de aquarismo (BALDISSEROTTO \& GOMES, 2013; BUCKUP et al., 2007). No entanto, o Brasil conta com apenas cerca de 140 espécies de mixosporídeos conhecidas (OKAMURA et al., 2018), o que representa apenas cerca de 5\% da fauna mundial conhecida. Embora estudos envolvendo mixosporídeos parasitas de peixes de importância econômica da América do Sul vêm recebendo maior atenção nos últimos anos (ADRIANO et al., 2005a, 2005b; 2006; 2009a, 2009b; 2012; AZEVEDO et al., 2005; 2010; 2013; CARRIERO et al., 2013; EIRAS et al., 2010; MATHEWS et al., 2016; NALDONI et al., 2011; ZATTI et al., 2017, 2018a, 2018b) os estudos com foco na relação parasita hospedeiro são ainda escassos, mas alguns têm demonstrado o potencial de algumas espécies para causar danos em peixes nativos em sistemas de criação (ADRIANO et al., 2005a; 2006; MARTINS et al., 1997; NALDONI et al., 2009).

De acordo com Hartikainen et al., (2014), em um trabalho pioneiro na detecção de mixosporídeos em amostras de água, o uso do $e D N A$ representa um meio proativo de reconhecer potenciais agentes infecciosos possibilitando avaliar melhor a possibilidade de mortalidades e

surtos de doenças. Como uma alternativa de abordagem e uma ferramenta complementar, a detecção de DNA do parasita em amostras ambientais é cada vez mais empregada em água doce e marinha (AUDEMARD et al., 2006; HUNG \& REMAIS 2008; STRAND et al., 2014). A detecção e quantificação de agentes de doenças em amostras ambientais oferecem um potencial único para informar sobre a ecologia e epidemiologia das interações hospedeiro-parasita ao contornar abordagens parasitológicas tradicionais (FONTES et al., 2016). 
As tecnologias utilizadas para o estudo do DNA ambiental evoluíram nos últimos anos, aumentando a capacidade de detectar pequenas quantidades de DNA e a capacidade de abranger uma maior variedade de ambientes (BOHMANN, 2014). O eDNA pode oferecer uma detecção precoce e uma avaliação antecipada dos riscos de doenças, antes que animais aquáticos, principalmente peixes, sejam acometidos.

Até o momento, para grande parte dos estudos dos mixosporídeos, no estágio mixosporo, em peixes, é necessária a captura dos mesmos, dissecção, análise microscópica e histológica do parasita, com a complementação da análise molecular. Para o estágio actinosporo, em oligoquetas, estes são coletados partir de sedimentos e mantidos em laboratório, na espera da liberação dos actinosporos que são analisados por microscopia em contraste de fase e por técnicas de biologia molecular. Obtido o material biológico, este é submetido às análises morfológica e molecular. Desta forma é esperado que a metodologia utilizada nesse estudo possa ser empregada no monitoramento de mixosporídeos em pisciculturas brasileiras e também anteriormente das capturas dos hospedeiros. 


\section{Hipótese}

Análises de DNA ambiental através de PCR Convencional e PCR em Tempo Real são métodos eficientes para a detecção de mixosporídeos em amostras de água de pisciculturas. 


\section{Objetivos}

\subsection{Objetivo Geral}

Utilizar as técnicas cPCR e qPCR para o diagnóstico de mixosporídeos em amostras de água de pisciculturas.

\subsection{Objetivos Específicos}

4.2.1 Coletar água de pisciculturas do estado de São Paulo para posterior pesquisa de DNA de mixosporídeos;

4.2.2 Aperfeiçoar um método para a extração de DNA de mixosporídeos a partir da membrana de nitrato de celulose;

4.2.3 Avaliar a cPCR na detecção de mixosporídeos em amostras de água de pisciculturas a partir da análise do SSrDNA;

4.2.4 Testar a sensibilidade e a especificidade da qPCR para detecção de mixosporídeos em amostras de água de pisciculturas a partir da análise do SSrDNA; 


\section{Materiais e Métodos}

\subsection{Coleta de amostras de água suspeitas em pisciculturas para análise de DNA}

Amostras de água foram coletadas durante os meses de fevereiro e março de 2018 e 2019 , em dois sistemas de criação de peixes no interior do estado de São Paulo, Brasil. O primeiro local é um sistema de criação de Tambaqui (Colossoma macropomum Cuvier, 1816), Tambacu (híbrido resultante do cruzamento entre Colossoma macropomum Cuvier, 1816 х Piaractus mesopotamicus Holmberg, 1997), Pirarara (Katsuwonus pelamis Linnaeus, 1758) e Piau (Leporinus friderici Bloch, 1794) localizado no município de Porto Ferreira, SP Brasil. O segundo é um sistema de criação de Lambaris (Astyanax spp.), localizado na cidade de Pirassununga no Centro Nacional de Pesquisa e Conversação de Peixes Continentais (CEPTA). Estas localidades foram escolhidas devido ao fato de que já foram identificados, anteriormente, peixes e oligoquetas infectados por mixosporídeos, como descritos nos trabalhos de Carriero et al., 2011; Milanin et al.,2015a, 2016; Moreira et al., 2013. Por esse motivo, as amostras de água coletadas nas pisciculturas foram identificadas como amostras suspeitas.

Todas as amostras de água foram coletadas a aproximadamente 1 metro de distância da borda dos tanques e $30 \mathrm{~cm}$ abaixo da superfície da água, em garrafas plásticas estéreis de 1 litro, seguindo os protocolos de coleta de água estabelecido por Gomes et al., 2017 (Figura 3).

Figura 3. Coleta de amostras de água em um sistema de criação de peixes no município de Porto Ferreira, SP, Brasil.

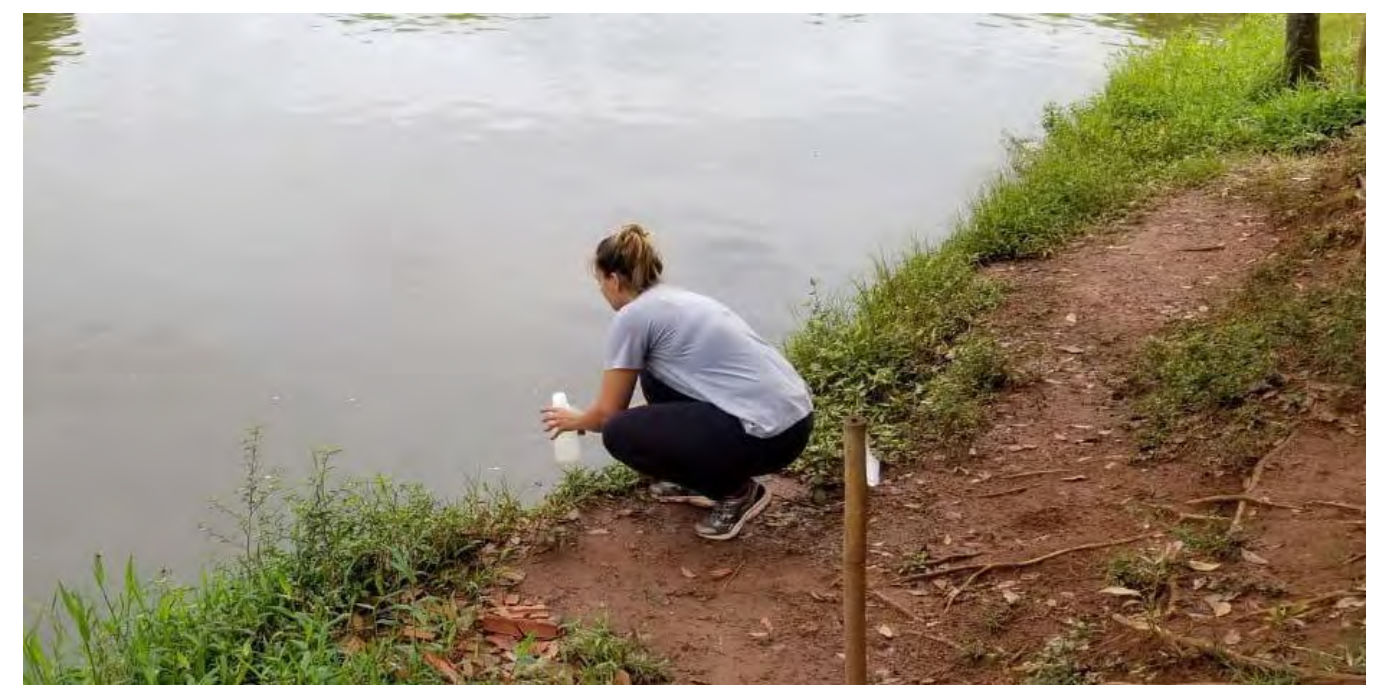


As coletas foram realizadas em diferentes pontos dentro do mesmo tanque da piscicultura de forma a representar todo o sistema. Após a coleta, as amostras suspeitas foram armazenadas em gelo e conduzidas para o Laboratório de Imunologia de Parasitas do Departamento de Medicina Veterinária da Faculdade de Zootecnia e Engenharia de Alimentos - FZEA/USP.

No total foram coletadas 48 amostras, sendo 24 oriundas do sistema de criação de peixes do município de Porto Ferreira e 24 do sistema de criação de peixes do município de Pirassununga.

\subsubsection{Filtração das amostras de água suspeitas coletadas}

As etapas de filtração das amostras suspeitas seguiram o protocolo descrito por Hallet e Bartholomew (2006), com algumas adequações às nossas condições de trabalho. Inicialmente, cada amostra suspeita coletada (1 litro) foi dividida em frações de $500 \mathrm{~mL}$ para a filtração. Foi utilizado um sistema completo de filtração à vácuo de $500 \mathrm{~mL}$ de vidro (Uniglas) composto por: copo graduado, pinça em alumínio, funil de placa porosa com diâmetro de $47 \mathrm{~mm}$ e Erlenmeyer com capacidade de 1 litro (Figura 4).

As amostras foram filtradas (pressão de $400 \mathrm{~nm} \mathrm{Hg}$ ) através da membrana de nitrato de celulose estéril (Santorius), de porosidade de $0,45 \mu \mathrm{m}$ e $47 \mathrm{~mm}$ de diâmetro. A opção da porosidade da membrana de $0,45 \mu \mathrm{m}$ foi devido ao tamanho dos esporos de mixosporídeos presentes na água, retendo, assim, todo material alvo de detecção.

Cada membrana após a filtração foi dobrada com auxílio de uma pinça esterilizada, e em seguida, foi colocada dentro de microtubo de $2,0 \mathrm{~mL}$ e armazenadas a $-20^{\circ} \mathrm{C}$.

Figura 4. Sistema completo de filtração à vácuo de $500 \mathrm{~mL}$.

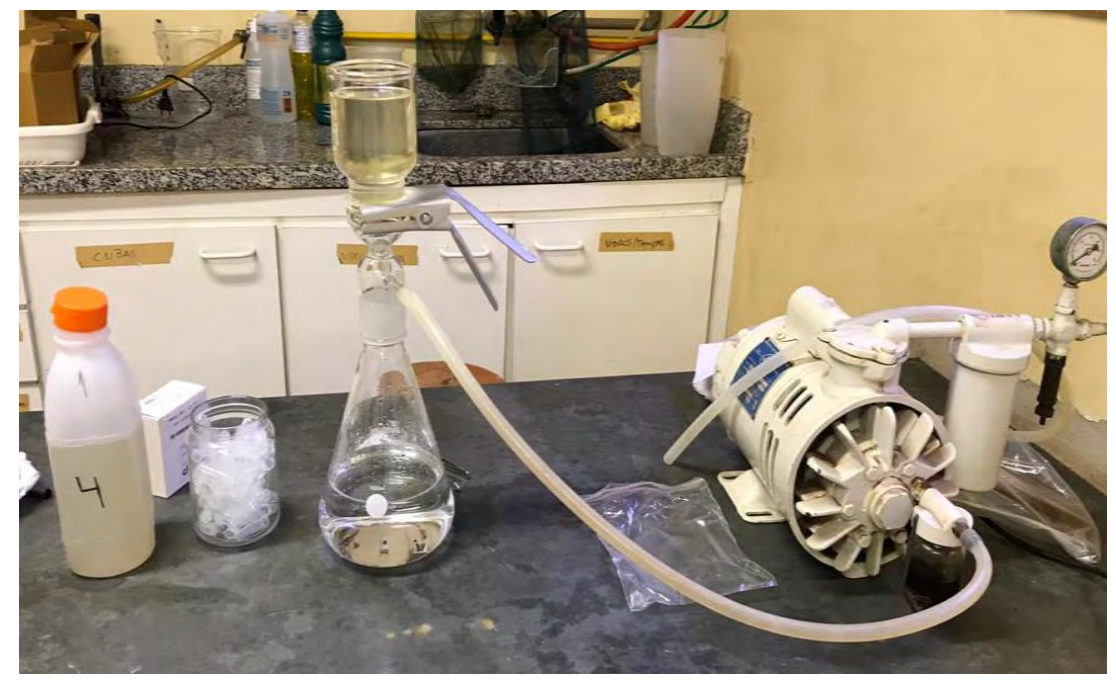




\subsubsection{Extração de DNA das membranas de nitrato de celulose}

Cada microtubo contendo uma membrana foi mantido a temperatura ambiente e em seguida, levado a um concentrador à vácuo, modelo 5301, Eppendorf AG (Eppendorf, Applied Biosystems, California, USA), para a secagem total da membrana. Esse procedimento de secagem durou aproximadamente 2 horas.

Após a secagem das membranas, foi adicionado 1,5 mL de acetona P.A. EMSURE® ACS, ISO,Reag. Ph Eur, em cada microtubo. Os microtubos foram levados ao vórtex, até a degradação total da membrana, aproximadamente, 30 minutos. Logo após a degradação da membrana, o material foi centrifugado por 1 minuto a $6.000 \mathrm{x} \mathrm{g} \mathrm{em} \mathrm{temperatura} \mathrm{ambiente,}$ sendo o sobrenadante descartado e o pellet armazenado. $\mathrm{O}$ tratamento com acetona foi repetido para assegurar a dissolução completa da membrana e a liberação do material retido no processo de filtração.

Em cada microtubo contendo o material retido foi adicionado 1,5 $\mathrm{mL}$ de Etanol P.A. EMPARTA® ACS, e essa mistura foi levada ao vórtex para garantir a suspensão do sedimento. Em seguida, cada amostra foi centrifugada e o sobrenadante descartado. Para a total evaporação do álcool, todas as amostras foram novamente levadas ao concentrador a vácuo e, em seguida, armazenadas $\mathrm{a}-20{ }^{\circ} \mathrm{C}$.

O DNA foi extraído utilizando DNeasy Blood \& Tissue Kit (QIAGEN Inc., California, USA) com as seguintes adequações do protocolo: para a etapa de lise, as amostras foram incubadas over nigth, a $56{ }^{\circ} \mathrm{C}$ com a adição de $180 \mu \mathrm{L}$ de tampão ATL e $20 \mu \mathrm{L}$ Proteinase K. Após o período de incubação, as amostras foram centrifugadas por 1 minuto a 6.000 x g, e, em seguida, foram adicionados $200 \mu \mathrm{L}$ do tampão AL e as amostras foram homogeneizadas em vórtex. Posteriormente, as amostras foram colocadas em banho maria em temperatura de $70{ }^{\circ} \mathrm{C}$, por 10 minutos. Em seguida, foram adicionados $200 \mu \mathrm{L}$ de Etanol P.A. nas amostras e novamente homogeneizadas em vórtex. Após, $800 \mu \mathrm{L}$ do sobrenadante de cada amostra foram transferidos para uma coluna ( "Mini spin column") acoplado a um microtubo e foi centrifugada por 1 minuto, a $6.000 \mathrm{x} \mathrm{g}$, sendo todo o eluato descartado. Ato continuo, adicionou-se a coluna $500 \mu \mathrm{L}$ do tampão AW1 que centrifugado por 1 minuto, a 6.000 x g, sendo todo o eluato descartado. Iniciou-se a etapa de lavagem. Adicionou-se a coluna $500 \mu \mathrm{L}$ do tampão AW2 e novamente houve a centrifugação por 1 minuto, a 6.000 x g, sendo todo o eluato descartado. 
Essa etapa de lavagem com o tampão AW2 foi repetida, com a segunda centrifugação a $10.000 \mathrm{x}$ g por 1 minuto, para garantir a total secagem da coluna. Dando seguimento, a coluna foi colocada em um novo microtubo de $1,5 \mathrm{~mL}$. Para a eluição foi realizada adicionado $60 \mu \mathrm{L}$ do tampão AE. Após a adição as amostras foram incubadas por 1 minuto em temperatura ambiente, e, em seguida, foram centrifugadas a 10.000 x g por 1 minuto. Uma nova eluição foi realizada usando o mesmo volume de tampão AE.

O DNA extraído foi quantificado em espectrofotômetro NanoDrop 2000 (Thermo Scientific, Wilmington, Delaware USA).

\subsection{Validação das etapas de filtração e extração de DNA com amostras-controle}

Para validar os procedimentos das etapas de filtração das amostras de água suspeitas e da extração de DNA das membranas de nitrato de celulose, descritos nos itens 5.1.1 e 5.1.2, foram utilizados dois cistos de mixosporídeos dos principais gêneros, Myxobolus Bütschli, 1882 e Henneguya Thélohan, 1892.

Os dois cistos foram coletados de peixes infectados da Bacia Amazônica, no rio Tapajós, na cidade de Santarém, do estado do Pará, Brasil. O primeiro cisto foi extraído dos filamentos branquiais do peixe Colossoma macropomum Cuvier, 1816 (Tambaqui) e o segundo cisto foi extraído dos filamentos branquiais do Piaractus brachypomus, Cuvier, 1818 (Pirapitinga). Este material biológico foi obtido a partir de material de projetos em desenvolvimento no Laboratório de Imunologia de Parasitas da FZEA-USP.

Cada cisto foi rompido separadamente em uma placa de Petri com auxílio de lâmina de bisturi, sendo o conteúdo misturado em 1 litro de água filtrada. Cada litro de água contendo o material de cada cisto rompido foi filtrado utilizando o mesmo sistema de filtração à vácuo, e o DNA foi extraído da membrana de nitrato de celulose seguindo os mesmos procedimentos realizados para as amostras de água suspeitas coletadas nas psiculturas, como descrito nos itens 5.1.1 e 5.1.2.

As duas amostras obtidas para validar as etapas de filtração e extração de DNA foram denominadas de amostras-controle. A amostra-controle 1 foi visualizada como pertencente ao gênero Myxobolus Bütschli, 1882, e a amostra-controle 2 foi identificada como pertencente ao gênero Henneguya Thélohan, 1892. 
Os primers escolhidos para a validação das etapas de filtração e extração de DNA foram os MilF (forward) 5' - ATTTGGCAGCGAGAGGTGAA - 3' e MilR2 (reverse) 5' CCCGGGTCGGCATAGTTTAC -3' (personal communication). Primers específicos para o subfilo Myxozoa e foram esquematizados a partir de todas as sequências de mixosporídeos descritas na América do Sul depositadas no GenBank. Os primers amplificam uma região conservada da SSrDNA dos mixosporídeos. Estes foram construídos por Milanin et al., (dados não publicados) e amplificam um fragmento de aproximadamente 155 pares de bases (Tabela 2).

\subsubsection{Realização da PCR Convencional com as amostras-controle}

As primeiras PCRs Convencionais foram realizadas com as amostras-controle. Assim, as reações de cPCR foram realizadas contendo 22,5 $\mu \mathrm{L}$ de Platinum® PCR SuperMix 1X (Thermo Fisher Scientific Inc., USA), 0,5 $\mu \mathrm{M}$ de cada primer específico e $2 \mu \mathrm{L}$ do DNA controle diluído. As reações de amplificação foram realizadas em termociclador Hamburg AG 22331 (Eppendorf, Applied Biosystems, California, USA) sob as seguintes condições de ciclagem: uma primeira etapa de desnaturação inicial a $95^{\circ} \mathrm{C}$, durante 5 minutos, seguida por 35 ciclos de desnaturação a $95{ }^{\circ} \mathrm{C}$, por 30 segundos: hibridização a $60{ }^{\circ} \mathrm{C}$, durante 30 segundos e extensão a $72{ }^{\circ} \mathrm{C}$, durante 60 segundos, finalizando com uma etapa de alongamento a $72{ }^{\circ} \mathrm{C}$, estendida para 3 minutos. Para essa reação foram utilizados os primers MilF e MilR2.

Os produtos da cPCR foram visualizados por eletroforese em gel de agarose a 1,5\%, em tampão TAE (Tris-acetato - EDTA), corados com SybrSafe DNA (Invitrogen, Life Technologies, CA, EUA) e analisados em um transiluminador Stratagene 2020E. Os tamanhos dos fragmentos amplificados foram comparados com o padrão $1 \mathrm{~Kb}$. plus DNA Ladder (Invitrogen life Technologies, CA, EUA). Em seguida, os produtos de cPCR foram purificados, utilizando o kit de purificação PCR Purification Kit (QIAGEN Inc., California, USA), e então enviados para sequenciamento.

Os produtos do SSrDNA amplificados com os primers MilF e MilR2 através das reações de cPCR foram sequenciados utilizando o kit BigDye ${ }^{\circledR}$ Terminator v3.1 Cycle Sequencing (Applied BiosystemsTM Inc., CA, EUA) e um sequenciador ABI 3730 DNA (Applied BiosystemsTM Inc., CA, EUA). 
Para o sequenciamento foram utilizados os primers MilF e MilR2. As sequências obtidas foram visualizadas, editadas e alinhadas no programa Bioedit Sequence Alignment Editor versão 7.2.5 (HALL, 1999) e, em seguida, estas foram comparadas juntamente com outras sequências de mixosporídeos já descritos e depositadas no GenBank usando o programa Basic Local Aligment Search Tool (BLASTn) National Center for Biotechnology (NCBI).

\subsection{Realização da PCR Convencional em amostras suspeitas}

\subsubsection{PCR Convencional com os primers MX5 e MX3}

5.3.1.1 Escolha dos primers para reação de PCR Convencional para amplificação de DNA das amostras suspeitas

Os primers escolhidos para as reações de cPCR para amplificação parcial do SSrDNA foram MX5 (forward): 5' - CTGCGGACGGCTCAGTAAATCAGT - 3' e MX3 (reverse): 5' - CCAGGACATCTTAGGGCATCACAGA - 3' (ANDREE et al., 1999), e que juntos amplificam um fragmento, de aproximadamente 1700 pares de bases. Pesquisas envolvendo mixoporídeos realizadas no Laboratório de Imunologia de Parasitas da FZEA-USP já vêm utilizando esses primers em diversos estudos como Carriero et al., (2013), Adriano et al., (2005a; 2012) e Milanin et al., (2010) (Tabela 2).

\subsubsection{Curva padrão para a definição do limiar de detecção de DNA com os primers MX5 e MX3}

Para a curva padrão foi utilizada, como controle positivo, uma amostra cujo o DNA já tinha sido extraído, quantificado e sequenciado, de Henneguya pellucida Adriano, Arana e Cordeiro, 2005. Amostra cedida a partir de projetos em desenvolvimento no Laboratório de Imunologia de Parasitas e de concentração definida no NanoDrop 2000 (Thermo Scientific, Wilmington, Delaware USA).

Para a avaliação do limite de detecção da técnica com os primers MX5/MX3, foi utilizada a amostra contendo DNA de H. pellucida e esta foi diluída na razão 10 em 6 pontos. Desta forma, as diluições de DNA variaram de $1 \mathrm{ng}$ à $0,1 \times 10^{-4} \mathrm{ng}$. 
Para a amplificação do SSrDNA as diluições contendo DNA da amostra de H. pellucida foram submetidas as reações de cPCR, realizadas com $2 \mu \mathrm{L}$ do DNA controle diluído, $22,5 \mu \mathrm{L}$ de Platinum ${ }^{\circledR}$ PCR SuperMix 1X (Thermo Fisher Scientific Inc, USA), 0,5 $\mu$ M de cada primers MX3 e MX5.

As reações de amplificação foram realizadas em um termociclador Hamburg AG 22331 (Eppendorf, Applied Biosystems, California, USA) sob as seguintes condições de ciclagem: uma primeira etapa de desnaturação inicial a $95^{\circ} \mathrm{C}$, durante 5 minutos, seguida por 35 ciclos de desnaturação a $95{ }^{\circ} \mathrm{C}$, por 60 segundos; anelamento a $60^{\circ} \mathrm{C}$, durante 60 segundos e extensão a $72{ }^{\circ} \mathrm{C}$, durante 130 segundos, finalizando com uma etapa de extensão a $72{ }^{\circ} \mathrm{C}$ por 5 minutos.

Os produtos de amplificação foram visualizados em eletroforese em gel de agarose a 1,5\%, em tampão Tris-Acetato-EDTA (TAE), corados com SybrSafe DNA (Invitrogen, Life Technologies, CA, EUA) e analisados em um transiluminador Stratagene 2020E. Os tamanhos dos fragmentos amplificados foram comparados com o padrão $1 \mathrm{~Kb}$. plus DNA Ladder (Invitrogen Life Technologies, CA, EUA).

\subsubsection{PCR Convencional com DNA das amostras suspeitas com os primers MX5 e MX3}

Para as reações de cPCR todas as 48 amostras de DNA de água suspeitas foram quantificadas em Espesctrofotômetro NanoDrop 2000 (Thermo Scientific, Wilmington, Delaware USA) e, posteriormente, estas foram diluídas ou concentradas, com a finalidade de terem a mesma concentração de DNA, $2,5 \mathrm{ng} / \mu \mathrm{L}$. Como foram adicionadas $2 \mu \mathrm{L}$ de DNA de cada amostra, foram adicionadas em cada reação $5 \mathrm{ng} / \mathrm{uL}$ de DNA.

As reações de cPCR para a detecção de DNA de mixosporídeos em amostras suspeitas foram as mesmas utilizadas para a curva padrão, bem como para verificação de amplificação (Item 5.3.1.2).

\subsubsection{PCR Convencional com os primers HpelF e HpelR}

5.3.2.1 Escolha dos primers para reação de PCR Convencional para amplificação de DNA das amostras suspeitas

Com o objetivo de otimizar um teste específico para Henneguya pellucida, foram construídos os primers HpelF (forward) 5' -CTCTGTTGGTAGGGTGAGTGGG - 3' e HpelR (reverse) 5' -ATCGAGTAGACCGCACACTGTC - 3'. Para tanto, foram selecionadas 
sequências do SSrDNA de mixosporídeos descritos na América do Sul depositadas no GenBank e a sequência de Henneguya pellucida (KF296352) descrita por Adriano et al., (2005) em espécies de peixes do CEPTA, localizado no município de Pirassununga, estado de São Paulo, Brasil, infectando Piaractus mesopotamicus, Holmberg 1887. As sequências foram alinhadas pelo programa Bioedit Sequence Alignment Editor versão 7.2.5 (HALL, 1999) e, regiões conservadas para H. pellucida foram selecionadas no Programa Primer-BLAST (NCBI) para o desenho dos oligonucleotídeos HpelF e HpelR, que flanqueiam uma região de 150 pares de bases da SSrDNA (Tabela 2).

\subsubsection{Curva padrão para a definição do limiar de detecção de DNA com os primers HpelF e HpelR}

A curva padrão para os primers HpelF e HpelR foi realizada com a amostra controle de Heneguya pellucida foi diluída na razão 10 em 6 diluições. As concentrações das diluições variaram de 1 ng à $0,1 \times 10^{-4}$ ng de DNA.

As reações de cPCR com os primers HpelF e HpelF foram realizadas com $2 \mu \mathrm{L}$ do DNA controle diluído, 22,5 $\mu \mathrm{L}$ de Platinum ${ }^{\circledR}$ PCR SuperMix 1X (Thermo Fisher Scientific Inc, USA), $0,5 \mu \mathrm{M}$ de cada primers HpelF e HpelF. As reações de amplificação foram realizadas num termociclador Hamburg AG 22331 (Eppendorf, Applied Biosystems, California, USA) sob as seguintes condições de ciclagem: uma primeira etapa de desnaturação inicial a $95^{\circ} \mathrm{C}$, durante 5 minutos, seguida por 35 ciclos de desnaturação a $95^{\circ} \mathrm{C}$, por 30 segundos: anelamento a $62{ }^{\circ} \mathrm{C}$, durante 30 segundos e extensão a $72{ }^{\circ} \mathrm{C}$, durante 60 segundos, finalizando com uma etapa de extensão/polimerização a $72^{\circ} \mathrm{C}$, por 2 minutos.

A amplificação foi visualizada em gel de agarose como descrito no item 5.3.1.2.

5.3.2.3 Especificidade dos primers HpelF e HpelR para detecção de DNA de Henneguya pellucida

Foram realizados testes de sensibilidade dos primers HpelF de HpelR com amostras de outros mixosporídeos, incluindo uma amostra de DNA do actinosporo Aurantiactinomyxon tipo 1 e uma amostra de DNA de Myxobolus macroplasmodialis além da amostra de DNA de $H$. pellucida para validar a especificidade dos primers.

5.3.2.4 PCR Convencional com DNA obtidos das amostras suspeitas com os primers HpelF e HpelR 
Para as reações de cPCR todas as 48 amostras suspeitas foram quantificadas no Espesctrofotômetro NanoDrop 2000 (Thermo Scientific, Wilmington, Delaware, USA) e posteriormente estas foram diluídas ou concentradas, com a finalidade de terem a mesma concentração de DNA, $2,5 \mathrm{ng} / \mu \mathrm{L}$ de DNA.

As reações para a detecção de mixosporídeos em amostras suspeitas foram as mesmas utilizadas para a curva padrão, bem como para verificação de amplificação (item 5.3.1.2).

\subsection{Realização da PCR em Tempo Real em amostras suspeitas}

Neste estudo, foram desenvolvidos dois sistemas para detectar o produto das reações de qPCR: o sistema TaqMan® e o sistema do corante SYBR Green®.

Em ambos os sistemas as amostras foram feitas em duplicatas em placas e os dados foram calculados em média. As duplicatas que apresentaram um desvio padrão de $\mathrm{Ct}>0,5$ foram refeitas.

\subsubsection{Sistema TaqMan®}

O sistema TaqMan® escolhido utilizou uma probe fluorescente para possibilitar a detecção de DNA de mixsporídeos, da qPCR conforme esse se acumula durante os ciclos da reação.

Os primers MilF e MilR2 utilizados para as reações da qPCR foram construídos a partir de uma combinação específica de sequências do SSrDNA de mixosporídeos depositadas no GenBank, em região bastante conservada para estes parasitas como descrito no item 5.2.

Milanin et al., (dados não publicados) construíram para as reações de qPCR juntamente com os primers MilF e MilR2 uma probe marcadora denominada AMARO 5'GCCAAGGACTAACAAA -3', a qual foi obtida a partir do alinhamento das sequências de mixosporídeos descritos na América do Sul e depositadas no GenBank.

As reações de qPCR ocorreram seguindo as seguintes etapas: a combinação de primers e probe na reação de qPCR foram determinadas de acordo com o TaqMan® Normas do Protocolo Universal PCR Master Mix (Applied BiosystemsTM Inc., CA, EU). Inicialmente, para um volume de reação de $10 \mathrm{uL}$, foram utilizados $200 \mathrm{nM}$ de cada primer (Applied Biosystems Inc., CA, EU, $120 \mathrm{mM}$ de probe (Applied BiosystemsTM Inc., CA, EU, $5 \mu \mathrm{L}$ de TaqMan® Universal PCR MasterMix (Applied BiosystemsTM Inc., CA, EU, 5 ng de DNA extraído e 1 $\mu \mathrm{L}$ água ultrapura Mili-Q ${ }^{\circledR}$ (Thermo Scientific, Wilmington, Delaware USA). As reações de 
amplificação foram conduzidas no termociclador Applied Biosytems 7500 Real-Time PCR Systems (Applied Biosystems Inc., CA, EU).

O protocolo de amplificação constitui-se, inicialmente, de 1 ciclo de 20 segundos a $95^{\circ} \mathrm{C}$, seguido de 40 ciclos com desnaturação a $95^{\circ} \mathrm{C}$ por 3 segundos cada, anelamento/extensão a $60{ }^{\circ} \mathrm{C}$ por 30 segundos.

A análise da amplificação realizada pela qPCR foi analisada utilizando-se da quantificação absoluta. Na quantificação absoluta o número de cópias do SSrDNA de cada amostra foi determinado baseando-se na curva padrão.

5.4.1.1 Curva de eficiência da reação com os primers MilF, MilR e a probe AMARO

Para obter a curva de eficiência de amplificação da reação de qPCR foram realizadas reações utilizando um pool de 150 actinosporos. O DNA do pool de actinosporos foi extraído utilizando o DNeasy Blood \& Tissue kit (QIAGEN Inc., California, USA). Após, amplificouse o segmento de DNA, utilizando os primers MilF e MilR2, por meio da qPCR. O produto da reação foi purificado e a confirmação de uma única banda do tamanho esperado foi visualizado por eletroforese em gel de agarose. Houve a quantificação do produto de PCR purificado obtivendo $3,8 \mathrm{ng} / \mu \mathrm{L}$.

Para a realização da curva de eficiência de amplificação da reação de qPCR foram feitas 6 diluições seriadas na razão 10, com uma variação de $3,8 \mathrm{ng}$ à $3,8 \times 10^{-5} \mathrm{ng}$.

A eficiência de amplificação da qPCR é a taxa na qual um amplicon é gerado, geralmente expressa em porcentagem. O slope de uma curva padrão é comumente utilizado para estimar a eficiência de amplificação de uma reação de qPCR.

A curva padrão de qPCR foi graficamente representada como um gráfico de regressão linear semi-log do valor do Threshold cycle $(\mathrm{Ct})$ em comparação ao log da quantidade inicial de DNA, pela equação da reta $[\mathrm{Y}=\mathrm{B} \mathrm{X}+\mathrm{A}$ ], em que $\mathrm{Y}$ é a variável dependente $(\mathrm{Cts}), \mathrm{X}$ é a variável independente (log), A é uma constante ( ponto em que a reta intercepta o eixo Y) e B é a constante do coeficiente de regressão $\left(\mathrm{R}^{2}\right)$.

Para verificar a eficiência da reação é necessário que o $R^{2}$ seja $>0,99$, para a validação e o valor de slope (inclinação da curva) ideal é de $-3,32$ que indica uma eficiência da reação de $100 \%(\mathrm{E}=1)$. O cálculo de estimativa da eficiência de um ensaio de qPCR é dado pela seguinte fórmula $\left[E=\left(10^{-1 / \text { slope }}-1\right) \times 100\right.$ ]. Na prática a eficiência de 90 a $110 \%$ é aceitável. 
Os seguintes parâmetros foram utilizados para converter a massa em ng para número de cópias: Produto de qPCR purificado $(3,8 \mathrm{ng})$ x $6,0221 \times 10^{23} / 155 \mathrm{pb} * 1 \times 10^{9} *$ peso molecular dos nucleotídeos (660 g/mol).

5.4.1.2 Curva padrão para definição do limiar de detecção de DNA com os primers MilF, MilR e a probe AMARO

Para a construção da curva padrão para a definição do limiar de detecção foi utilizado DNA de H. pellucida e realizou-se uma diluição seriada na razão 10 em 6 pontos seguindo a curva padrão realizada na cPCR. As concentrações das diluições variaram de $0,1 \mathrm{ng}$ à $0,1 \times 10^{-5} \mathrm{ng}$.

O ciclo de corte do ensaio foi definido tecnicamente no $\mathrm{Ct} 35$, em que as amostras com $\mathrm{Ct}$ a cima deste valor foram consideradas negativas quanto a presença de DNA de mixosporídeos.

5.4.1.3 Realização da PCR em Tempo Real com DNA obtidos das amostras suspeitas com os primers MilF e MilR2 e a probe AMARO

As reações das amostras suspeitas foram realizadas em duplicatas, com o protocolo descritos no item 5.4.1.

\subsubsection{Sequenciamento de DNA das amostras suspeitas}

Os produtos do SSrDNA amplificados através das reações de qPCR foram utilizando o kit BigDye ${ }^{\circledR}$ Terminator v3.1 Cycle Sequencing (Applied Biosystems Inc., CA, EUA) e um sequenciador ABI 3730 DNA (Applied Biosystems Inc., CA, EU).

Para o sequenciamento de todas as amostras suspeitas positivas $(\mathrm{Ct} \leq 35)$ na $\mathrm{qPCR}$ foi utilizado o primer MilF.

\subsubsection{Análises das sequências obtidas}

As sequências obtidas foram visualizadas, editadas e alinhadas no programa BioEdit 7.1.3.0 (Hall, 1999), e, em seguida, foram comparadas juntamente com outras sequências de mixosporídeos já descritos e com sequências depositadas no GenBank usando o programa Basic Local Aligment Search Tool (BLASTn) National Center for Biotechnology (NCBI).

\subsubsection{Estimativa do número de cópias do SSrDNA}

Para estimar o número de cópias do SSrDNA em 1 litro de água coletada, a quantificação obtida de DNA de cada amostra suspeita $(\mathrm{ng} / \mu \mathrm{L})$ pelo espectrofotômetro NanoDrop das extrações de DNA de todas as amostras suspeitas foram multiplicadas por 120 (valor em $\mu \mathrm{L}$ da 
eluição do DNA na etapa de extração). Obtivemos assim as quantidades totais em ng de cada amostra suspeita. Esse valor foi correlacionado com o número de cópias do SSrDNA calculado para cada amostra suspeita. O cálculo do número de cópias do SSrDNA em 5 ng de DNA de cada amostra foi através da equação inversa do log (ver item 5.4.1.1).

Nas reações de qPCR foram pipetadas 5 ng de DNA de cada amostra suspeita e a partir dos resultados obtidos pode-se relacionar com dados publicados nos trabalhos (HALLETT \& BARTHOLOMEW, 2006; KELLEY et al., 2004) que determinaram que cada célula (presumivelmente cada núcleo) de Myxobolus cerebralis, obtém 104 cópias do SSrDNA, e que um mixosporo possui 5 células, mais 6 núcleos (ELMATBOULI et al., 1995), portanto possui 624 cópias do SSrDNA. E que um actinosporo, Triactinomyxon, é composto por 71 células ou núcleos (3 células valvares, 3 células capsulogênicas, 64 células germinativas e 1 célula envolvente de esporoplasma (EL-MATBOULI \& HOFFMANN 1998), o que equivale a 7384 cópias por mixosporo. A partir destes dados podemos calcular e inferir quantos esporos poderiam estar presentes em cada litro de água coletada.

\subsubsection{Sistema SYBR Green®}

O sistema do corante $S Y B R$ Green® possui ligação altamente específica ao DNA duplafita, para detectar o produto da PCR conforme ele se acumula durante os ciclos da reação.

Os primers utilizados para as reações da qPCR, com o sistema SYBR Green®, foram construídos com o objetivo de identificar uma única espécie de mixosporídeo dentro dos sistemas de criação de peixes, os primers HpelF e HpelR (descritos no item 5.3.2.1).

$\mathrm{O}$ volume total da reação de $10 \mu \mathrm{L}$ foi composto de $300 \mathrm{nM}$ de cada primer (Applied Biosystems Inc., CA, EUA), 5 uL de SYBR Green ${ }^{\circledR}$ Universal PCR Master Mix (Applied Biosystems Inc., CA, EUA), $2 \mu$ de DNA foram utilizados e 1,8 $\mu \mathrm{L}$ água ultrapura Mili-Q® (Thermo Scientific, Wilmington, Delaware, USA). Os primers utilizados na reação de qPCR foram os HpelF e HpelR.

O protocolo de amplificação constitui-se de inicialmente 1 ciclo de 20 segundos a $95{ }^{\circ} \mathrm{C}$, seguido de 40 ciclos com desnaturação a $95^{\circ} \mathrm{C}$ por 3 segundos cada, anelamento/ extensão a $60{ }^{\circ} \mathrm{C}$ por 30 segundos mais a etapa de curva de melting com um ciclo a $95^{\circ} \mathrm{C}$ por 15 segundos, outra etapa a $60{ }^{\circ} \mathrm{C}$ por 1 minuto, outra etapa a $95^{\circ} \mathrm{C}$ por 15 segundos e uma última a $60^{\circ} \mathrm{C}$ por 15 segundos. 
As reações de amplificação foram conduzidas no termociclador Applied Biosytems 7500 Real-Time PCR Systems (Applied Biosystems Inc., CA, EUA). Também foi realizada a curva de dissociação, conhecida como curva de melting, após a amplificação do DNA alvo para verificar a especificidade do produto amplificado. A análise de curva de melting foi realizada através de uma tempetatura especifica, temperatura de melting (Tm). A Tm é a temperatura na qual metade das fitas de DNA está na forma de fita simples e a outra metade na forma de dupla helice.

\subsubsection{Curva de eficiência da reação com os primers HpelF e HpelR}

Para avaliar a eficiência de amplificação da reação da qPCR foi construída uma curva de diluição em série de 6 pontos, partindo de 0,1 ng à $0,1 \times 10^{-5}$ ng de DNA de Henneguya pellucida. A curva padrão foi obtida pela relação entre o Ct e o log da concentração de DNA nas amostras padrões, e a partir da inclinação da reta foi calculado a eficiência da amplificação.

\subsection{Primers utilizados nas reações de PCR Convencional e PCR em Tempo Real}

Todos os primers e probe esquematizados neste estudo e os escolhidos a partir de estudos anteriores, para a amplificação e sequenciamento do SSrDNA, foram descriminados e esquematizados (Tabela 2 e Figura 5).

Tabela 2. Sequências de primers e probe utilizados para amplificação e sequenciamento do SSrDNA na PCR Convencional e PCR em Tempo Real deste estudo.

\begin{tabular}{|c|c|c|}
\hline $\begin{array}{c}\text { Primers } \\
\text { e probe }\end{array}$ & Sequência 5' $-\mathbf{3}$, & Referência \\
\hline MilF** & ATTTGGCAGCGAGAGGTGAA & Milanin et al., (dados não publicados) \\
\hline MilR2** & CCCGGGTCGGCATAGTTTAC & Milanin et al., (dados não publicados) \\
\hline AMARO* & GCCAAGGACTAACAAA & Milanin et al., (dados não publicados) \\
\hline MX5 & CTGCGGACGGCTCAGTAAATCAGT & Andree et al., (1999) \\
\hline MX3 & CCAGGACATCTTAGGGCATCACAGA & Andree et al., (1999) \\
\hline HpelF & CTCTGTTGGTAGGGTGAGTGGG & Neste estudo \\
\hline HpelR & ATCGAGTAGACCGCACACTGTC & Neste estudo \\
\hline *probe \\
$* *$ primers usados para o sequenciamento do SSrDNA
\end{tabular}


Figura 5. Representação esquematizada da localização dos primers e probe utilizados para amplificação e sequenciamento do SSrDNA na PCR Convencional e PCR em Tempo Real.

\section{Probe AMARO}

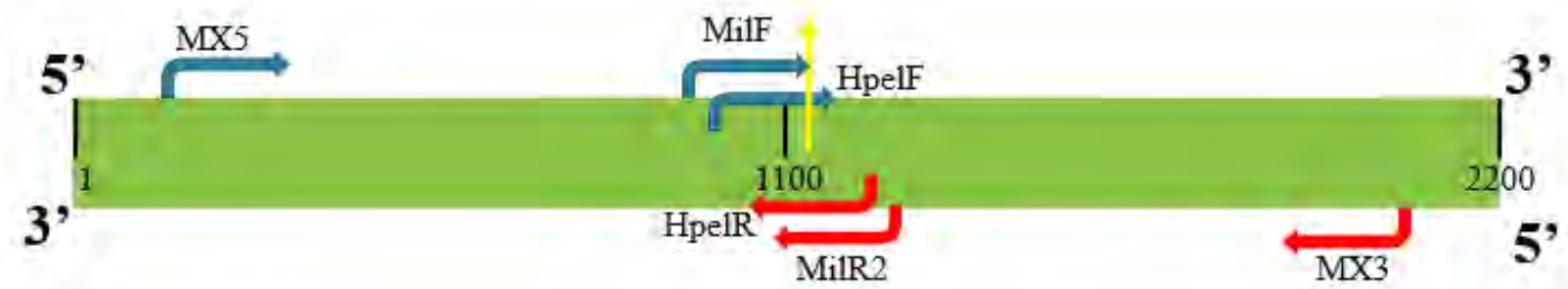




\section{Resultados}

\subsection{Coleta de amostras suspeitas de água, filtração das amostras e extração de DNA}

Foram analisadas 48 amostras de água provenientes de duas pisciculturas do estado de São Paulo. Desta forma, detectamos DNA de mixosporídeos disponíveis na água quando analisada por PCR Convencional e PCR em Tempo Real. As concentrações de DNA obtidas das amostras suspeitas variaram entre 1,6 ng/ $\mu \mathrm{L}$ a 53,2 $\mathrm{ng} / \mu \mathrm{L}$, com um valor médio de 9,747 ng/ $\mu \mathrm{L}$ (Tabela $3)$.

Tabela 3. Concentração de DNA extraído das amostras de água coletadas das pisciculturas do CEPTA (CE) e de Porto Ferreira (PF) em ng/ $\mu \mathrm{L}$

\begin{tabular}{|c|c|c|c|}
\hline $\begin{array}{c}\text { Amostras } \\
(\mathbf{C E})\end{array}$ & $\begin{array}{c}\text { Concentração de } \\
\text { DNA }(\mathbf{n g} / \boldsymbol{\mu L})\end{array}$ & $\begin{array}{c}\text { Amostras } \\
(\mathbf{P F})\end{array}$ & $\begin{array}{c}\text { Concentração de } \\
\text { DNA }(\mathbf{n g} / \boldsymbol{\mu} \mathbf{L})\end{array}$ \\
\hline 01 & 1,8 & 01 & 27,6 \\
02 & 4,2 & 02 & 17,9 \\
03 & 3,8 & 03 & 18,2 \\
04 & 2,4 & 04 & 22,5 \\
05 & 3,1 & 05 & 26,4 \\
06 & 1,6 & 06 & 16,5 \\
07 & 39,8 & 07 & 21,7 \\
08 & 8,4 & 08 & 3,0 \\
09 & 2,3 & 09 & 18,9 \\
10 & 4,3 & 10 & 7,6 \\
11 & 3,0 & 11 & 2,8 \\
12 & 8,6 & 12 & 11,8 \\
13 & 5,3 & 13 & 6,5 \\
14 & 13,4 & 14 & 6,3 \\
15 & 6,8 & 15 & 8,1 \\
16 & 3,8 & 16 & 17,5 \\
17 & 9,5 & 17 & 8,0 \\
18 & 4,6 & 18 & 8,2 \\
19 & 3,3 & 19 & 6,9 \\
20 & 53,2 & 20 & 8,3 \\
21 & 4,9 & 21 & 9,8 \\
22 & 2,5 & 22 & 9,7 \\
23 & 2,7 & 23 & 14,5 \\
24 & 2,4 & 24 & 27,6 \\
\hline
\end{tabular}




\subsection{Validação das etapas de filtração e extração de DNA com as amostras-controle}

As concentrações de DNA obtidas das duas amostras-controle variaram entre 36,2 ng/ $\mu \mathrm{L}$ e $41,1 \mathrm{ng} / \mu \mathrm{L}$, com um valor médio de $38,65 \mathrm{ng} / \mu \mathrm{L}$. Os valores do grau de pureza de DNA variaram entre 1,72 e 1,78 com um valor médio de 1,75 .

A fim de validar a eficiência do método utilizado para a filtração e extração de DNA das membranas de nitrato de celulose, foram realizadas reações de cPCR para a amplificação do SSrDNA das amostras-controle. As amostras-controle foram "batizadas" com mixósporos de mixosporídeos como descrito no item 5.2.

\subsubsection{Realização da PCR Convencional com as amostras-controle}

As reações de cPCR foram realizadas utilizando duas amostras como controle: uma com 41,1 ng/uL de DNA e outra com 36,2 ng/uL de DNA. As reações com as duas amostras controle foram realizadas com o conjunto de primers MilF e MilR2 (Figura 6).

Figura 6. Eletroforese em gel de agarose 1,5\% corado com $\mathrm{SyBr}$ Safe A. Marcador de Peso Molecular $1 \mathrm{~Kb}$. (1100 pares de bases); B. Produto de PCR do controle 1; C. Produto de PCR do controle 2; D. Controle Negativo.

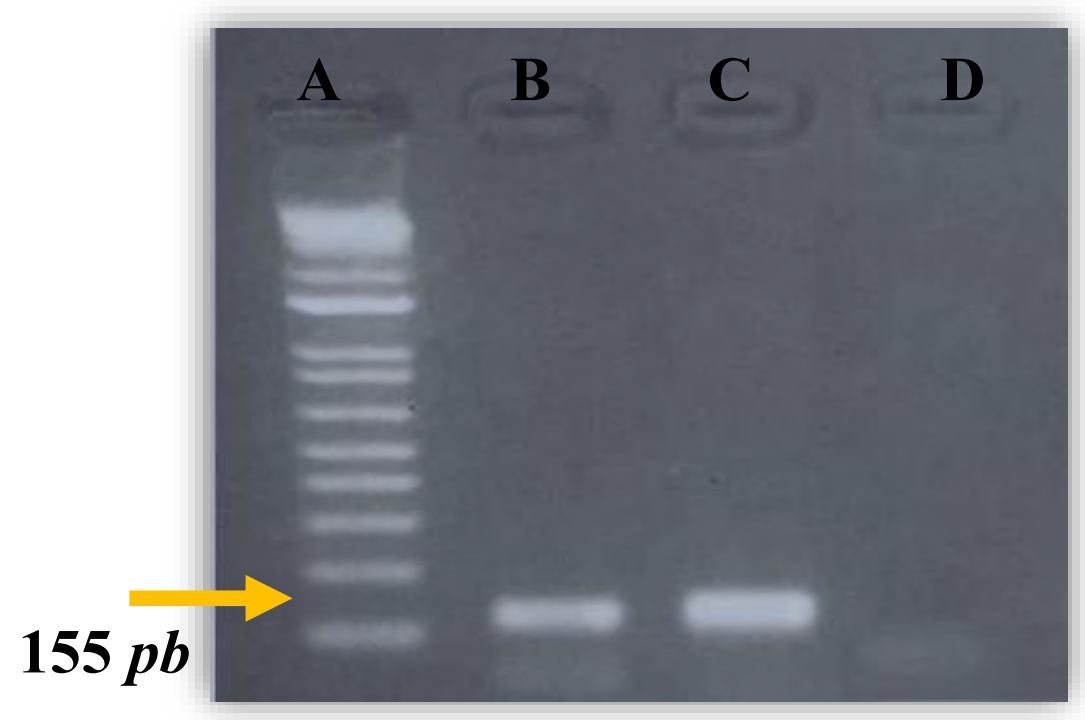

\subsubsection{Sequenciamento e análise das sequências obtidas das amostras-controle}

A sequência obtida do SSrDNA utilizando os primers MilF e MilR2 para a amostracontrole positivo 1 gerou um fragmento de $133 \mathrm{pb}$. 
Após a pesquisa BLASTn na busca de similaridades da amostra controle 1 (Figura 7), foram obtidas um total de 100 sequências, das quais todas correspondentes a mixosporídeos (82 mixosporos e 18 actinosporos).

Figura 7. Pesquisa BLASTn com a sequência obtida com a amostra-controle 1.

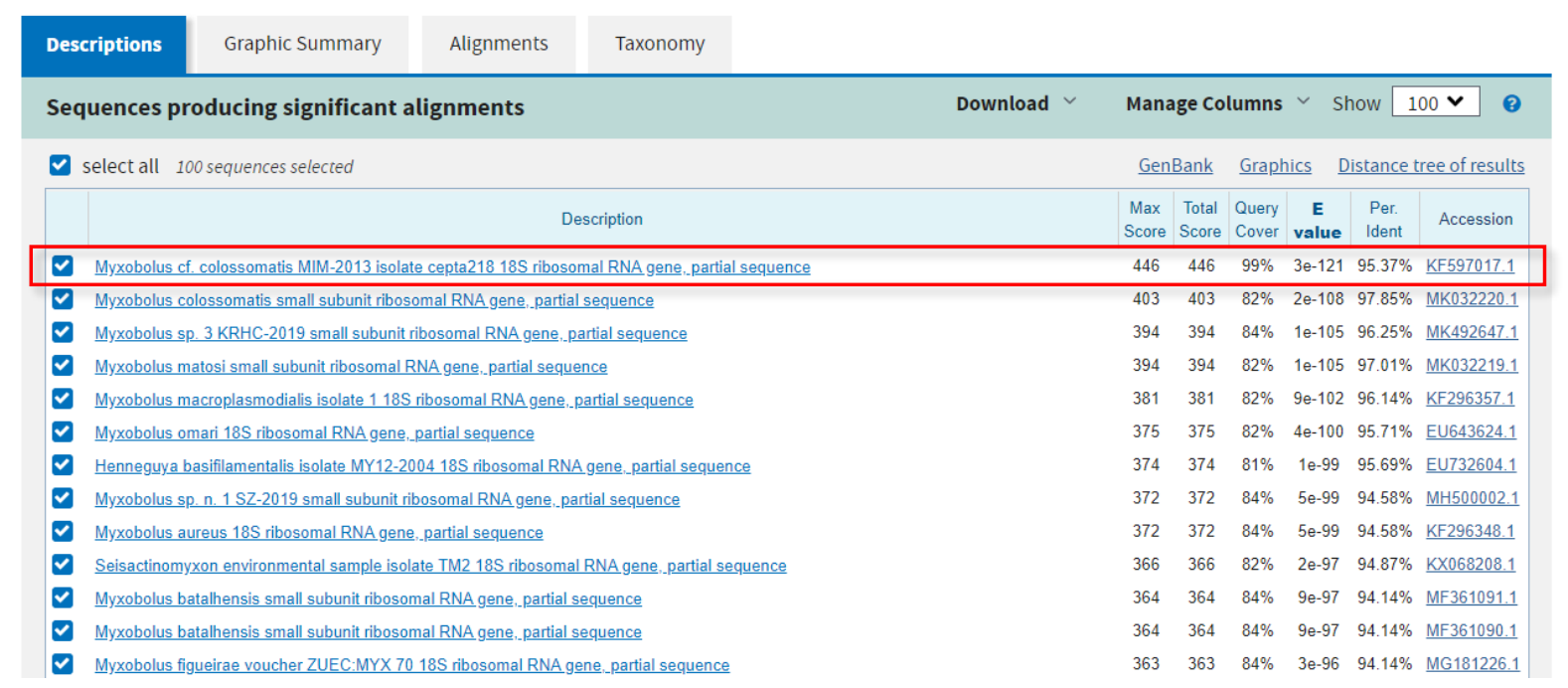

As maiores similaridades encontradas para a amostra-controle 1 foram de 95, 97 e $96 \%$ com SSrDNA de Myxobolus cf. colossomatis (KF597017.1), Myxobolus colossomatis (MK032220.1), e Myxobolus sp. 3 (MK492647.1), respectivamente, confirmando que o produto amplificado pela PCR é de um mixosporídeos do gênero Myxobolus Bütschli, 1882, como identificado inicialmente no rompimento do cisto.

A sequência do produto de PCR do controle 2 apresentou baixa qualidade, com picos sobrepostos impossibilitando o alinhamento e consequentemente a análise da sequência.

\subsection{Realização da PCR Convencional}

\subsubsection{PCR Convencional com os primers MX5 e MX3}

\subsubsection{Curva padrão para a definição do limiar de detecção de DNA com os primers MX5 e MX3}

As amplificações das reações de cPCR para a detecção da curva padrão utilizaram os primers MX5 e MX3 (Figura 8). A partir dos resultados obtidos pela curva padrão da cPCR, é 
possível definir que essa técnica é capaz de detectar até quantia de $0,1 \times 10^{-3} \mathrm{ng} / \mu \mathrm{L}$ de DNA de H. pellucida.

Figura 8. Eletroforese em gel de agarose 1,5\% corado com SyBr Safe; A. Marcador de Peso Molecular $1 \mathrm{~Kb}$.; 1. ao 6. Pontos da curva padrão da cPCR com os primers MX5 e MX3 em diluições de DNA controle variando de 1 ng a $0,1_{x} 10^{-4} \mathrm{ng} ; 1.1 \mathrm{ng}$ de DNA de H. pellucida; 2. $0,1 \mathrm{ng}$ de DNA de $H$. pellucida; 3. $0,1 \times 10^{-1} \mathrm{ng}$ de DNA de H. pellucida; 4. $0,1_{x} 10^{-2} \mathrm{ng}$ de DNA de H. pellucida; 5. $0,1 \times 10^{-3} \mathrm{ng}$ de DNA de H. pellucida; $6.0,1 \times 10^{-4} \mathrm{ng}$ de DNA de H. pellucida; B. Contorole Negativo.

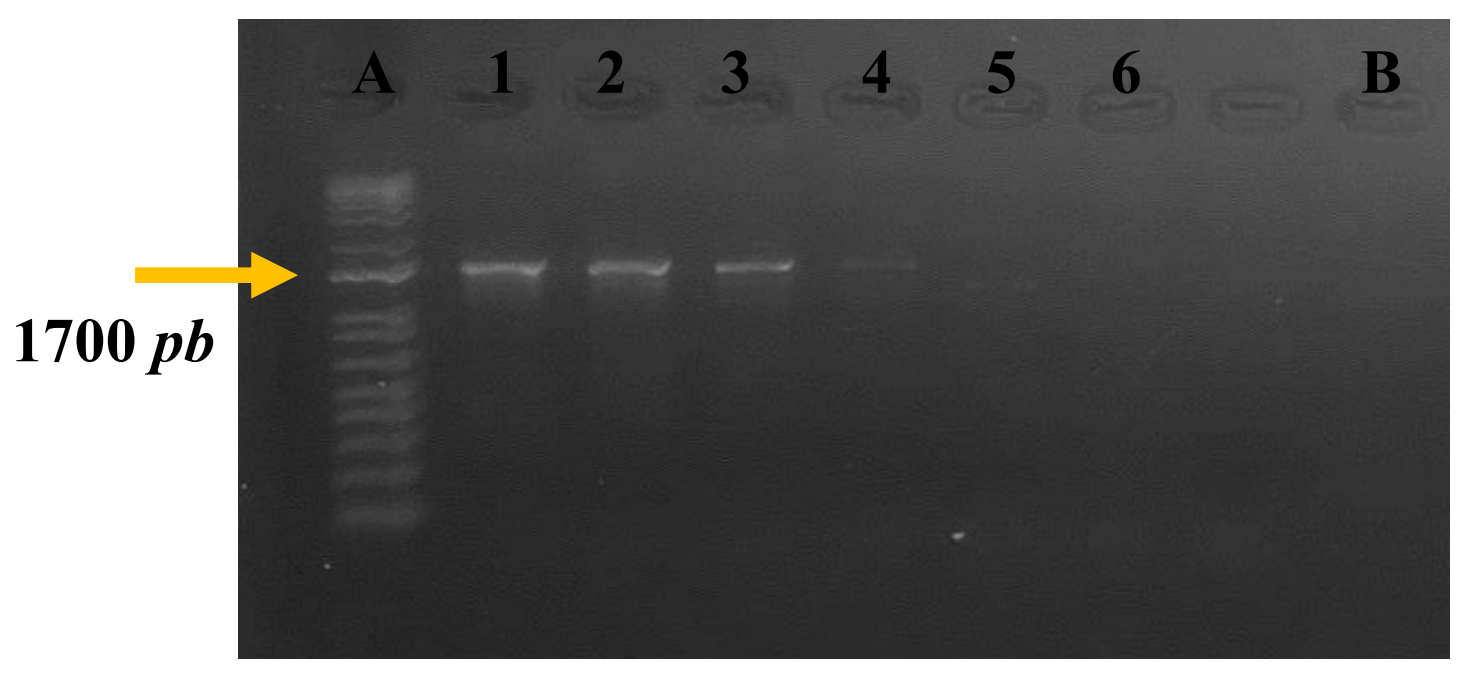

6.3.1.2 PCR Convencional com DNA das amostras suspeitas com os primers MX5 e MX3

Foram feitas reações de cPCR para as 48 amostras suspeitas de DNA coletadas nas pisciculturas, localizadas no município de Porto Ferreira (24 amostras) e no CEPTA na cidade de Pirassununga (24 amostras). As amostras suspeitas coletadas nos dois municípios no interior do Estado de São Paulo foram submetidas primeiramente as reações de cPCR com os primers MX5 e MX3.

Dentre as 24 amostras coletadas no CEPTA (CE) na cidade de Pirassununga, 15 mostraramse positivas quanto à presença de DNA de mixosporídeos, de acordo com as amplificações visualizados no gel de agarose em UV (Figuras 9 e 10). 
Figura 9. Eletroforese em gel de agarose 1,5\% corado com $\mathrm{SyBr}$ Safe do produto de cPCR das amostras suspeitas coletadas no CEPTA com os primers MX5 e MX3; A. Marcador de Peso Molecular 1 Kb.; 1. a 12. Produto de PCR com DNA das amostras água suspeitas coletadas no CEPTA; B. Controle Negativo.

\section{$\begin{array}{lllllllllllllll}\text { A } & 1 & 2 & 3 & 4 & 5 & 6 & 7 & 8 & 9 & 10 & 11 & 12 & \text { B }\end{array}$}

\section{$1700 p b$}

Figura 10. Eletroforese em gel de agarose 1,5\% corado com $\mathrm{SyBr}$ Safe do produto de cPCR das amostras suspeitas coletadas no CEPTA com os primers MX5 e MX3; A. Marcador de Peso Molecular $1 \mathrm{~Kb}$.; 13. a 24. Produto de PCR com DNA das amostras água suspeitas coletadas no CEPTA; B. Controle Negativo.

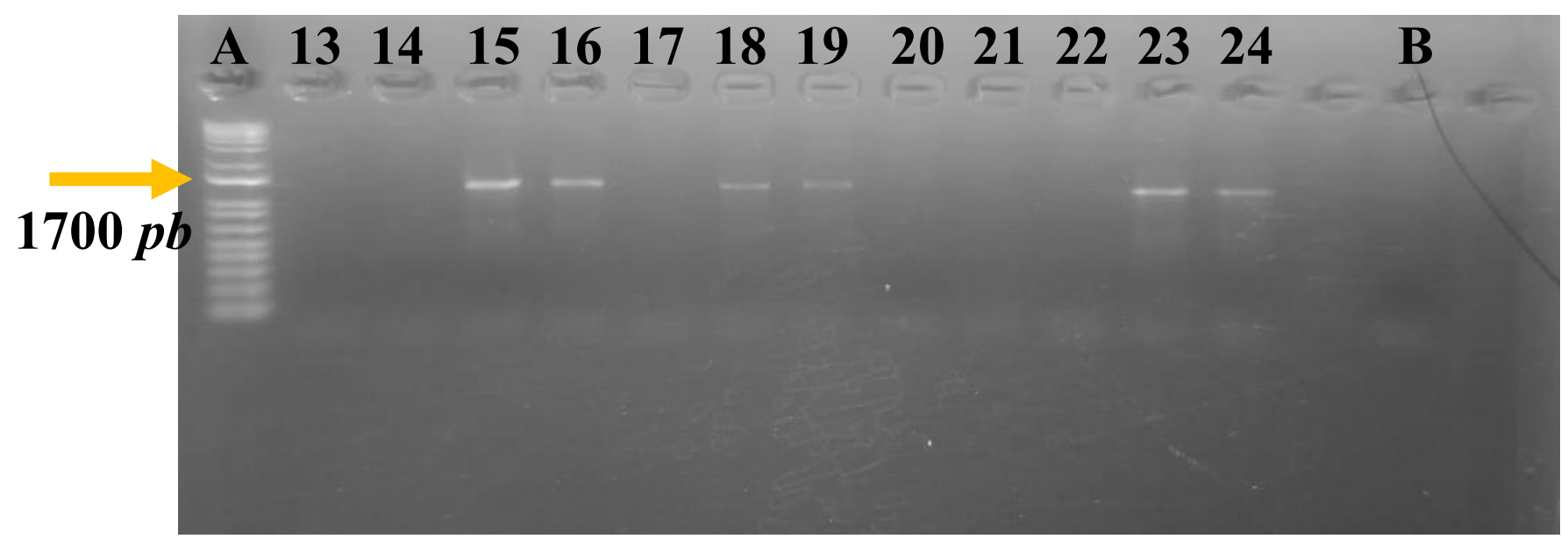

De acordo com as bandas mostradas na eletroforese em gel de agarose no tamanho esperado, 1.700 pares de bases, para a amplificação realizada com os primers MX3-MX5, as amostras 2, $3,4,5,6,7,9,10,12,15,16,18,19,23$ e 24 amplificaram. Desta forma, através do teste aplicado, 62,5\% das amostras analisadas são positivas para a presença de mixosporídeos.

Das 24 amostras coletadas no município de Porto Ferreira em uma criação de peixes, 9 mostraram-se positivas quanto à presença de DNA de mixosporídeos (Figuras 11 e 12). 
Figura 11. Eletroforese em gel de agarose 1,5\% corado com $\mathrm{SyBr}$ Safe, do produto de cPCR das amostras suspeitas coletadas na piscicultura de Porto Ferreira com os primers MX5 e MX3; A. Marcador de Peso Molecular 1 Kb.; 1. a 12. Produto de PCR com DNA das amostras água suspeitas coletadas na piscicultura da cidade de Porto Ferreira; B. Controle Negativo.

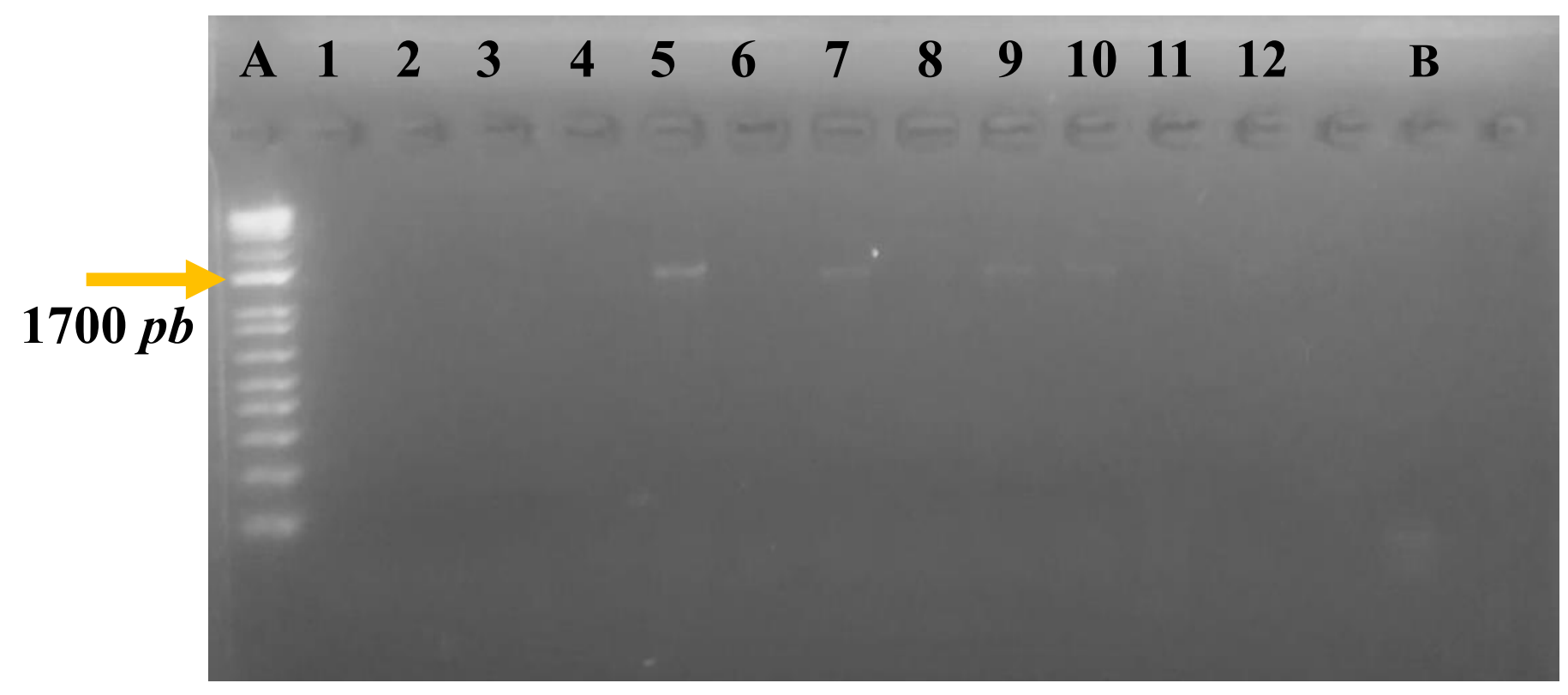

Figura 12. Eletroforese em gel de agarose 1,5\% corado com SyBr Safe, do produto de cPCR das amostras suspeitas coletadas na piscicultura de Porto Ferreira com os primers MX5 e MX3; A. Marcador de Peso Molecular $1 K b$.; 13. a 24. Produto de PCR com DNA das amostras água suspeitas coletadas na piscicultura da cidade de Porto Ferreira; B. Controle Negativo.

A $1314151617 \quad 18 \quad 19202122 \quad 2324$

\section{$1700 p b$}

As amostras 5,7 ,9, 10, 14, 16, 21, 22 e 24 amplificaram aproximadamente 1.700 pares de bases, ou seja, 37,5\% das amostras amplificaram quanto à presença de mixosporídeos na água do tanque. 


\subsubsection{PCR Convencional com os primers HpelF e HpelR}

\subsubsection{Curva padrão para a definição do limiar de detecção de DNA com os primers HpelF e HpelR}

As amplificações das reações de cPCR para a detecção da curva padrão utilizaram os primers HpelF e HpelR (Figura 13). A partir dos resultados obtidos pela curva padrão da cPCR, essa técnica é capaz de detectar até quantia de $0,1 \mathrm{ng} / \mu \mathrm{L}$ de DNA de H. pellucida.

Figura 13. Eletroforese em gel de agarose 1,5\% corado com SyBr Safe; A. Marcador de Peso Molecular $1 K b$.; 1. ao 6. Pontos da curva padrão da cPCR com os primers HpelF e HpelR em diluições de DNA controle variando de $1 \mathrm{ng}$ a $0,1 \times 10^{-4} \mathrm{ng} ; \mathbf{1}$. $1 \mathrm{ng}$ de DNA de H. pellucida; 2. $0,1 \mathrm{ng}$ de DNA de H. pellucida; 3. $0,1 \times 10^{-1} \mathrm{ng}$ de DNA de H. pellucida; 4. $0,1 \times 10^{-2} \mathrm{ng}$ de DNA de H. pellucida; 5. $0,1 \times 10^{-3} \mathrm{ng}$ de DNA de H. pellucida; 6. $0,1 \times 10^{-4} \mathrm{ng}$ de DNA de H. pellucida; B. Contorole Negativo.

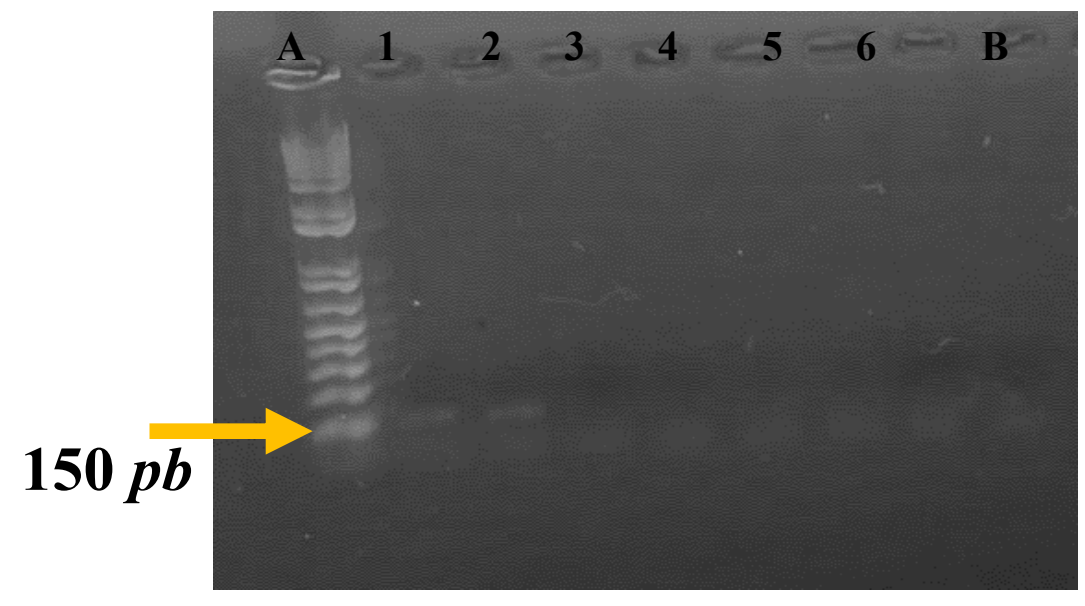

6.3.2.2 Especificidade dos primers HpelF e HpelR para detecção de DNA de Henneguya pellucida

Para avaliar a especificidade do conjunto de primers desenvolvidos especificamente para a espécie $H$. pellucida foram produzidos testes de verificação na cPCR com amostra de DNA de outros mixosporídeos. As reações foram realizadas utilizando DNA de actinosporo Aurantiactinomyxon tipo 1, DNA de mixosporo Myxobolus macroplasmodialis além da amostra de DNA de H. pellucida. O tamanho esperado da banda no gel de agarose foi de 150 pares de bases (Figura 14).

Os resultados mostraram que os primers HpelF e HpelR desenvolvidos para a espécie $H$. pellucida não amplificaram outros DNA de mixosporídeos. Desta forma, conclui-se que são específicos apenas para $H$. pellucida. 
Figura 14. Gel de agarose $1,5 \%$ corado com SyBr Safe; A. Marcador de Peso Molecular 1 Kb.; B. Produto de PCR com DNA de actinosporo (Aurantiacnomyxon tipo 1); C. Produto de PCR com DNA de mixosporo (Myxobolus macroplasmodialis); D. Controle Negativo; E. Produto de PCR com DNA de H. pellucida.

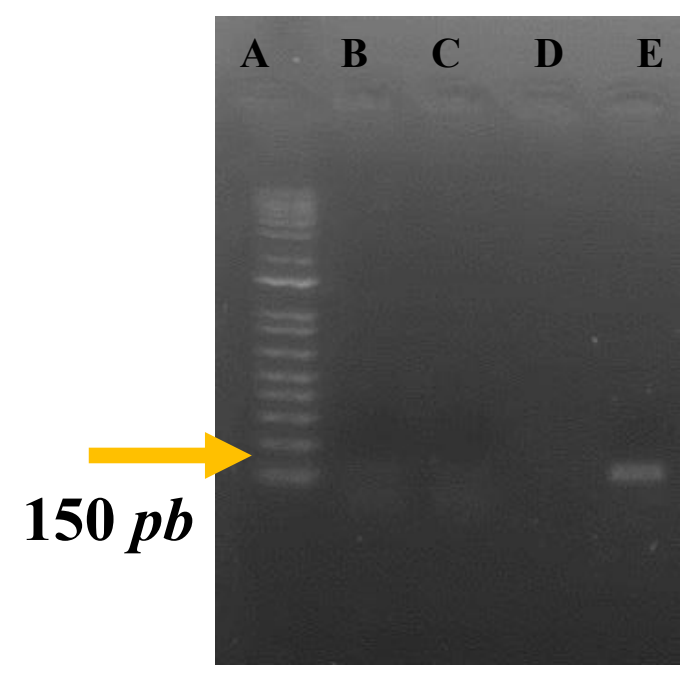

6.3.2.3 PCR Convencional com DNA das amostras suspeitas com os primers HpelF e HpelR

Todas as 48 amostras de água suspeitas coletadas nas duas psiculturas também foram submetidas às reações de cPCR com os primers HpelF e HpelR, após os resultados satisfatórios de especificidade dos primers (item 6.3.2.2).

Dentre as 24 amostras coletadas no CEPTA na cidade de Pirassununga, 3 amostras amplificaram quanto à presença de DNA de H. pellucida, de acordo com as amplificações visualizadas na eletroforese em gel de agarose (Figuras 15). 
Figura 15. Eletroforese em gel de agarose $1,5 \%$ na presença de $S y B r$ Safe, do produto de cPCR das amostras suspeitas do CEPTA com os primers HpelF e HpelR; A. Marcador de Peso Molecular 1Kb.; 1. a 12. Produto de PCR com DNA das amostras água suspeitas coletadas no CEPTA; B. Controle Negativo.

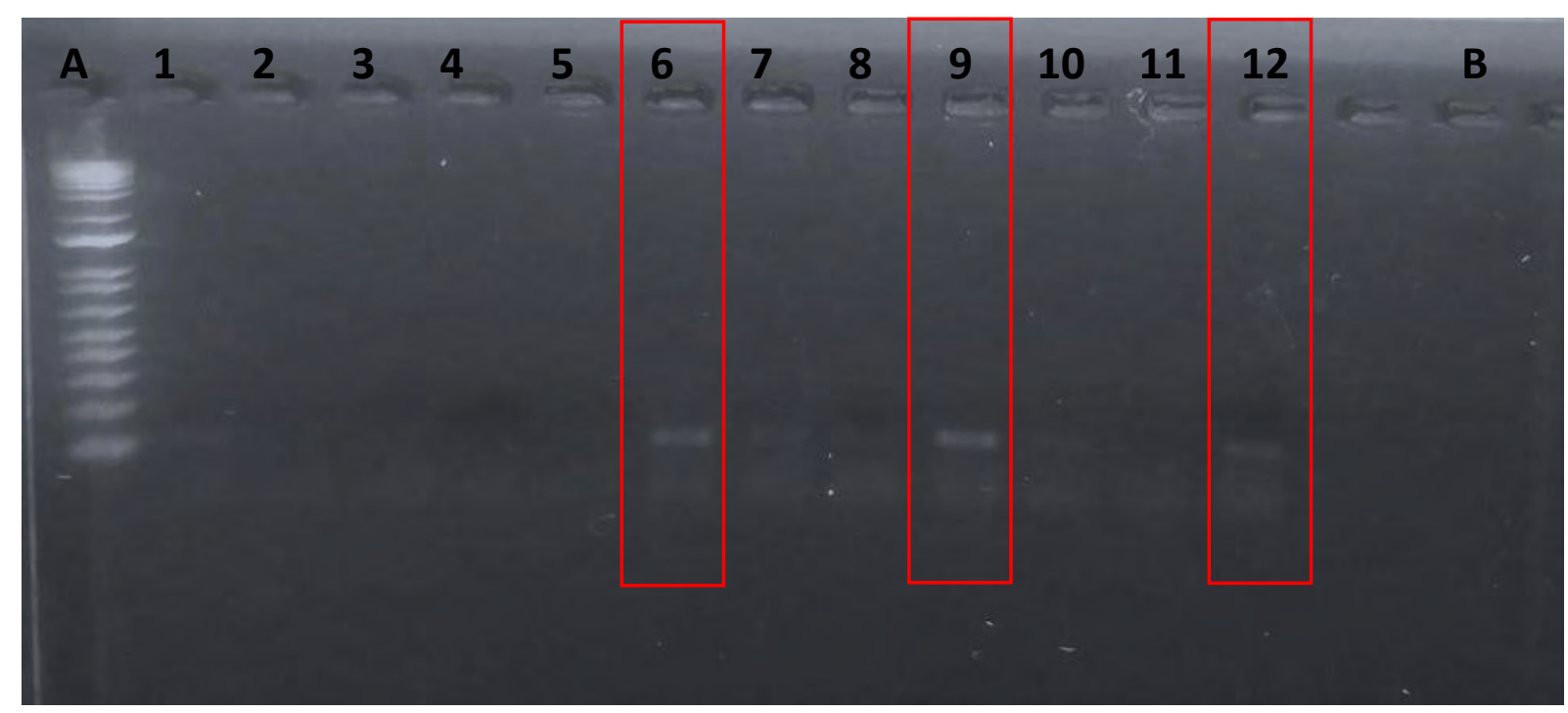

Dentre as 24 amostras suspeitas coletadas no município de Porto Ferreira em uma criação de peixes, nenhuma amostra amplificou quanto à presença de DNA de H. pellucida. Acreditase que esta espécie -Henneguya pellucida- não esteja presente nesse tanque de peixes, embora haja a amplificação de DNA de mixosporídeo em geral com os primers MX5 e MX3. Desta forma, presume-se que há outras espécies de mixosporídeos, como relatado no item 6.3.1.2.

Os resultados das reações de cPCR realizadas com conjuntos de primers diferentes com as mesmas 48 amostras, mostraram que 24 amostras suspeitas amplificaram quanto à presença de mixosporídeos com o conjunto de primers MX5 - MX3, e com o conjunto de primers HpelF - HpelR, 3 amostras amplificaram quanto à presença de H. pellucida (Tabela 4).

Tabela 4. Resultados das cPCR com os conjuntos de primers MX5 - MX3 e HpelF - HpelR das 48 amostras suspeitas de DNA coletadas nas pisciculturas do CEPTA (CE) e Porto Ferreira (PF).

\begin{tabular}{|c|c|c|}
\hline Amostras & $\begin{array}{c}\text { Resultados } \\
\text { MX5/MX3 }\end{array}$ & $\begin{array}{c}\text { Resultados } \\
\text { HpelF/HpelR }\end{array}$ \\
\hline CE 01 & - & - \\
CE 02 & + & - \\
CE 03 & + & - \\
CE 04 & + & - \\
CE 05 & + & - \\
CE 06 & + & + \\
CE 07 & + & - \\
CE 08 & - & - \\
CE 09 & + & + \\
CE 10 & + & - \\
\hline
\end{tabular}




\begin{tabular}{|l|l|l|} 
CE 11 & - & - \\
CE 12 & + & + \\
CE 13 & - & - \\
CE 14 & - & - \\
CE 15 & + & - \\
CE 16 & + & - \\
CE 17 & - & - \\
CE 18 & + & - \\
CE 19 & + & - \\
CE 20 & - & - \\
CE 21 & - & - \\
CE 22 & - & - \\
CE 23 & + & - \\
CE 24 & + & - \\
PF 01 & - & - \\
PF 02 & - & - \\
PF 03 & - & - \\
PF 04 & - & - \\
PF 05 & + & - \\
PF 06 & - & - \\
PF 07 & + & - \\
PF 08 & - & - \\
PF 09 & + & - \\
PF 10 & + & - \\
PF 11 & - & - \\
PF 12 & - & - \\
PF 13 & - & - \\
PF 14 & - & - \\
PF 15 & + & - \\
PF 16 & - & - \\
PF 17 & + & - \\
PF 19 & - & - \\
PF 20 & - & - \\
PF 21 & - & - \\
PF 22 & - & - \\
PF 23 & - & - \\
PF & - & - \\
\hline & - & - \\
\hline & - & - \\
\hline & - & - \\
\hline
\end{tabular}

\subsection{Realização da PCR em Tempo Real}

\subsubsection{Sistema TaqMan®}

6.4.1.1 Curva de eficiência da reação com os primers MilF, MilR2 e a probe AMARO 
A curva de eficiência da amplificação mostrou uma variação de 500.000 cópias, (média do Ct 6: 20,736) até 5 cópias, (média do Ct 1: 37,488) (Tabela 5.). O valor do $\mathrm{R}^{2}$ foi de 0,9982 , o do slope foi de -3,3368. A eficiência da reação foi de 99,38\%.

Tabela 5. Resultado da eficiência da reação com os primers MilF, MilR2 e probe AMARO, na qPCR utilizando como alvo DNA de actinosporos (pool de 150 actinosporos) em diluições de 3,8 a $3,8 \times 10^{-5}$ ng de DNA.

\begin{tabular}{|c|c|c|c|}
\hline $\begin{array}{c}\text { Diluição do } \\
\text { DNA de } \\
\text { actinosporo } \\
(\mathbf{n g})\end{array}$ & $\begin{array}{c}\text { Número de cópias } \\
\text { amplificadas do } \\
\text { SSrDNA }\end{array}$ & Log & Média do Ct \\
\hline 3,8 & 500000 & 5,698970004 & 20,89671707 \\
$3,8 \times 10^{-1}$ & 50000 & 4,698970004 & 23,82810402 \\
$3,8 \times 10^{-2}$ & 5000 & 3,698970004 & 27,09329414 \\
$3,8 \times 10^{-3}$ & 500 & 2,698970004 & 30,46067619 \\
$3,8 \times 10^{-4}$ & 50 & 1,698970004 & 33,65071869 \\
$3,8 \times 10^{-5}$ & 5 & 37,6092453 & 37,6092453 \\
\hline
\end{tabular}

O primeiro ponto da curva, o mais concentrado com 3,8 ng de DNA, amplificou a partir de 500.000 cópias (média do Ct 6: 20,736); o segundo ponto com 3,8 x 10 $10^{-1} \mathrm{ng} / \mathrm{com} 50.000$ cópias (Ct 5: 23,93); o terceiro ponto 3,8 $\times 10^{-2} \mathrm{ng}$ com 5000 cópias (Ct 4: 27,09); o quarto ponto $3,8 \times 10^{-3} \mathrm{ng}$ com 500 cópias (Ct 5: 30,51); o quinto ponto $3,8 \times 10^{-4} \mathrm{ng}$ com 50 cópias (Ct 5: 33,80); e o sexto e último ponto com $3,8 \times 10^{-5} \mathrm{ng}$ com 5 cópias (Ct 6: 37,48).

Figura 16. Gráfico da curva padrão de eficiência da reação com os primers MilF, MilR2 e probe AMARO, na qPCR utilizando como alvo DNA de actinosporos em diluições de 3,8 a 3,8 x $10^{-5}$ cópias de DNA.

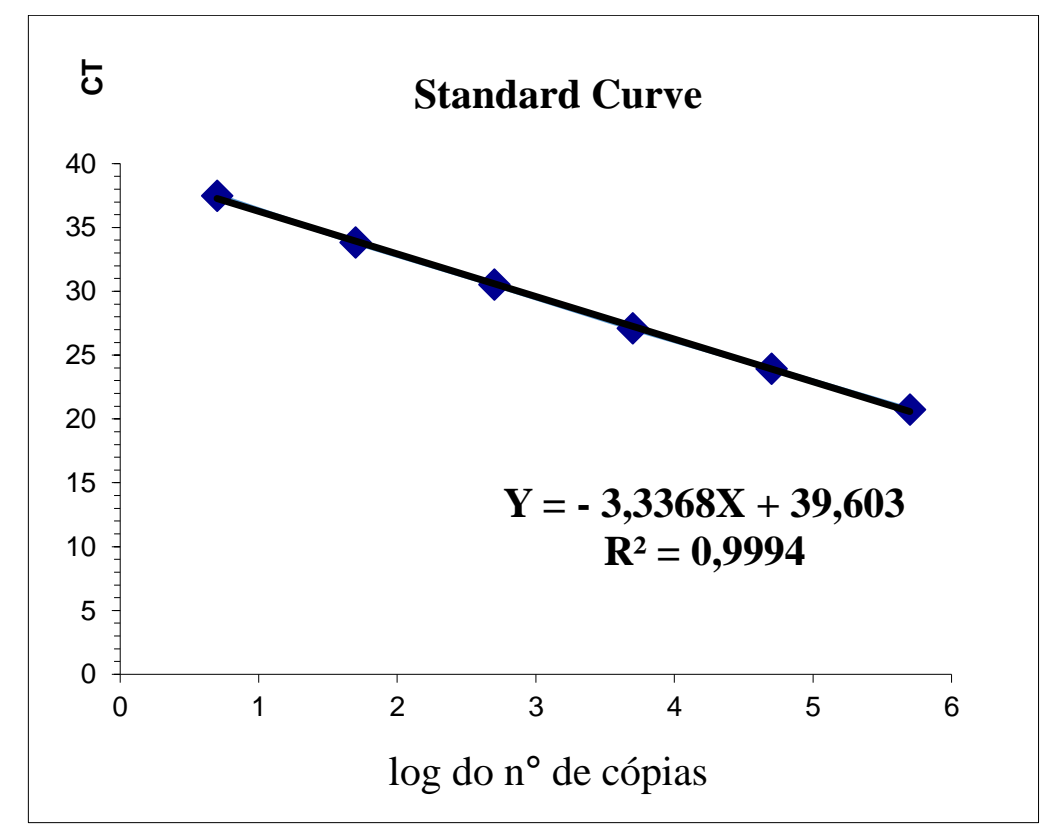


6.4.1.2 Curva padrão para definição do limiar de detecção de DNA com os primers MilF, MilR2 e a probe AMARO

O limiar de ciclos ou ciclo threshold $(\mathrm{Ct})$ foi determinado a partir do $\mathrm{Ct} \geq 35$, em que as amostras acima desse valor foram consideradas negativas quanto à presença de mixosporídeos.

O valor do limiar detectável $(\mathrm{Ct} 35)$ corresponde a 25 cópias do SSrDNA. Esse valor foi estabelecido tecnicamente, pois, a partir do $\mathrm{Ct} 35$, as duplicatas perdem qualidade e começam a ter diferenças de mais de $0,5 \mathrm{Ct}$, além da eficiência da amplificação cair muito nessa faixa. Desta forma o método desenvolvido no estudo foi capaz de detectar a partir de 25 cópias do SSrDNA de mixosporídeos.

Cada ponto da curva padrão gerada da diluição de DNA de mixosporídeos foi relacionada ao número de cópias do SSrDNA amplificadas na qPCR (Tabela 6).

Tabela 6. Curva padrão para definição do limiar de detecção de DNA de mixosporídeos com os primers MilF, MilR2 e a probe AMARO, utilizando como alvo DNA de Henneguya pellucida em diluições de 0,1 a $0,1^{\times} 10^{-5} \mathrm{ng}$ de DNA.

\begin{tabular}{|c|c|c|}
\hline $\begin{array}{c}\text { Diluição do } \\
\text { DNA de Henneguya } \\
\text { pellucida } \text { (ng) }\end{array}$ & Média do Ct & $\begin{array}{c}\text { Número de cópias } \\
\text { amplificadas do SSrDNA }\end{array}$ \\
\hline 0,1 & 19,738 & 913725 \\
$0,1 \times 10^{-1}$ & 22,825 & 107777 \\
$0,1 \times 10^{-2}$ & 26,070 & 11396 \\
$0,1 \times 10^{-3}$ & 29,226 & 1281 \\
$0,1 \times 10^{-4}$ & 32,462 & 136 \\
$0,1 \times 10^{-5}$ & 35,022 & 23 \\
\hline
\end{tabular}

Nota-se que o ponto da curva mais diluído $\left(0,1 \times 10^{-5} \mathrm{ng}\right)$ mostrou-se negativo $(\mathrm{Ct} 35)$, portanto foi determinado que a qPCR detecta até quantidades de $0,1_{\times} 10^{-4} \mathrm{ng} / \mathrm{uL}$. 
Figura 17. Gráfico da curva padrão para definição do limiar de detecção de DNA de mixosporídeos com os primers MilF, MilR2 e a probe AMARO, utilizando como alvo DNA de Henneguya pellucida em diluições de 0,1 a $0,1^{\times} 10^{-5}$ ng de DNA.

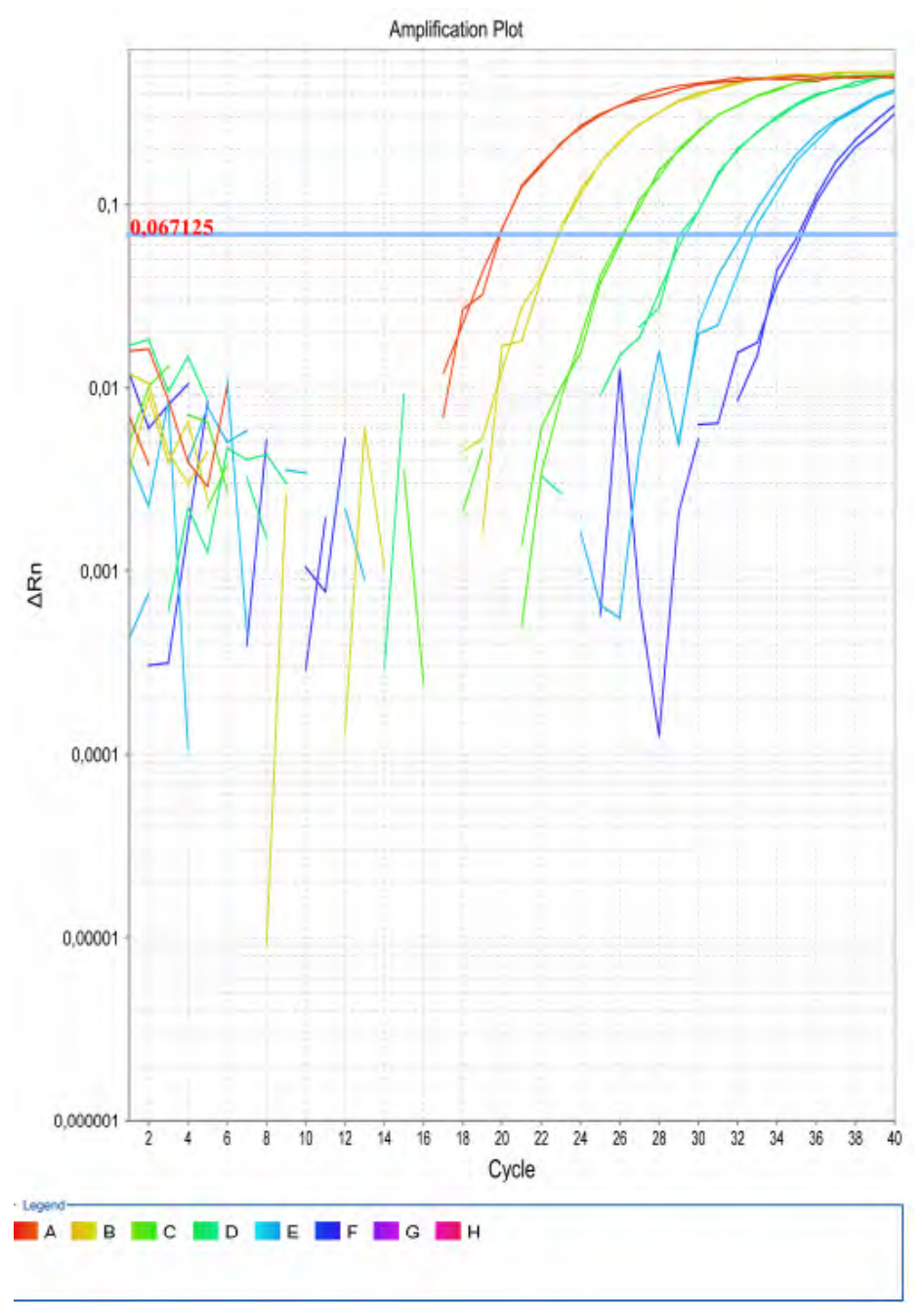

6.4.1.3 Realização da PCR em Tempo Real com DNA obtido das amostras de água suspeitas com os primers MilF, MilR2 e a probe AMARO

6.4.1.3.1 Amostras suspeitas coletadas no CEPTA na cidade de Pirassununga, SP, Brasil

Das 24 amostras coletadas na piscicultura do CEPTA da cidade de Pirassununga, todas as reações de cPCR amplificaram, ou seja, 100\% das amostras detectaram a presença de DNA de mixosporídeos, com $\mathrm{Ct}<35$ (Tabela 7). 
Tabela 7. Resultados das reações de PCR em Tempo Real com os primers MilF, MilR2 e a probe AMARO, utilizando o DNA das amostras suspeitas coletadas no CEPTA (CE): Ct médio das duplicatas; números de cópias do SSrDNA; diagnóstico final.

\begin{tabular}{|c|c|c|c|}
\hline $\begin{array}{c}\text { Amostras } \\
\text { (CE) }\end{array}$ & Média do Ct & $\begin{array}{l}\text { Número de } \\
\text { cópias } \\
\text { do } \\
\text { SSrDNA } \\
\end{array}$ & Diagnóstico \\
\hline 01 & 31,15 & 337 & + \\
\hline 02 & 31,45 & 274 & + \\
\hline 03 & 30,81 & 428 & + \\
\hline 04 & 31,62 & 244 & + \\
\hline 05 & 32,52 & 130 & + \\
\hline 06 & 30,48 & 537 & + \\
\hline 07 & 32,45 & 137 & + \\
\hline 08 & 33,64 & 60 & + \\
\hline 09 & 31,51 & 262 & + \\
\hline 10 & 29,76 & 882 & + \\
\hline 11 & 33,25 & 79 & + \\
\hline 12 & 31,73 & 225 & + \\
\hline 13 & 30,99 & 378 & + \\
\hline 14 & 34,22 & 40 & + \\
\hline 15 & 32,24 & 159 & + \\
\hline 16 & 30,95 & 386 & + \\
\hline 17 & 34,84 & 26 & + \\
\hline 18 & 32,67 & 118 & + \\
\hline 19 & 31,24 & 316 & + \\
\hline 20 & 34,52 & 33 & + \\
\hline 21 & 29,64 & 957 & + \\
\hline 22 & 29,90 & 800 & + \\
\hline 23 & 30,59 & 497 & + \\
\hline 24 & 28,22 & 2567 & + \\
\hline
\end{tabular}

6.4.1.3.2 Amostras suspeitas coletadas na psicultura da cidade de Porto Ferreira, SP, Brasil

Das 24 amostras coletadas no município de Porto Ferreira, 16 amplificaram, ou seja, 66,66\% das amostras detectaram a presença de DNA de mixosporídeos, com $\mathrm{Ct}<35$ (Tabela 8). 
Tabela 8. Resultados das reações de qPCR com os primers MilF, MilR2 e a probe AMARO, utilizando o DNA das amostras suspeitas coletadas em Porto Ferreira (PF): Ct médio das duplicatas, números de cópias do SSrDNA, diagnóstico final.

\begin{tabular}{|c|c|c|c|}
\hline $\begin{array}{c}\text { Amostras } \\
\text { (PF) }\end{array}$ & Média do $\mathbf{C t}$ & $\begin{array}{l}\text { Número de } \\
\text { cópias } \\
\text { do } \\
\text { SSrDNA }\end{array}$ & Diagnóstico \\
\hline 01 & 33,89 & 51 & + \\
\hline 02 & 25,91 & 12729 & + \\
\hline 03 & 27,53 & 4133 & + \\
\hline 04 & 33,55 & 64 & + \\
\hline 05 & 31,75 & 222 & + \\
\hline 06 & 33,53 & 65 & + \\
\hline 07 & 29,39 & 1138 & + \\
\hline 08 & 34,86 & 26 & + \\
\hline 09 & 37,16 & 5 & - \\
\hline 10 & 35,86 & 13 & - \\
\hline 11 & 28,75 & 1781 & + \\
\hline 12 & 35,90 & 6 & - \\
\hline 13 & 36,93 & 6 & - \\
\hline 14 & 32,14 & 170 & + \\
\hline 15 & 36,35 & 9 & - \\
\hline 16 & 32,687 & 117 & + \\
\hline 17 & 33,67 & 59 & + \\
\hline 18 & 34,76 & 28 & + \\
\hline 19 & 35,11 & 22 & - \\
\hline 20 & 36,39 & 9 & - \\
\hline 21 & 35,61 & 15 & - \\
\hline 22 & 34,35 & 37 & + \\
\hline 23 & 31,73 & 260 & + \\
\hline 24 & 33,43 & 69 & + \\
\hline
\end{tabular}

6.4.1.4 Sequenciamento e análise das sequências obtidas de DNA das amostras suspeitas

As sequências obtidas com os primers MilF, MilR2 e a probe AMARO de amostras suspeitas que se mostraram positivas quanto à presença de DNA de mixosporídeos foram alinhadas e editadas manualmente, através do programa Bioedit Sequence Alignment Editor versão 7.2.5 (HALL, 1999).

Todas as 40 amostras que amplificaram com $\mathrm{Ct}<35$ nas reações de qPCR com os primers MilF, MilR2 e a probe AMARO foram enviadas para sequenciamento. No entanto, alguns dos resultados foram insatisfatórios, uma vez que obtiveram eletroferogramas com picos sobrepostos que impediram a determinação exata das sequências das amostras. A inviabilização do sequenciamento pode ser pelo fato de que cada amostra suspeita tivesse mais de uma espécie de mixosporídeos, tendo em vista que uma mistura de DNAs impossibilita o alinhamento de 
sequências concisas. Dentre os sequenciamentos, foram escolhidos 4 resultados para a confirmação da existência de DNA de mixosporídeos nas amostras de água coletadas nas pisciculturas do interior do estado de São Paulo.

A primeira amostra do CEPTA, CE 9, enviada para sequenciamento, mostrou maior similaridade com Myxobolus matosi (MK032219.1), Myxobolus sp. (MN239502.1), e Sphaeromyxa sp. (MK573247.1) com 90, 89 e $90 \%$ respectivamente. Confirmando que as sequências positivas deste estudo são de DNA de mixosporídeos (Figura 18).

Figura 18. Comparação da sequência da amostra CE 9, através do algoritmo Basic Local Alignment Search Tool Nucleotide (BLASTn), com outras sequências depositadas no GenBank.

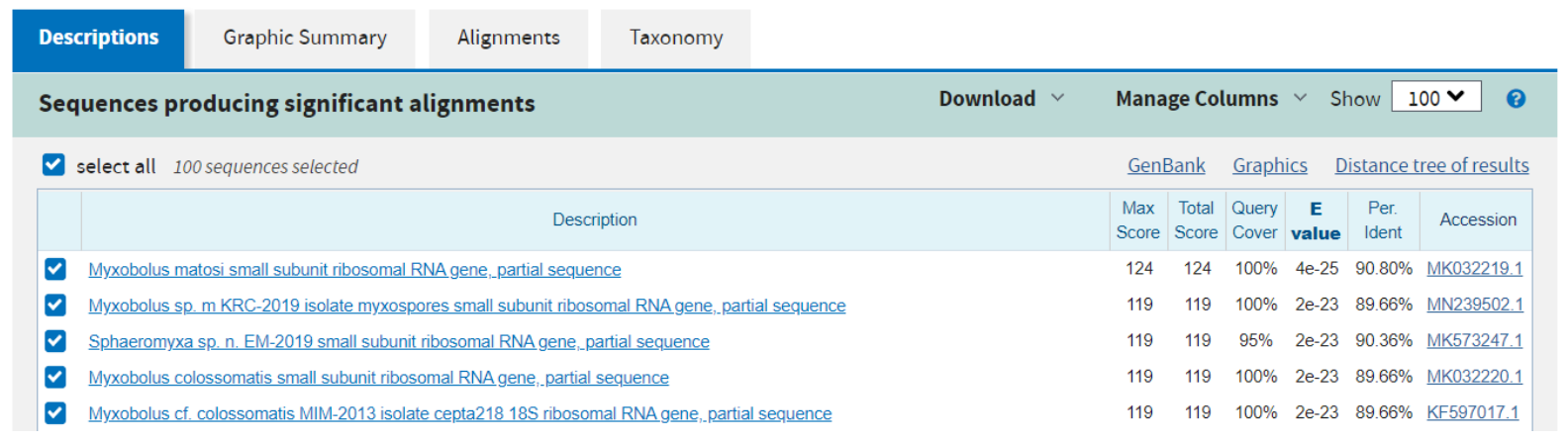

A segunda amostra do CEPTA, CE 10, mostrou maior similaridade com Aurantiactinomyxon (KX068207.1), Thelohanellus sp. (MF765753.1) e Myxobolus figueirae (MG181226.1), com 95, 93 e 93\% respectivamente. Confirmando que as sequências positivas deste estudo são de DNA de mixosporídeos (Figura 19).

Figura 19. Comparação da sequência da amostra CE 10, através do algoritmo Basic Local Alignment Search Tool Nucleotide (BLASTn), com outras sequências depositadas no GenBank.

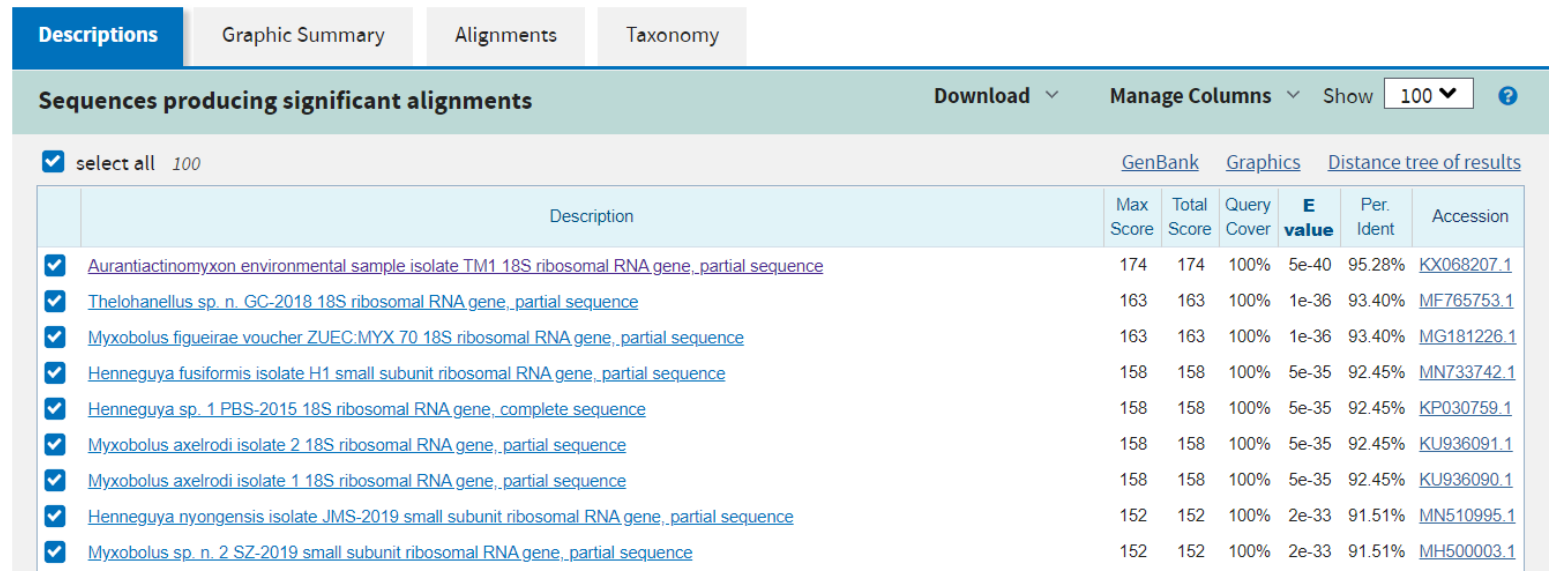


A terceira amostra, CE 13, mostrou maior similaridade com Myxobolus sp. (MN239502.1), Myxobolus colossomatis (MK032220.1) e Myxobolus matosi (MK032219.1) ambos com $92 \%$. Confirmando que as sequências positivas deste estudo são de DNA de mixosporídeos (Figura 20).

Figura 20. Comparação da sequência da amostra CE 13, através do algoritmo Basic Local Alignment Search Tool Nucleotide (BLASTn), com outras sequências depositadas no GenBank.

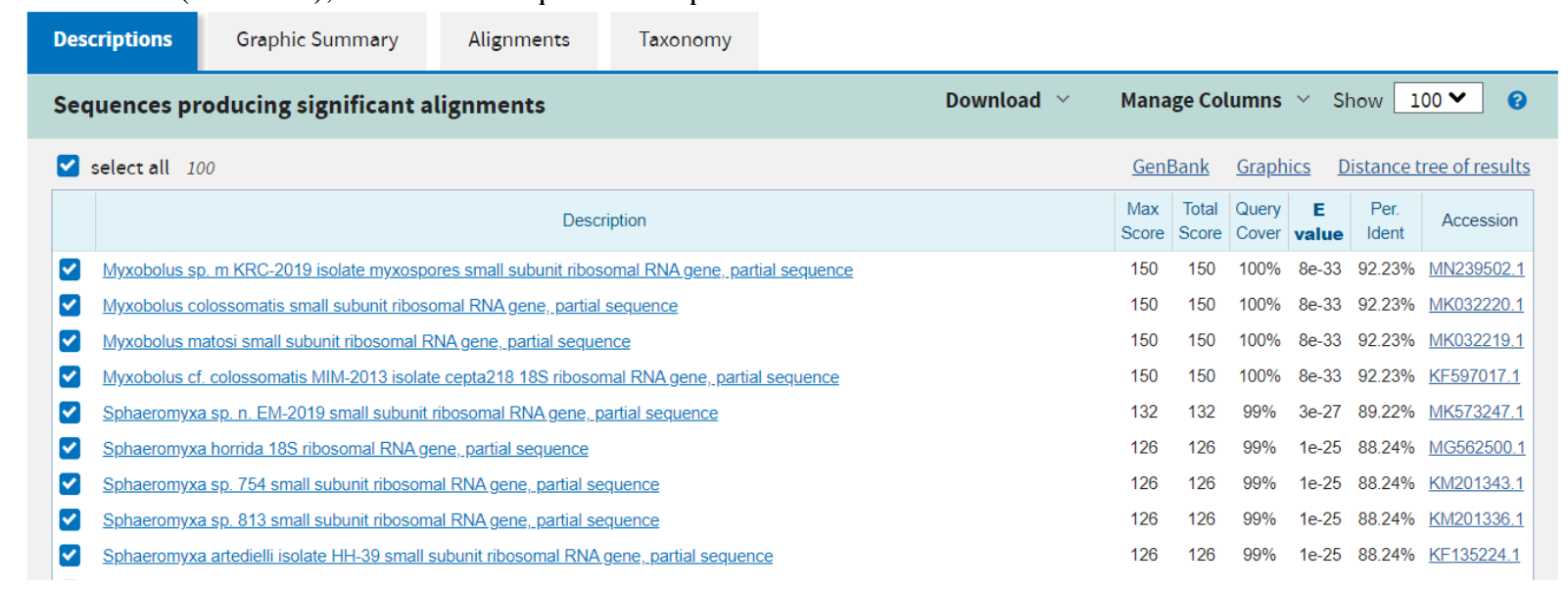

A quarta amostra, CE 21, mostrou maior similaridade com Myxobolus sp. (MN239502.1), Sphaeromyxa sp. (MK573247.1) e Myxobolus colossomatis (MK032220.1) todas com $86 \%$. Confirmando que as sequências positivas deste estudo são de DNA de mixosporídeos (Figura 21).

Figura 21. Comparação da sequência da amostra CE 21, através do algoritmo Basic Local Alignment Search Tool Nucleotide (BLASTn), com outras sequências depositadas no GenBank.

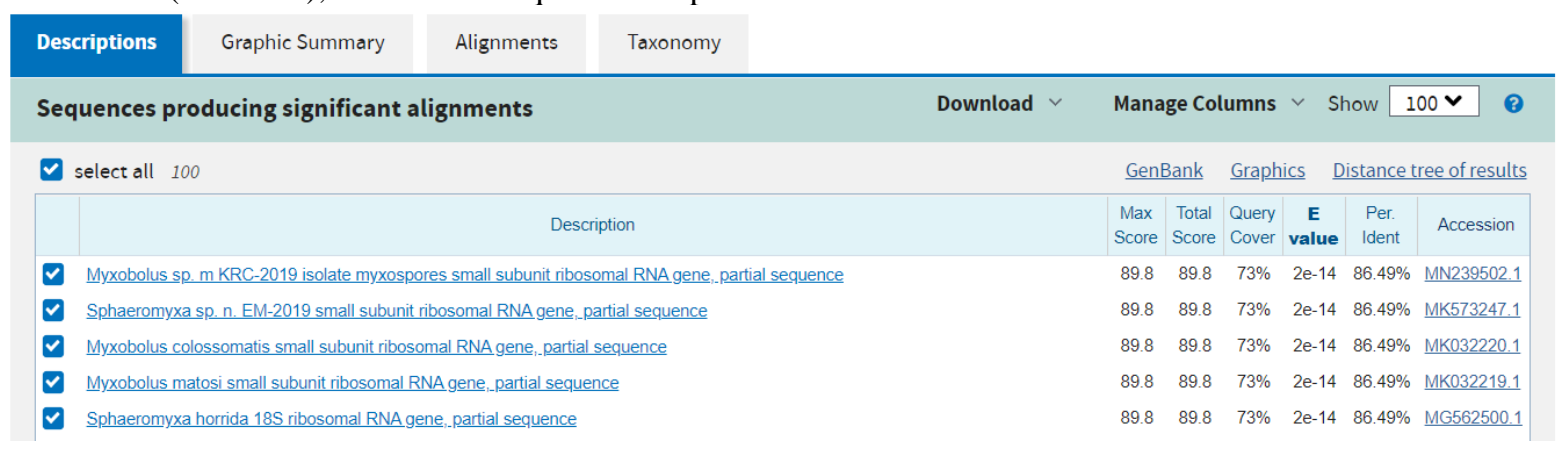

\subsubsection{Estimativa do número de cópias do SSrDNA}

Correlacionando a quantificação obtida pelo espectrofotômetro NanoDrop das extrações de DNA de todas as amostras suspeitas com o número de cópias do SSrDNA em 5 ng que foram colocadas nas reações, podemos inferir quantos esporos do estágio mixosporo de 
mixosporídeos ou e esporos do estágio de actnosporo, há em cada litro de água filtrada (Tabela 9).

Tabela 9. Resultados do valor total em ng de DNA das amostras suspeitas e a estimativa do número de cópias do SSrDNA presentes em cada litro de água suspeita coletada nas pisciculturas.

\begin{tabular}{|c|c|c|c|c|}
\hline Amostras & $\begin{array}{l}\text { Valor total da } \\
\text { extração de } \\
\text { DNA das } \\
\text { amostras (ng) }\end{array}$ & $\begin{array}{c}\text { Número de } \\
\text { cópias } \\
\text { do } \\
\text { SSrDNA } \\
\text { em } 120 \text { ng } \\
\end{array}$ & $\begin{array}{l}\text { Quantidade de } \\
\text { mixosporos de } \\
\text { Myxobolus/ } \\
\text { Henneguya spp. }\end{array}$ & $\begin{array}{l}\text { Quantidade de } \\
\text { actinosporo } \\
\text { triactinomyxon }\end{array}$ \\
\hline CE 01 & 216 & 14558,4 & 23 & 1 \\
\hline CE 02 & 504 & 27619,2 & 44 & 3 \\
\hline CE 03 & 456 & 39033,6 & 62 & 5 \\
\hline CE 04 & 288 & 14054,4 & 22 & 2 \\
\hline CE 05 & 372 & 9672,0 & 15 & 1 \\
\hline CE 06 & 192 & 20620,8 & 33 & 2 \\
\hline CE 07 & 4776 & 130862,4 & 209 & 1 \\
\hline CE 08 & 1008 & 12096,0 & 19 & 1 \\
\hline CE 09 & 276 & 14462,4 & 23 & 2 \\
\hline CE 10 & 516 & 91022,4 & 145 & 12 \\
\hline CE 11 & 360 & 5688,0 & 9 & 1 \\
\hline CE 12 & 1032 & 46440,0 & 74 & 6 \\
\hline CE 13 & 636 & 48081,6 & 77 & 6 \\
\hline CE 14 & 1608 & 12864,0 & 20 & 1 \\
\hline CE 15 & 816 & 129744,00 & 207 & 17 \\
\hline CE 16 & 456 & 35203,2 & 56 & 4 \\
\hline CE 17 & 1140 & 5928,0 & 9 & 1 \\
\hline CE18 & 552 & 13027,2 & 20 & 1 \\
\hline CE 19 & 396 & 25027,2 & 40 & 3 \\
\hline CE 20 & 6384 & 42134,4 & 67 & 5 \\
\hline CE 21 & 588 & 112543,2 & 180 & 15 \\
\hline CE 22 & 300 & 19200 & 30 & 3 \\
\hline CE 23 & 324 & 32205,6 & 51 & 3 \\
\hline CE 24 & 288 & 147859,2 & 236 & 20 \\
\hline PF 01 & 3312 & 33782,4 & 54 & 4 \\
\hline PF 02 & 2148 & 5468378,4 & 8763 & 740 \\
\hline PF 03 & 2184 & 1805294,4 & 2893 & 244 \\
\hline PF 04 & 2700 & 34560,0 & 55 & 4 \\
\hline PF 05 & 3168 & 140659,2 & 225 & 19 \\
\hline PF 06 & 1980 & 25740,0 & 41 & 3 \\
\hline PF 07 & 2604 & 592670,4 & 949 & 80 \\
\hline PF 08 & 360 & 1872,0 & 3 & 0 \\
\hline PF 09 & 2268 & 2268,0 & 3 & 0 \\
\hline PF 10 & 912 & 2371,2 & 3 & 0 \\
\hline PF 11 & 336 & 119683,2 & 191 & 16 \\
\hline PF 12 & 1416 & 1699,2 & 2 & 0 \\
\hline PF 13 & 780 & 936,0 & 1 & 0 \\
\hline PF 14 & 756 & 25704,0 & 41 & 3 \\
\hline PF 15 & 972 & 1749,6 & 2 & 0 \\
\hline
\end{tabular}




\begin{tabular}{|c|c|c|c|c|} 
PF 16 & 2100 & 49140,0 & 78 & 7 \\
PF 17 & 960 & 11328,0 & 18 & 1 \\
PF18 & 984 & 5510,4 & 8 & 1 \\
PF 19 & 828 & 3643,2 & 5 & 0 \\
PF 20 & 996 & 1792,8 & 2 & 0 \\
PF 21 & 1188 & 3564,0 & 5 & 0 \\
PF 22 & 1164 & 8613,6 & 13 & 1 \\
PF 23 & 1740 & 90480,0 & 145 & 12 \\
PF 24 & 3312 & 45705,6 & 73 & 6 \\
\hline
\end{tabular}

\subsubsection{Sistema SYBR Green ${ }^{\circledR}$}

\subsubsection{Curva de melting}

A curva de melting foi diretamente relacionada ao conteúdo de Guanina e Citosina amplificado. A curva mostrou que não houve amplificação inespecífica e dímeros de primers (Figura 22). A temperatura na qual a metade do produto de qPCR estava dissociada e a outra metade estava hibridada foi em $82^{\circ} \mathrm{C}$.

Figura 22. Gráfico da análise da curva de melting os primers HpelF e HpelR utilizando como alvo DNA de Hennuguya pellucida.

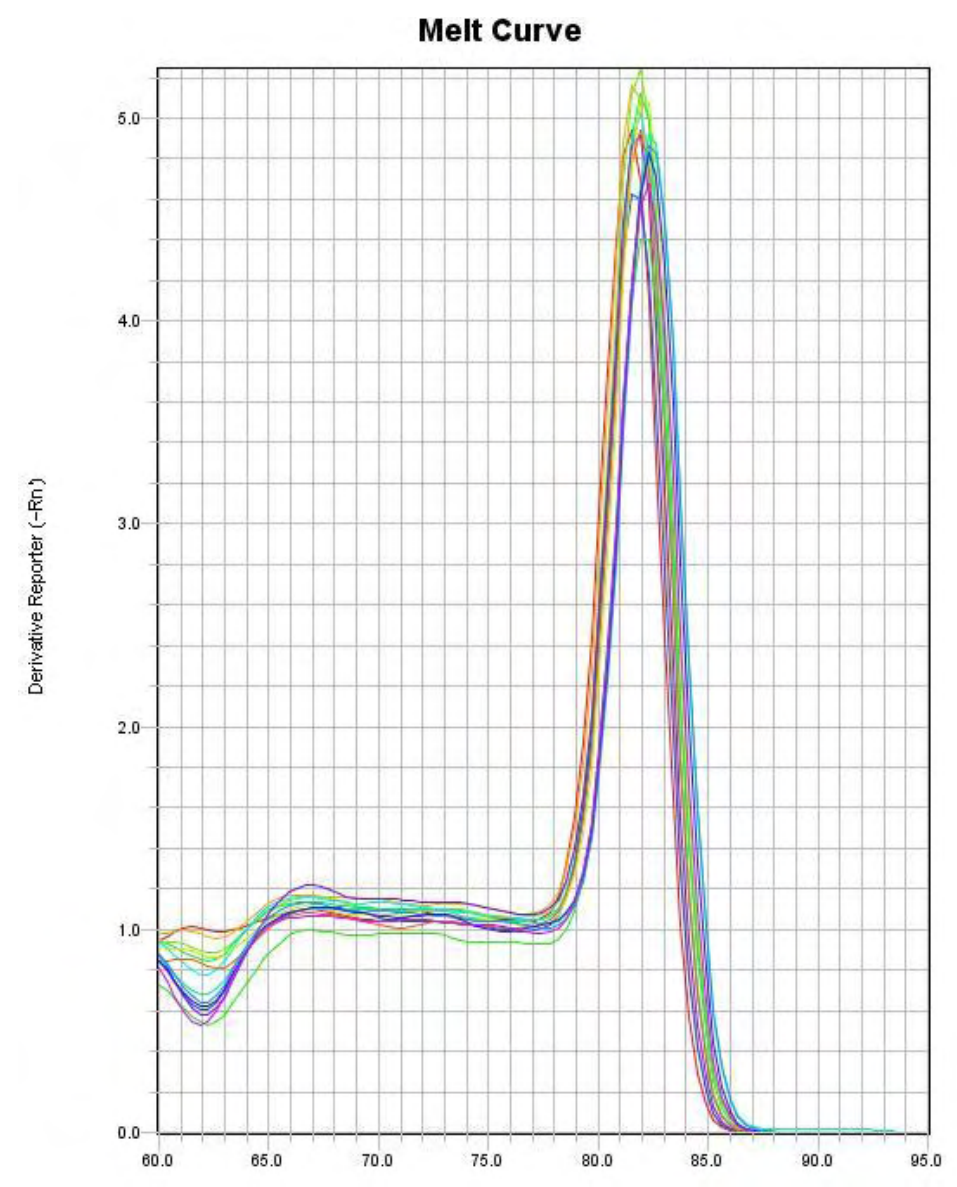


Para a construção da curva de eficiência na qPCR com os primers HeplF e HpelR, foi utilizado DNA da espécie $H$. pellucida como amostra controle positivo. A partir da eficiência estimada de $64,46 \%$, foi detectado que os primers mostraram uma baixa eficiência na qPCR. Por esse motivo, as amostras suspeitas não foram submetidas às reações de qPCR com o conjunto de primers.

Figura 23. Gráfico da curva padrão de eficiência da reação com os primers HpelF e HpelR, utilizando como alvo DNA de Henneguya pellucida em diluições de 0,1 a $0,1^{\times} 10^{-5}$ ng de DNA.

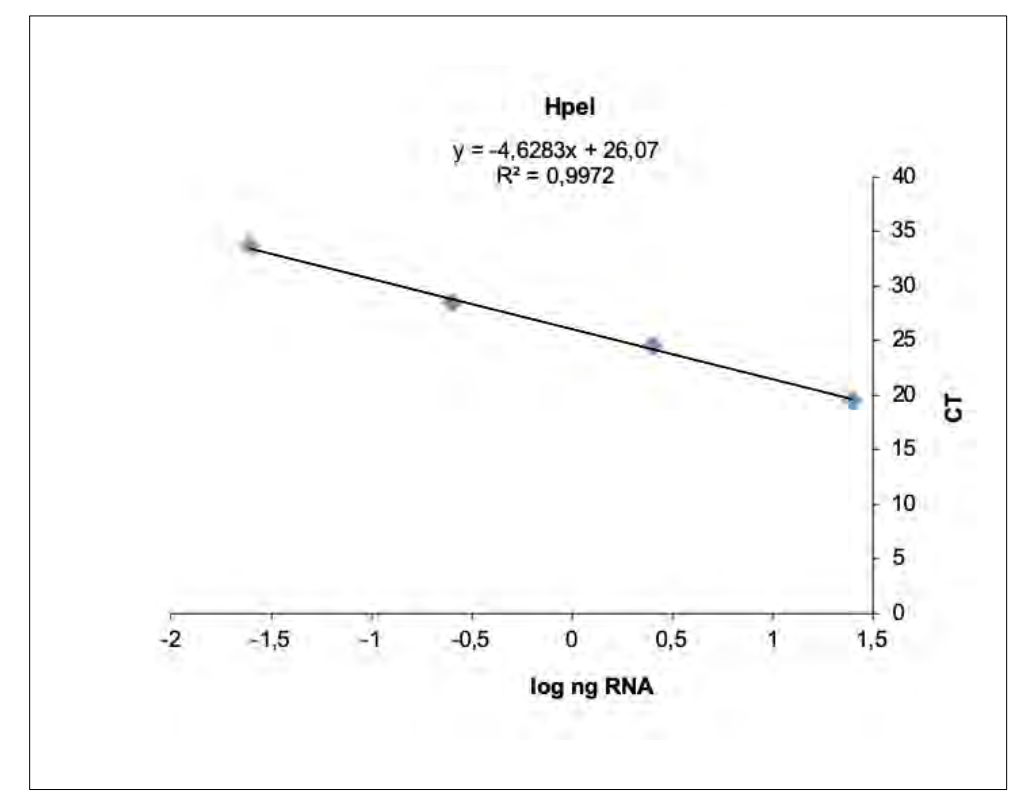

\subsection{Comparação entre as técnicas de PCR Convencional e PCR em Tempo Real para detecção de DNA de mixosporídeos em amostras de água suspeitas coletadas em pisciculturas}

Quando comparados os resultados encontrados para as técnicas de PCRs, a qPCR detectou mais amostras positivas $(83,33 \%)$ quando comparadas a cPCR $(50 \%)$ e a qPCR também as quantificou (Tabela 10).

As capacidades de detecção das curvas padrão realizadas mostram resultados diferentes, em que a qPCR mostrou maior capacidade de detecção de DNA, detectando até $0,1 \times 10^{-4} \mathrm{ng}$ de DNA, enquanto a cPCR a mínima detecção ocorreu com $0,1 \times 10^{-3}$ ng de DNA. 
Entre todas as 40 amostras positivas inferidas na qPCR, 12 não amplificaram na cPCR, mostrando que os testes na qPCR apresentaram maior sensibilidade quando comparados aos testes produzidos na $\mathrm{CPCR}$.

No entanto, 3 amostras que resultaram positivas no cPCR mostraram-se negativas ao qPCR, podendo inferir que os primers $\mathrm{MX} 5 / \mathrm{MX} 3$ não são tão sensíveis quanto os oligonucleotídeos construídos para a qPCR, visto que a o limiar da curva padrão da cPCR foi inferior à da qPCR. Provavelmente os primers MX5 e MX3 não são tão específicos apenas para Myxozoa, fora que as reações de qPCR utilizaram uma probe TaqMan®, que aumentou a especificidade do ensaio.

Tabela 10. Comparação dos resultados da PCR Convencional e a PCR em Tempo Real com todas as 48 amostras de DNA coletadas nas psiculturas.

\begin{tabular}{|c|c|c|}
\hline Amostras & $\begin{array}{c}\text { Primers } \\
\text { MX5/MX3 } \\
\text { cPCR } \\
\end{array}$ & $\begin{array}{c}\text { Primers } \\
\text { Milf/MilR2 } \\
+ \text { probe AMARO } \\
\text { qPCR }\end{array}$ \\
\hline CE 01 & - & + \\
\hline CE 02 & + & + \\
\hline CE 03 & + & + \\
\hline CE 04 & + & + \\
\hline CE 05 & + & + \\
\hline CE 06 & + & + \\
\hline CE 07 & + & + \\
\hline CE 08 & - & + \\
\hline CE 09 & + & + \\
\hline CE 10 & + & + \\
\hline CE 11 & - & + \\
\hline CE 12 & + & + \\
\hline CE 13 & - & + \\
\hline CE 14 & - & + \\
\hline CE 15 & + & + \\
\hline CE 16 & + & + \\
\hline CE 17 & - & + \\
\hline CE 18 & + & + \\
\hline CE 19 & + & + \\
\hline CE 20 & - & + \\
\hline CE 21 & - & + \\
\hline CE 22 & - & + \\
\hline CE 23 & + & + \\
\hline CE 24 & + & + \\
\hline PF 01 & - & - \\
\hline PF 02 & - & + \\
\hline PF 03 & - & + \\
\hline
\end{tabular}




\begin{tabular}{|lll|} 
PF 04 & - & - \\
PF 05 & + & + \\
PF 06 & - & + \\
PF 07 & + & + \\
PF 08 & - & - \\
PF 09 & + & + \\
PF 10 & + & + \\
PF 11 & - & - \\
PF 12 & - & - \\
PF 13 & - & - \\
PF 14 & + & + \\
PF 15 & - & - \\
PF 16 & + & + \\
PF 17 & - & - \\
PF 18 & - & - \\
PF 19 & - & - \\
PF 20 & - & - \\
PF 21 & + & - \\
PF 22 & + & + \\
PF 23 & - & - \\
PF 24 & + & + \\
\hline
\end{tabular}




\section{Discussão}

Neste estudo, a abordagem de DNA ambiental foi utilizada para detectar e quantificar a presença de um importante parasita comumente encontrado em pisciculturas brasileiras. As análises de $e D N A$ estão revolucionando a forma como as pesquisas sobre a biodiversidade envolvendo mixosporídeos estão sendo conduzidas (RICHEY et al., 2020). Os resultados obtidos mostraram-se adequados para avaliar, detectar e quantificar ao DNA mixosporídeos.

De acordo com Turner et al., (2014) o DNA se acumula mais nos sedimentos do que na superfície da água, entretanto as coletas de água das pisciculturas neste estudo foram feitas sem sedimentos e padronizadas a 1 metro da borda e $30 \mathrm{~cm}$ abaixo da superfície (GOMES et al., 2017) e mesmo assim, a quantidade de DNA detectado foi de acordo com o esperado. Outro fator importante para os resultados satisfatórios foi o tempo entre a coleta e a filtragem de água. De acordo com Eichmiller et al., (2016) a coleta da água deve ser feita com utensílios estéreis e a água deve ser filtrada o mais rápido possível para não subestimar a quantidade de $e D N A$, tendo em vista que degradação do DNA ocorre em altas temperaturas. E por se tratar de um ambiente tropical, com temperaturas mais elevadas, a degradação pode ocorrer mais rapidamente.

Diversos estudos foram desenvolvidos para detecção e identificação de mixosporídeos em amostras de tecido e órgãos de peixes e/ou em oligoquetas, tanto em ambientes naturais quanto em sistemas de criação no Brasil (ADRIANO et al., 2002; 2005a; CAPODIFOGLIO et al., 2015; 2016; CARRIEIRO 2013; 2019; MARTINS \& SOUZA, 1997; MILANIN et al., 2010; 2015; 2018; 2018b; MOREIRA et al., 2014; NALDONI et al., 2019; 2011). Entretanto, a detecção através de amostras de água ainda não havia sido realizada no Brasil, sendo este um estudo pioneiro no continente Sul Americano.

A forma tradicional para detectar e descrever novas espécies de mixosporídeos necessitam da captura dos hospedeiros, para a obtenção de plasmódios, e quando não há a presença visível de infecções ou altas taxas de mortalidades de peixes, a detecção dos parasitas pode ser desafiadora (FONTES et al., 2016). A detecção do parasita utilizando amostras ambientais é uma nova e promissora alternativa de monitoramento, em que detecta a presença ou ausência do parasita no ambiente aquático baseando-se puramente na coleta de amostras de água. Uma estratégia de monitoramento que não requer a captura dos hospedeiros (peixes e anelídeos) 
(ROBSON et al.,2016). Mostrou-se, nesse estudo, um alto potencial para melhorar a maneira de identificação e monitoramento de patógenos e surtos que acometem a aquicultura.

A detecção de endoparasitas nas águas de pisciculturas será de grande benefício para os produtores, visto que neste momento o cultivo de peixes em tanques no Brasil tem dado sinais de plena consolidação, com muitos produtores apostando alto nas safras (SCHULTER \& VIEIRA FILHO 2017; 2018). Alertar-se aos problemas que os mixosporídeos podem resultar é de extrema necessidade para que não ocorram perdas econômicas. A adoção de medidas profiláticas, como a estabelecida no presente estudo, pode ser imprescindível para os sistemas de criação que sofrem ou sofrerão com a influência dos patógenos.

Neste estudo utilizamos um protocolo de filtração, extração de DNA a partir de membranas de nitrocelulose e testes de cPCR e qPCR para detecção de DNA de mixosporídeos em amostras de água de pisciculturas. O estudo foi fundamentado no protocolo de filtragem e extração de DNA desenvolvido por Hallet e Bartholomew (2006) para a detecção de Ceratomyxa shasta, em amostras de água de rio nos Estados Unidos, associado ao protocolo de coleta da água desenvolvido por Gomes et al., (2017) no estudo de eDNA para prever surtos de protozoários parasitas em pisciculturas.

A ocorrência de mixosporídeos na água de pisciculturas do presente estudo foi detectada em níveis variados entre as amostras coletadas. As razões específicas para variação são difíceis de determinar com base apenas em nossos resultados. No entanto, a variação da carga de parasitas pode ser devida a condições ambientais, matérias orgânicas, fluxo da água, entre outros fatores. Além disso, a ocorrência de mixosporídeos pode ser influenciada pela dinâmica de transmissão entre os parasitas e os hospedeiros, e a sazonalidade que pode influenciar na carga parasitária (HALLETT \& BARTHOLOMEW, 2006; HALLETT et al., 2012).

Curvas padrão foram construídas a partir dos valores de uma amostra de DNA de $H$. pellucida, contendo uma quantidade conhecida de DNA alvo (10 ng). Os valores obtidos juntamente com os resultados das amostras suspeitas adquiridos foram relacionados e determinados quanto a presença ou ausência de DNA de mixosporídeos.

Na reação de qPCR, o limite de detecção foi estabelecido no Ct 35. Desta forma, determinamos que o método detectaria a presença de até 25 cópias do gene SSrDNA de mixosporídeos, a partir de um núcleo de mixosporo/actinosporo, mostrando-se ser sensível à pouca quantidade de DNA disponível. 
Segundo Kelley et al., (2004) e Hallet e Bartholomew (2006) os mixosporos de Myxobolus cerebralis apresentam 5 células e 6 núcleos e no interior de cada núcleo o SSrDNA se repete 104 vezes (ELMATBOULI et al., 1995). Portanto os mixósporos de M. cerebralis, apresentam 624 cópias do SSrDNA e um actinosporo (Triactinomyxon) de M. cerebralis é composto por 71 células ou núcleos ( 3 células valvares, 3 células capsulogênicas, 64 células germinativas e 1 célula envolvente de esporoplasma), de acordo com El-Matbouli \& Hoffmann (1998), o que equivale a 7384 cópias por esporo do gene. Logo, podemos inferir que em cada $17 \mathrm{~mL}$ de água coletada nos sistemas de criação de Porto Ferreira (amostra PF 2: 12729 cópias do SSrDNA) estariam presentes 20 mixosporos, ou, aproximadamente, 2 actinosporos. $\mathrm{Na}$ psicultura do CEPTA (amostra CE 21: 957 cópias do SSrDNA), em cada $17 \mathrm{~mL}$ de água estariam presentes 2 esporos de mixosporo.

De acordo com Andree et al., (1997) e Bartholomew et al., (1997), os parasitas mixosporídeos, tanto no estágio actinosporo quanto no mixosporo, possuem a mesma constituição gênica (SSrDNA). Portanto, os mesmos métodos moleculares podem ser utilizados para detectar os parasitas em ambos os hospedeiros (invertebrados e vertebrados) no ambiente aquático. Esta semelhança, logo, não permite a distinção do estágio de infecção do hospedeiro vertebrado (mixosporo) do estágio de infecção do hospedeiro invertebrado (actinosporo). A detecção ocorre a partir da presença de qualquer tipo de esporo de mixosporídeos livre na água.

Quando correlacionamos o fato de que as coletas de eDNA (amostras de água), foram coletadas em águas mais superficiais dos sistemas de criação, $30 \mathrm{~cm}$ abaixo da superfície, podemos inferir que a captura de esporos no estágio de actinosporo foi maior do que a captura dos esporos no estágio de mixosporo, visto que o estágio actinosporo apresenta processos caudais o que facilita sua flutuação em ambientes aquáticos.

Diversas espécies de mixosporídeos foram descritas em peixes oriundos de águas Sul Americanas. Dentre estas, inúmeras foram identificadas em espécimes de peixes das águas do rio Mogi-Guaçu, tais como: Myxobolus porofilus Adriano, Arana, Ceccarelli e Cordeiro, 2002, infectando a cavidade abdominal de Prochilodus lineatus Valenciennes, 1847, descrito por Adriano et al., (2002), Henneguya piaractus Martins \& Souza, 1997 encontrado nas lamelas branquiais de Piaractus mesopotamicus Holmberg, 1887 descrito por Adriano et al., (2005a), Myxobolus cuneus Adriano, Arana e Cordeiro, 2006, infectando a vesícula biliar, bexiga urinária, brânquias, baço, nadadeiras, superfície da cabeça, fígado e coração de peixes P. mesopotamicus, descrito por Adriano et al., (2006), Henneguya caudalongula Adriano, Arana e Cordeiro, 2005, infectando as brânquias de P. lineatus descrito por Adriano et al., 
(2005c), Myxobolus macroplasmodiolis Molnár, Ranzani-Paiva, Eiras e Rodrigues, 1998, infectando a cavidade abdominal de Salminus brasiliensis Cuvier, 1816, descrito por Molnár et al., (1998) e Carriero et al., (2013), Henneguya pellucida Adriano, Arana e Cordeiro, 2005 infectando a serosa da cavidade visceral de P. mesopotamicus descrito por Adriano et al., (2005a) e Carriero et al., (2013), Hennegura azevedoi Barassa, Adriano, Cordeiro, Arana e Ceccarelli 2012, infectando as brânquias de Leporinus obtusidens Valenciennes, 1837, descrito por Barassa et al., (2012), Henneguya rotunda Moreira, Adriano, Silva, Ceccarelli e Maia, 2014, infectando o arco branquial e as barbatanas de S. brasiliensis descrito por Moreira et al., (2014), Henneguya visibilis Moreira, Adriano, Silva, Ceccarelli e Maia, 2014, infectando o tecido conjuntivo das nadadeiras de espécimes de L. obtusidens descrito por Moreira et al., (2014), Myxobolus porofilus Adriano, Arana e Cordeiro, 2002, comprimindo a parede da cavidade visceral, infectando P. lineatus descrito por Adriano et al., (2002) e Zatti et al., (2016). Desta forma, existe a possibilidade de que alguns dos parasitas descritos em peixes do rio Mogi-Guaçu possam ser os mesmos que foram identificados através do eDNA nas pisciculturas, visto que o rio Mogi atravessa zonas urbanas das cidades de Porto Ferreira e o distrito de Cachoeira de Emas em Pirassununga e ambos os sistemas de criação são abastecidos pelas águas do rio.

Dentre os resultados obtidos nos sequenciamentos, pode-se destacar que a amostra CE 9, coletada no sistema de criação de peixes do CEPTA-Pirassununga, que mostrou similaridade de 90\% com Sphaeromyxa sp. Os membros do gênero Sphaeromyxa Thélohan, 1892, possuem um caráter único dentre os parasitas do subfilo Myxozoa, filamentos polares característicos em forma de fita (LOM \& DYKOVÁ, 2006). No gênero, existem aproximadamente 50 espécies descritas infectando os sistemas biliares hepáticos de peixes, principalmente marinhos (CHEN et al., 2020; MILLER et al., 2018). A maioria dos Sphaeromyxa sp. estão distribuídos nos ambientes marinhos em todo o mundo e há poucas espécies relatadas infectando hospedeiros de água doce, como a espécie Sphaeromyxa tuanfengensis Hsieh e Gong 1993, descrita infectando Coilia nasus Temminck e Schlegel 1846, em águas do rio Yangtze, China e a espécie Sphaeromyxa pultai Tripathi 1953, descrita infectando Odontamblyopus rubicundus Hamilton 1822, no rio Hooghly, Índia. Ainda não houve descrição do gênero infectando peixes de águas brasileiras, e no continente Sul Americano o referido gênero apenas foi descrito infectando peixes marinhos na Argentina e no Uruguai. 
Há uma pequena parcela do gênero de mixosporídeos infectando peixes em águas dulcícolas no mundo. No entanto, há possibilidade de que Sphaeromyxa sp. possa estar presente no sistema de criação do CEPTA-Pirassununga e/ou no rio Mogi-Guaçu infectando os peixes.

Os resultados obtidos nesse estudo mostraram que a detecção de DNA de mixosporídeos a partir de amostras de água pode ser um método rápido de monitoramento para determinar a abundância desses endoparasitas em tanques comerciais. As perspectivas, a partir desses resultados iniciais, são de expansão nas análises para a implementação de testes com a construção de primers específicos para espécies já relatadas como patogênicas. Desta forma, quando confirmada a existência de patógenos, os criadores poderão alternar as espécies de peixes daquele determinado sistema de criação, uma vez que os mixosporídeos apresentam especificidade tanto ao hospedeiro quanto ao tecido que infectam (BÉKÉSI; SZÉKELY; MOLNÁR, 2002).

Assim, se no sistema de criação de peixes do CEPTA houvesse o cultivo da espécie Piaractus mesopotamicus ao invés de Astyanax spp. deveria ocorrer uma alternância de espécie para controlar a propagação dos endoparasitas e evitar a ocorrência de problemas como lesões na membrana serosa da cavidade visceral e na bexiga natatória e inflamações, o que poderia acarretar surtos com alta mortalidade. Seria a medida profilática mais adequada.

Pesquisadores brasileiros vêm se empenhando nas últimas décadas para ampliar o conhecimento da diversidade de mixosporídeos principalmente em peixes de importância comercial, o que tem viabilizado um forte progresso no conhecimento da diversidade destes parasitas e estudos dos danos causados aos seus hospedeiros (ADRIANO \& OLIVEIRA, 2018; ADRIANO et al., 2012; CAPODIFOGLIO et al., 2015; 2016, 2019; MARTINS \& SOUZA, 1997; ZATTI et al., 2017a, 2017b).

Apesar do avanço no conhecimento desses organismos, até o momento, muitos aspectos envolvendo a diversidade, ciclo de vida, patologia e evolução das espécies ainda são inexplorados, principalmente no Brasil, pais que abriga a maior diversidade de espécies de peixes de água doce do mundo (SCHAEFER,1998). Como inúmeras espécies de peixes são amplamente utilizadas na piscicultura, e muitas outras têm potencial para tal, conhecer os parasitas que estão presentes nos peixes, os danos causados, podem ser úteis na implementação de medidas de controle, na avaliação de resistências às drogas e na adoção de medidas profiláticas, como a descrita neste estudo, visando controlar os níveis de infecção, minimizando os efeitos negativos na produção incorporadas à piscicultura. 
A abordagem tradicional de levantamento de amostragem e identificação de mixosporídeos em peixes é trabalhosa, demorada, e envolve a captura e dissecação dos exemplares, seguido do exame microscópico do tecido infectado (AZEVEDO, et al., 2009; FEIJÓ et al., 2008, NALDONI et al., 2009, 2014). Desta forma, propõe-se que esses testes desenvolvidos sejam realizados anteriormente dos diagnósticos tradicionais.

As técnicas de PCRs trazem muitas vantagens para os diagnósticos de parasitas: a alta sensibilidade e o tempo de execução da técnica em relação aos outros métodos de diagnósticos tradicionais (IKONOMOPOULOS et al., 2003).

Neste estudo todas as amostras positivas das reações de qPCR foram sequenciadas para a confirmação do método aplicado, entretanto não foi possível obter resultados de todas as amostras enviadas para sequenciamento. A qualidade da amostra de PCR é um dos fatores mais críticos no sequenciamento. Sabe-se que é muito importante que a reação de PCR esteja livre de contaminantes (OLIVEIRA, 2010). Mesmo com as dificuldades para aquisição dos sequenciamentos foi possível obter resultados confirmatórios em que as sequências obtidas se tratavam unicamente de mixosporídeos.

Há relatos da alta sensibilidade da qPCR em relação à cPCR (GRIFFIN et al, 2008; 2009) confirmando que a qPCR fornecem um método rápido, mais sensível e quantificável. Os sistemas em tempo real com PCR são aperfeiçoados pela introdução de uma probe marcada com fluorescência (TaqMan ${ }^{\circledR}$ ), que permite o desenvolvimento de um método apenas para a detecção do produto de amplificação especifica (HALLET \& BARTHOLOMEW, 2006; GRIFFIN et al., 2009) assim, mesmo que exista DNA de outros organismos, a amplificação não ocorre, portanto, não havendo falso-positivo como inferimos que ocorreu na cPCR. Desta forma, concluímos que a qPCR apresentou-se como a melhor ferramenta de diagnóstico de mixosporídeos através da água de sistemas de criação quando comparada com a cPCR. 


\section{Conclusões}

1) As reações de PCR foram capazes de detectar DNA de mixosporídeos a partir de amostras de água de pisciculturas.

2) A metodologia empregada na filtração mostrou-se eficiente para a obtenção de DNA de mixosporídeos naturalmente presentes na água.

3) Os resultados obtidos pelas técnicas cPCR e qPCR mostraram que ambas as técnicas detectam DNA do parasita em amostras ambientais.

4) A técnica de qPCR apresentou maior vantagem no monitoramento quando comparada à de $\mathrm{cPCR}$, pois conseguiu identificar um maior número de amostras positivas e quantificá-las. 


\section{Referências Bibliográficas}

ADRIANO, E. A.; ARANA, S.; ALVES, A. L.; SILVA, M. R. M.; CECCARELLI, P. S.; HENRIQUE-SILVA, F.; MAIA, A. A. M. Myxobolus cordeiroi n. sp., a parasite of Zungaro jahu (Siluriformes: Pimelodiade) from Brazilian Pantanal: Morphology, phylogeny and histopathology. Veterinary Parasitology, (162) 221-229, 2009a.

ADRIANO, E. A.; ARANA, S.; CARRIERO, M. M.; NALDONI, J.; CECCARELLI, P. S., MAIA, A. A. M. Light, electron microscopy and histopathology of Myxobolus salminus n. sp., a parasite of Salminus brasiliensis from the Brazilian Pantanal. Veterinary Parasitology, (165) 25-29, 2009b.

ADRIANO, E. A.; ARANA, S.; CORDEIRO, N. S. Histopathology and ultrastructure of Myxobolus cuneus n. sp. infecting the connective tissue of Piaractus mesopotamicus (Pisces: Characidae) cultivated in Brazil. Parasite, (3) 137-42, 2006.

ADRIANO, E. A.; ARANA, S.; CORDEIRO, N. S. An ultrastructural and histopathological study of Henneguya pellucida n. sp. (Myxosporea: Myxobolidae) infecting Piaractus mesopotamicus (Characidae) cultivated in Brazil. Parasite, (12) 221-227, 2005a.

ADRIANO, E. A.; ARANA, S.; CORDEIRO, N. S. Histophatology and ultrastructure of Henneguya caudalongula sp. n. infecting Prochilodus lineatus (Pisces: Prochilodontidae) cultivated in the state of São Paulo, Brazil. Memórias do Instituto Oswaldo Cruz, (100) 177$181,2005 b$.

ADRIANO, E. A.; ARANA, S.; CECCARELLI, P. C.; CORDEIRO, N. S. Light and scanning electron microscopy of Myxobolus porofilus sp. n. (Myxosporea: Myxobolidae) infecting the visceral cavity of Prochilodus lineatus (Pisces: Characiformes; Prochilodontidae) cultivated in Brazil. Folia Parasitologica, (49) 259-262, 2002.

ADRIANO, E. A.; CARRIERO, M. M.; MAIA A. A. M.; SILVA M. R. M.; NALDONI J.; CECCARELLI P. S.; ARANA, S. Phylogenetic and host-parasite relationship analysis of Henneguya multiplasmodialis n. sp. infecting Pseudoplatystoma spp. in Brazilian Pantanal wetland. Veterinary Parasitology, (185) 110-120, 2012.

ADRIANO, E. A; OLIVEIRA, O. M. P. Myxosporea in Catálogo Taxonômico da Fauna do Brasil. PNUD. http://fauna.jbrj.gov.br/fauna/faunadobrasil/152799 (Acessado em Nov 2019). 
ADRIANO, E. A.; OKAMURA, B. Motility, morphology and phylogeny of theplasmodial worm, Ceratomyxa vermiformis n. sp. (Cnidaria: Myxozoa:Myxosporea). Parasitology, (144) 158-168, 2017.

ALAMA-BERMEJO, G.; ŠÍMA R.; RAGA, J. A.; HOLZER, A. S. Understanding myxozoan infection dynamics in the sea: seasonality and transmission of Ceratomyxa puntazzi. Jornal of Parasitology, (43) 771-780, 2013.

ALONSO, A.; MARTINS, P.; ALBARRAN, C.; GARCIA, P.; PRIMORAC, D. FERNANDES DE SIMON, L.; GARCIA-HIRSCHFED, J.; SANCHO, M.; FERNANDES-PIQUERAS, J. Specific quantification of human genomes from low copy number DNA samples in forenses and ancient DNA studies. Croat Med. J, (44), 273-280, 2003.

ANDREE, K.B.; GRESOVIAC, S.J.; HEDRICK, R.P. Small subunit ribosomal RNA sequences unite alternate actinosporean and myxosporean stages of Myxobolus cerebralis the causative agent of whirling disease in salmonid fish. Journal of Eukaryot Microbiol, (44) 208-215, 1997.

ANTONELLI, L. Impact de la parasitologie sur la pisciculture en Corse. Suivi des parasitoses et étude des transferts de parasites depuis la faune sauvage vers les poissons élevés en mer ouverte. Thèse Doctorat, Université de Corse, Pasquale Paoli, 2010.

ATKINSON, S. D. Diversity, life cycles and population genetics of freshwater Myxozoa from the Pacific Northwest of North America. PhD Thesis, School of Chemistry \& Molecular Bioscience, The University of Queensland, Australia, 220, 2011.

AUDEMARD, C.; RAGONE, C. L. M.; PAYNTER, K. T.; REECE, K. S.; BURRESON, E. M. Real-time PCR investigation of parasite ecology: in situ determination of oyster parasite Perkinsus marinus transmission dynamics in lower Chesapeake Bay. Parasitology, (132) 827-842, 2006.

AUSTIN, B.; NEWAJ-FYZUL, A. Diagnosis and Control of Fish and Shellfish Diseases. John Wiley \& Sons Ltd, 320, 2017.

AZEVEDO, R. K.; VIEIRA, D. H. M. D.; VIEIRA, G. H.; SILVA, R. J., MATOS, E.; ABDALLAH, V. D. Phylogeny, ultrastructure and histopathology of Myxobolus lomi sp. nov., a parasite of Prochilodus lineatus (Valenciennes, 1836) (Characiformes: Prochilodontidae). Parasitology International, (63) 303-307, 2013. 
AZEVEDO, C.; CASAL, G.; MENDONÇA, I.; CARVALHO, E.; MATOS, P.; MATOS, E. Light and electron microscopy of Myxobolus sciades n. sp. (Myxozoa), a parasite of the gills of the Brazilian fish Sciades herzbergii (Block, 1794) (Teleostei: Ariidae). Memórias do Instituto Oswaldo Cruz, (105) 203-207, 2010.

AZEVEDO, C.; CASAL, G.; MENDONÇA, I.; MATOS, E. Fine structure of Henneguya hemiodopsis sp. n. (Myxozoa), a parasite of the gills of the Brazilian teleostean fish Hemiodopsis microlepes (Hemiodontidae). Memória do Instituto Oswaldo Cruz, (104) 975 979, 2009.

AZEVEDO, C.; CORRAL, L.; MATOS, E. Ultrastructure of Triangulamyxa amazônica $\mathrm{n}$. gen. and n sp. (Myxozoa, Myxosporea), a parasite of the Amazonian freshwter fish, Sphoeroides tetudineus (Teleostei, Tetrodontidae). European Journal of Protistology, (41) 57-63, 2005.

BALDISSEROTTO, B.; GOMES, L. C. Espécies nativas para piscicultura no Brasil. Editora UFSM, Santa Maria, (2) 608, 2013.

BASS, D.; STENTIFORD, G. D.; LITTLEWOOD, D. T. J.; HARTIKAINEN, H. (2015). Diverse application of environmental DNA methodos in parasitology. Trends in Parasitilogy, (237), 8-16, 2015.

BARTOŠOVA-SOJKOVA, P.; HRABCOVA, M.; PECKOVA, H.; PATRA, S.; KODADKOVA, A.; JURAJDA, P.; TYML, T.; HOLZER, A. S. Hidden diversity and evolutionary trends in malacosporean parasites (Cnidaria: Myxozoa) identified using molecular phylogenetics. International Journal for Parasitology, (44) 565-577, 2014.

BARTHOLOMEW J. L.; LOTAN T. Myxozoan polar display structural and functional variation. Parasit Vectores, (9) 549, 2010.

BARTHOLOMEW, J. L.; WHIPPLE, M. J.; STEVENS, D. G.; FRYER J. L. The life cycle of Ceratomyxa shasta, a myxosporean parasite of salmonids, requires a freshwater polychaete as an alternate host. Journal of Parasitology, (83) 859-868, 1997.

BARASSA, B.; ADRIANO, E. A.; CORDEIRO, N. S.; ARANA, S.; CECCARELli, P. S. Morphology and host - parasite interaction of Henneguya azevedoi n. sp., parasite of gills of Leporinus obtusidens from Mogi Guaçu River, Brazil. Parasitology Research, (110)887-894, 2012.

BERMÚdEZ, R.; LOSADA, A. P.; VÁZQUEZ, S.; REDONDO, M. J.; ÁlVAREZPELLITERO, P.; QUIROGA, M. I. Light and electron microscopic studies on turbot Psetta 
maxima infected with Enteromyxum scophthalmi: histopathology of turbot enteromyxosis. Diseases of Aquatic Organisms, (89) 209-221, 2010.

BÉKÉSI, L.; SZÉKELY, C.; MOLNÁR, K. Atuais conhecimentos sobre Myxosporea (Myxozoa), parasitas de peixes. Um estágio alternativo dos parasitas no Brasil. Brazilian Journal Veterinary Research Animal Science, (39) 271-276, 2002.

BOHMANN, K.; EVAN, A.; GILBERT, M. T.; CARVALHO, G. R.; CREER, S.; KNAPP, M.; YU, D.W.; BRUYN, M. Environmental DNA for wildlife biology and biodiversity monitoring. Trends in Ecology \& Evolution, (29) 358-367, 2014.

BRABO, M. F.; SOARES, L. F. P.; SANTANA, J. V. M.; CAMPELO, D. A. V.; VERAS, G. C. Cenário atual da produção de pescado no mundo, no Brasil e no estado do Pará: ênfase na aquicultura. Acta of Fisheries and Aquatic Resources, (4) 50-58, 2016.

BEM-DAVID, J.; ATKINSON, S. D.; POLLAK, Y.; YOSSIFON, G.; SHAVIT, U.; BARTHOLOMEW, J. L.; LOTAN, T. Myxozoan polar tubules display structural and functional variation. Parasites \& Vectors, (9) 549, 2016.

BUCKUP, P.A.; MENEZES, N. A.; GHAZZI, M. S. Catálogo das espécies de peixes de água doce do Brasil. Rio Janeiro, Museu Nacional, 195, 2007.

CANNING, E. U.; OKAMURA, B. Biodiversity and evolution of the Myxozoa. Advances in Parasitology, (56) 43-131, 2004.

CARRIERO, M. M.; ADRIANO, E. A.; SILVA, M. R. M.; CECCARELlI, P. S.; MAIA, A. A. M. (2013). Molecular phylogeny of the Myxobolus and Henneguya genera with several new South American species. PLoS ONE, (8) 9, 2013.

CARRIERO, M. M. Taxonomia e filogenia molecular de Myxozoa parasitas de peixes de água doce oriundos de ambiente natural e de sistema de criação. Dissertação de Mestrado, Faculdade de Zootecnia e Engenharia de Alimentos, Universidade de São Paulo, 2011.

CAPODIFOGLIO K. R. H.; ADRIANO, E. A.; SILVA, M. R. M.; MAIA, A. A. M. The resolution of the taxonomic dilemma of Myxobolus colossomatis and description of two novel myxosporeans species of Colossoma macropomum from Amazon basin. Acta Tropica, (191) $17-23,2019$.

CAPODIFOGLIO, K. R. H.; ADRIANO, E. A; MILANIN, T.; MAIA, A. A. M. Morphological, ultrastructural and phylogenetic analyses of Myxobolus hilarii n. sp. (Myxozoa, 
Myxosporea), a renal parasite of farmed Brycon hilarii in Brazil. Parasitology International, (65) 184-190, 2016.

CAPODIFOGliO, K. R. H.; ADRIANO, E. A.; SILVA, M. R. S.; MAIA, A. A. M. Supplementary data of Henneguya leporinicola (Myxozoa, Myxosporea) a parasite of Leporinus macrocephalus from fish farms in the state of São Paulo, Brazil. Acta Parasitologica, (60) 451-458, 2015.

CASTAGNOLLI, N. Criação de peixes de água doce. Jaboticabal: FUNEP, 189, 1992.

CHANG, E. S.; NEUHOF, M.; RUBINSTEIN, N. D.; DIAMANT, A.; PHILIPPE, H.; HUCHON, D.; CARTWRIGHT, P. Genomic insights into the evolutionary origin of Myxozoa within Cnidaria. Proceedings of the National Academy of Sciences, (112) 14912-17, 2015.

CHEN, W.; YANG, C.; WHIPPS, C.M.; PENG, Z. Taxonomy on three novel species of Sphaeromyxa Thélohan 1892 (Myxozoa, Bivalvulida, Sphaeromyxidae) with insight into the evolution of the genus. Parasitology Research, (37), 2020.

COELHO, A. M. C. Padronização da técnica de reação em cadeia da polimerase com transcrição reversa em tempo real para quantificação dos vírus quiméricos FA17D/DEN1, 2, 3, 4 candidatos a vacina tetravalente contra a dengue. Dissertação de Mestrado Profissional em Tecnologia de Imunobiológicos. Fundação Oswaldo Cruz, Instituto de Tecnologia em Imunobiológicos, 2013.

COMBES, C. When is a parasite pathogen? Metazoan parasitic dis-eases: concluding remarks. Pathology in Marine Science. Academic Press Inc. Publisher, 331-340, 1990.

CRISCIONE, C. D.; POULIN, R.; BLOUIN, M.S. Molecular ecology of parasites: elucidating ecological and microevolutionary processes. Molecular Ecology, (14) 2247-2257, 2005.

EICHMILLER, J. J.; MILLER, L. M.; SORENSEN, P. W. Optimizing techniques to capture and extract environmental DNA for detection and quantification of fish. Molecular Ecology Resources.,(16) 56-68, 2016.

EIRAS, J. C.; LIMA, J. T.; CRUZ, C. F.; SARAIVA, A. A note on the infection of Scomberomorus brasiliensis (Osteichthyes, Scombridae) by Kudoa sp. (Myxozoa: Multivalvulida). Brazilian Journal of Biology, (74) 164-166, 2014.

EIRAS, J. C.; ADRIANO, E. A. Checklist of the species of the genus Henneguya Thélohan, 1892 (Myxozoa, Myxosporea, Myxobolidae) described beteween 2002 and 2012. Systematic Parasitology, (83) 95-104, 2012. 
EIRAS, J. C.; MONTEIRO, C. M.; BRASIL-SATO, M. C. Myxobolus franciscoi sp. nov. (Myxozoa: Myxosporea: Myxobolidae), a parasite of Prochilodus argenteus (Actinopterygii: Prochilodontidae) from the Upper São Francisco River, Brazil, with a revision of Myxobolus spp. from South America. Zoologia, (27) 131-137, 2010.

EIRAS, J. C.; TAKEMOTO, R. M.; PAVANELli, G. C.. Henneguya corruscans n. sp. (Myxozoa, Myxosporea, Myxobolidae), a parasite of Pseudoplatystoma corruscans (Osteichthyes, Pimelodidae) from the Paraná River, Brazil: a morphological and morphometric study. Veterinary Parasitology, (159) 154-158, 2009.

EIRAS, J. C. K.; MOLNÁR, Y. S. Synopsis of the species of Myxobolus Bütschli, 1882 (Myxozoa: Myxosporea: Myxobolidae). Systematic Parasitology, (61) 1-46, 2005.

EIRAS, J. C.; MALTA, J.;C.; VARELA, A.; PAVANELLI, G. C. Henneguya schizodon n. sp. (Myxozoa, Myxobolidae), a parasite of the Amazonian teleost fish Schizodon fasciatus (Characiformes, Anostomidae). Parasite, (11) 169-173, 2004.

EIRAS, J. C. Synopsis of species of the genus Henneguya Thelohan, 1892 (Myxozoa: Myxosporea: Myxobolidae. BMC Evolutionary Biology, (8) 139, 2002.

EL-MATBOULI, M.; HOFFMANN, R. W. Light and electron microscopic studies on the chronological development of Myxobolus cerebralis to the actinosporean stage in Tubifex tubifex. International Journal for Parasitolpgy, (28) 195-217, 1998.

EL-MATBOULI, M.; HOFFMANN, R. W.; MANDOK, C. Light and electron microscopic observations on the route of the triactinomyxon-sporoplasm of Myxobolus cerebralis from epidermis into rainbow trout cartilage. Journal of Fish Biology, (46) 919-935, 1995.

EVANS, N.; LINDNER, A.; RAIKOVA, E. V.; COLlinS, A. G.; CARTWRIGHT, P. Phylogenetic placement of the enigmatic parasite, Polypodium hydriforme, within the phylum Cnidaria. BMC Evolutionary Biology, (8) 139, 2008.

FAO - Food and Agriculture Organization of the United Nations - FAO Fisheries and Aquaculture Department, Roma, 1997

FAO - Food and Agriculture Organization of the United Nations - FAO Fisheries and Aquaculture Department, Roma, 2014

FAO - Food and Agriculture Organization of the United Nations - FAO Fisheries and Aquaculture Department, Roma, 2016. 
FENG, J. M.; XIONG, J.; ZHANG, J. Y.; YANG, Y. L.; YAO, B.; ZHOU, Z. G.; MIAO, W. New phylogenomic and comparative analyses provide corroborating evidence that Myxozoa is Cnidaria. Molecular Phylogenetics and Evolution, (81) 10-18, 2014.

FEIJÓ, M. M.; ARANA, S.; CECCARELLI, P. S.; ADRIANO, E. A. Light and scanning electron microscopy of Henneguya arapaima n. sp. (Myxozoa: Myxobolidae) and histology of infected sites in pirarucu (Arapaima gigas: Pisces: Arapaimidae) from the Araguaia River, Brazil. Veterinary Parasitology, (157) 59-64, 2008.

FEIST, S. W.; LONGSHAW, M. Phylum Myxozoa. In: WOO, P. T. K. Fish diseases and disorders: Protozoan and Metazoan infections. CAB International, Reino Unido, (2) 230296, 2006.

FIALA, I.; BARTOŠOVÁ-SOJKOVÁ, P.; OKAMURA, B.; HARTIKAINEN, H. Adaptive radiation and evolution within the Myxozoa. In: Okamura B, Gruhl A, Bartholomew JL (eds) Myxozoan evolution, ecology and development. Springer International Publishing, Cham, 6984, 2015.

FIALA, I.; BARTOŠOVÁ-SOJKOVÁ, P. History of myxozoan character evolution on the basis of rDNA and EF-2 data. BMC Evolutionary Biology, (10) 228, 2010.

FIALA, I. The phylogeny of Myxosporea (Myxozoa) based on small subunit ribosomal RNA gene analysis. International Journal for Parasitology, (36) 1521-1534, 2006.

FICETOLA, G. F.; MIAUD, C., POMPANON, F., TABERLET, P. Species detection using environmental DNA from water samples. Biology Letters, (4) 423-425, 2008.

FIGUEIREDO, H. C. P.; LEAL, C. A. G. Tecnologias aplicadas em sanidade de peixes. Revista Brasileira de Zootecnia, (37) 8-14, 2008.

FLEURANCE, R.; SAUVEGRAIN, C.; MARQUES, A.; LE BRETON, A.; GUEREAUD, C.; CHEREL, Y.; WYERS, M. Histopathological changes caused by Enteromyxum leei infection in farmed sea bream Sparus aurata. Diseases of Aquatic Organisms, (79) 219-228, 2008.

FONTES, A.; NIKOLIK, G.; RASMUSSEN, R.; IKEDA, V. Finding nemo: turning Brazil's economic turmoil into seafood business opportunities. Food \& Agribusiness Research and Advisory, 8, 2016.

FOOTT J. S.; STONE, R.; WISEMAN, E.; TRUE, K.; NICHOLS, K. Longevity of Ceratomyxa shasta and Parvicapsula mini - bicornis actinospore infectivity in the Klamath River. Journal of Aquatic Animal Health, (19) 77-83, 2007. 
GOMES, G.; HUTSON, K.; DOMINGOS, J.; CHUNG, C.; HAYWARD, S.; MILLER, T.; JERRY, D. Use of environmental DNA (eDNA) and water quality data to predict protozoan parasites outbreaks in fish farms. Aquaculture, (479) 467-473, 2017.

GOLDBERG, C. S.; STRICKLER, K. M.; PILlIOD, D. S. Moving environmentalDNA methods from concept to practice for monitoring aquaticmacroorganisms. Biological Conservation, (183) 1-3, 2015.

GRIFFIN, M. J.; POTE, L. M.; CAMUS, A. C.; MAUEL, M. J.; GREENWAY, T. E.; WISE, D. J. Application of a real-time PCR assay for the detection of Henneguya ictaluri in commercial channel catfish ponds. Diases of Aquatic Organisms, (86) 223-233, 2009.

GRIFFIN, M. J.; WISE, D. J.; CAMUS, A. C.; MANUEL, M. J.; GREENWAY, T. E.; POTE, L. M. A real-time polymerase chain reaction assay for the detection of the myxozoan parasite Henneguya ictaluri in channel catfish. Journal of Veterinary Diagnostic Investigation, (20) 559-566, 2008.

HALLET, S. L.; BARTHOLOMEW J. L. Myxobolus cerebralis and Ceratomyxa shasta. Fish Parasites: Pathobiology and Protection. CAB International , 2012.

HALLET, S. L., BARTHOLOMEW, J. L. Application of a real-time PCR assay to detect quatify the myxozoan parasite Ceratomyxa shasta in water samples. Diseases of Aquatic Organisms, (71) 109-118, 2006.

HALWART, M.; SOTO, D.; ARTHUR, J. R. Cage Aquaculture - Regional reviews and global overview. FAO Fisheries Technical Paper, Rome, (498) 241, 2007.

HARTIKAINEN, H.; GRUHL, A.; OKAMURA, B. Diversification and repeated morphological transitions in endoparasitic cnidarians (Myxozoa: Malacosporea). Molecular Phylogenetics and Evolution, (76) 261-269, 2014.

HASS, D. J; TORRES, A. C. D. Aplicações das técnicas de PCR no diagnóstico de doenças infecciosas dos animais. Revista Científica de Medicina Veterinária, (26), 2016.

HILLIS, D. M.; DIXON, M. T. Ribosomal DNA: molecular evolution and phylogenetic inference. The Quarterly Review of Biology, (66) 411-453, 1991.

HOFMANN, M.; GRIOT, C.; CHAIGNAT, V.; PERLER, L.; THÜR, B. Bluetongue disease reaches Switzerland. Schweizer Archiv für Tierheilkunde, (150) 49-56, 2008. 
HUNG, Y. W.; REMAIS, J. Quantitative detection of Schisto soma japonicum cercariae in water by real-time PCR. PLOS Neglected Tropical Diseases, (2) 337, 2008.

IKONOMOPOULOS, J.; KOKOTAS, S.; GAZOULI, M.; ZAVRAS, A.; STOITSIOU, M.; GORFOULIS, V.G. Molecular diagnosis of leishmaniosis in dogs: comparative application of traditional diagnostic methods and the proposed assay on clinical samples. Veterinary Parasitology, (113) 99-113, 2003.

ISHIMARU, K.; MATSUURA, T.; TSENEMOTO, K.; SHIRAKASHI, S. Seasonal monitoring of Kudoa yasunagai from sea water and aquaculture water using quantitative PCR. Diseases of Aquatic Organisms, (108) 45-52, 2014.

JIMÉNEZ-GURI, E.; PHILIPPE, H.; OKAMURA, K.; HOLLAND, P. W. H. Buddenbrockia is a cnidarian worm. Science, (317) 116-118, 2007.

JOHNSON, S. C. A review of the Impact of parasitic Copepods on marine aquaculture. Zoological Studies, (43) 229-243, 2004.

KELlEY, G.; ZAGMUTT, F.; LEUTENEGGER, C.; MYKLEBUST, K.; ADKISON, M.; MCDOWELL, T.; MARTY, G.; KAHLER, A.; BUSH, A.; GARDNER, I.; HEDRICK, R. Evaluation of Five Diagnostic Methods for the Detection and Quantification of Myxobolus cerebralis. Journal of veterinary diagnostic investigation : official publication of the American Association of Veterinary Laboratory Diagnosticians, (16) 202-211, 2004.

KODADKOVA, A.; BARTOŠOVA-SOJKOVA, P.; HOLZER, A. S.; FIALA, I. Bipteria vetusta $\mathrm{n}$. sp.-an old parasite in an old host: tracing the origin of myxosporean. International jornal for Parasitology, (45) 269-276, 2015.

KUBITZA, F. Panorama da Aquicultura: Tilápia. Panorama da Aquicultura, (10), 31-53, 2000 .

LOM, J.; DYKOVÁ, I. Myxozoan genera: definition and notes on taxonomy, life-cycle terminology and pathogenic species. Folia Parasitologica, (53) 1-36, 2006.

LONGSHAW, M.; LE DEUFF, R. M.; HARRIS, A. F.; FEIST, S. W. Development of proliferative kidney disease in rainbow trout, Oncorhynchus mykiss (Walbaum), following short-term exposure to Tetracapsula bryosalmonae infected bryozoans. Journal of Fish Diseases, (25), 443-449, 2002. 
LUQUE, J. L. Biologia, epidemiologia e controle de parasitos de peixes. In: XIII Congresso Brasileiro de Parasitologia Veterinária. Ouro Preto. Revista Brasileira de Parasitologia Veterinária, (13) 161-165, 2004.

MARKIW, M. E.; WOLF, K. Myxosoma cerebralis (Myxozoa: Myxosporea) etiologic agent of salmonid whirling disease requires tubificid worm (Annelida: Oligochaeta) in its life cycle. The Jounal of Protozoolozoology, (30) 561-564, 1983.

MARTINS, M. L.; SOUZA, V. N. Henneguya piaractus n. sp. (Myxozoa: Myxobolidae), a gill parasite of Piaractus mesopotamicus Holmberg, 1887 (Osteichthyes: Characidae), in Brazil. Revista Brasileira de Biologia, (57) 239-245, 1997.

MARTINS M. L. Pathology and behavioural efects associated with Henneguya sp. (Myxozoa: Myxobolidae) infections of captive pacu Piaractus mesopotamicus in Brazil. Journal of the World Aquaculture Society, (28) 297-300, 1997.

MATHEWS, P. D.; NALDONI, J.; MAIA, A. A. M.; ADRIANO, E. A. Morphology and small subunit rDNA-based phylogeny of Ceratomyxa amazonensis n. sp. parasite of Symphysodon discus, an ornamental freshwater fish from Amazon. Parasitology Research, (115) 4021-4025, 2016.

MERINO G.; BARANGE, M.; BLANCHARD, J. L.; HARLE, J.; HOLMES, R.; ALLEN, I.; et al. Can marine fisheries and aquaculture meet fish demand from a growing human population in a changing climate? Global Environmental Change, (22) 795- 806, 2012.

MILANIN, T.; MATHEWS, P. D.; MERTINS, O.; TAVARES, L. E. R.; SILVA, M. R. M.; MAIA, A. A. M. Molecular phylogeny of the gill parasite Henneguya (Myxosporea: Myxobolidae) infecting Astyanax lacustris (Teleostei: Characidae) from fish farm in Brazil. Microbial pathogenesis, (123) 372-376, 2018a.

MILANIN, T.; ATKINSON, S. D.; SILVA, M. R. M.; ALVES, R. G.; TAVARES, L. E. R.; RIBEIRO, A. M.; MAIA, A. A. M. Occurrence of two novel actinospore types (Cnidaria: Myxozoa) in fish farms in Mato Grosso do Sul state, Brazil. Parasitology Research, (117) 1757-1764, 2018b.

MILANIN, T.; ATKINSON, S. D.; SIlVA, M. R.; ALVES, R. G.; MAIA, A. M. A.; ADRIANO, E. A. Occurrence of two novel actinospore types (Cnidaria: Myxosporea) in Brazilian fish farms, and the creation of a novel actinospore collective group, Seisactinomyxon. Acta Parasitologica, (62) 121-128, 2017. 
MILANIN, T.; MAIA, A. A. M.; SILVA, M. R.; CARRIERO, M. M.; ADRIANO, E. A. Molecular phylogeny and ultrastructure of Myxobolus $c f$. cuneus, a parasite of patinga hybrid and Henneguya pseudoplatystoma, a parasite of pintado hybrid. Acta Parasitologica, (60) 442450, 2015a.

MILANIN, T. Mixosporídeos em oligoquetas (actinosporo) e em peixes (mixosporos) de pisciculturas dos estados de São Paulo e Mato Grosso do Sul, Brasil. Tese de Doutorado, Universidade Estadual de Campinas. São Paulo Brasil, p.108, 2015 b.

MILANIN, T.; EIRAS, J. C.; ARANA, S.; MAIA, A. M. A; ALVES, A. L.; SILVA, M. R. M., CARRIERO, M. M.; CECCARELli, P. S.; ADRIANO, E. A. Phylogeny, ultrastructure, histopathology and prevalence of Myxobolus oliveirai sp. nov., a parasite of Brycon hilarii (Characidae) in the Pantanal wetland, Brazil. Memórias do Instituto Oswaldo Cruz, (105) 762-769, 2010.

MILLER, T. L.; BARNETT, S. K.; SEYMOUR, J. E.; JENKINS, T.P.; MCNAMARA, M.; ADLARD, R. D. Biliary tract-infecting Myxosporeans from estuarine and reef stonefish (Scorpaeniformes: Synanceiidae) off eastern Australia, with descriptions of Sphaeromyxa horrida n. sp. and Myxidium lapipiscis n. sp. (Myxosporea: Bivalvulida). Journal Parasitol, (104) 254-261, 2018.

MOLNÁR, K.; RANZANI-PAIVA, M. J.; EIRAS, J. C.; RODRIGUES, E. L. Myxobolus macroplasmodialis sp. nov. (Myxozoa: Myxosporea), a parasite of the abdominal cavity of the Characid teleost, Salminus maxillosus, in Brazil. Acta Protozoologica, (37) 241-245, 1998.

MOLINA, A. L.; TOBO, P. R. Série Biologia Molecular Parte 2- Uso das Técnicas de biologia molecular para diagnóstico. Hospital Israelita Albert Einstein. São Paulo-SP, 2004.

MOREIRA G. S. A.; ADRIANO, E. A.; SILVA, M. R.; CECCARELli, P.; MAIA, A. A. The morphological and molecular characterization of Henneguya rotunda $\mathrm{n}$. sp., a parasite of the gill arch and fins of Salminus brasiliensis from the Mogi Guaçu River, Brazil. Parasitology Research, (113) 1703-1711, 2014.

MPA - Ministério da Pesca e Aquicultura. Boletim estatístico da pesca e aquicultura. Brasília, Brasil, 128, 2012.

NALDONI, J.; ZATTI, S. A.; SILVA, M. R. M.; MAIA, A. M. A.; ADRIANO, E. A. Morphological, ultrastructural, and phylogenetic analysis of two novel Myxobolus species 
(Cnidaria: Myxosporea) parasitizing bryconid fish from São Francisco River, Brazil. Parasitology International, 1-10, 2019.

NALDONI, J.; MAIA, A. M. A.; CORREA, L. L.; SILVA, M. R. M.; ADRIANO, E. A. Two new myxosporean species paratising Phractocephalus hemioliopterus from the Brazilian Amazon: morphology, ultrastructure and SSU-rDNA sequencing. Diseases of aquatic organisms, (128) 37-49, 2018.

NALDONI, J.; ZATTI, S.A.; CAPODIFOGLIO, K.R.H.; MILANIN, T.; MAIA, A.M.A.; SILVA, M.R.M.; ADRIANO, E.A. Host-parasite and phylogenetic relationships of Myxobolus filamentum sp. n. (Myxozoa: Myxosporea), a parasite of Brycon orthotaenia (Characiformes: Bryconidae) in Brazil. Folia Parasitologica, (62), 2015.

NALDONI, J.; MAIA, A. M. A.; SILVA, M. R. M.; ADRIANO, E. A. Henneguya cuniculator sp. nov., a parasite of spotted sorubim Pseudoplatystoma corruscans in the São Francisco Basin, Brazil. Diseases of Aquatic Organisms, (107) 211-221, 2014.

NALDONI, J.; ARANA, S.; MAIA, A. A.; SILVA, M. R.; CARRIERO, M. M.; CECCARElli, P. S.; TAVARES, L. E.; ADRIANO, E. A. Host-parasite-environment relationship, morphology and molecular analyses of Henneguya eirasi n. sp. parasite of two wild Pseudoplatystoma spp. in Pantanal Wetland, Brazil. Veterinary Parasitology, (177) 247$255,2011$.

NALDONI, J.; ARANA, S.; MAIA, A. A. M.; CECCARELLI, P. S.; TAVARES, L. E. R.; BORGES, F. A.; POZO, C. F.; ADRIANO, E. A., Henneguya pseudoplatystoma n. sp. causing reduction in epithelial area of gills in the farmed pintado, a South American catfish: Histopathology and ultrastructure, Veterinary Parasitology, (166) 52-59, 2009.

NESNIDAL, M. P.; HELMKAMPF, M.; BRUCHHAUS, I.; EL-MATBOULI, M.; HAUSDORF, B. New phylogenomic data support the monophyly of Lophophorata and an Ectoproct-Phoronid clade and indicate that Polyzoa and Kryptrochozoa are caused by systematic bias. BMC Evolutionary Biology, (13) 253, 2013.

NICKLAS, J. A.; BUEL, E. Development of na Alu*based, real-time PCR method for quantitation of human DNA in forenses samples. Journal of Forensis Sciences, (48), 936-944, 2003.

NOVAIS, C. M.; PIRES-ALVES, M. PCR em tempo real. Revista Biotecnologia Ciências e Desenvolvimento, (33) 10-13, 2004. 
ONO, E. A.; KUBITZA, F. Cultivo de peixes em tanques-rede. Embrapa Amazônica Ocidental, (2), 68, 1999.

OLIVEIRA, T. M. PCR em tempo real: métodos e aplicação. Universidade de Aveio. Departamento de Biologia. 2010.

OKAMURA, B.; HARTIGAN, A.; NALDONI, J. Extensive uncharted biodiversity: the parasite dimension. Integrative Comparative. Biology, (58) 1132-1145, 2018.

OKAMURA, B.; GRUHL, A.; BARTHOLOMEW, J. L. An introduction to myxozoan evolution, ecology and development. In Myxozoan Evolution, Ecology and Development. Springer International Publishing, 1-22, 2015a.

OKAMURA, B.; GRUH, A.; BARTHOLOMEW, J. L. Myxozoan Evolution, Ecology and Development. Springer Cham Heidelberg New York Dordrecht London, (1) 23-139, 2015b.

OKAMURA, B.; FEIST S. W. Emerging diseases in freshwater systems. Freshw Biol, (56) $627-637,2011$.

POTE, L.M.; HANSON, L. A.; SHIVAJI, R. Small subunit rRNA sequences link proliferative gill disease in channel catfish to Henneguya ictaluri n. sp. (Myxozoa: Myxosporea). Journal of Aquatic Animal Health, (12) 230-240, 2000.

RICHEY, C.; KENELTY, K.; VAN, K.; HOPKINS, S.; STEVENS, B.; MARTINEZ-LOPEZ, B.; HALlETT, S. ATKINSON, S.; BARTHOLOMEW, J.; SOTO, E. Validation of environmental DNA sampling for determination of Ceratonova shasta (Cnidaria: Myxozoa) distribution in Plumas National Forest, CA. Parasitology Research, (119) 2020.

ROBERTS, R. J. The Bacteriology of Teleosts. In: Roberts, R.J. Fish Pathology, (4) 339-382, 2012.

ROBSON, H.; NOBLE, T.; SAUNDERS, R.; ROBSON, S.; BURROWS, D.; JERRY, D. Finetuning for the tropics: Application of eDNA technology for invasive fish detection in tropical freshwater ecosystems. Molecular ecology resources, (16) 922-932, 2016.

RÜCKERT, S.; PALM, H.W.; KLIMPEL, S. Parasite fauna of seabass (Lates calcarifer) under mariculture conditions in Lampung Bay, Indonesia. Journal of Applied Ichthyology, (24) 321-327, 2008. 
SAIKI, R. K.; GELFAND, D. H.; STOFFEL, S.; SCHARF, S. J., HIGUCHI, R.; HORN, G. T.; MULLIS, K. B., ERLICH, H. A. Primer - direct enzymatic amplification of de DNA with thermostable DNA polymerase. Science, (239) 487-491, 1985.

SCHAEFER, S.A. Conflict and resolution: impact of new taxa on Phylogenetic studies of the Neotropical cascudinhos (Siluroidei: Loricariidae). Phylogeny and classification of Neotropical fishes, (603) 375-400, 1998.

SCHULTER, E. P.; VIEIRA FILHO, J. Desenvolvimento e potencial da tilapicultura no Brasil. Instituto de Pesquisa Econômica Aplicada - IPEA, (16) 177-201, 2018.

SCHULTER, E. P.; VIEIRA FILHO, J. Evolução da piscicultura no Brasil: diagnóstico e desenvolvimento da cadeia produtiva de tilápia. Rio de Janeiro. Instituto de Pesquisa Econômica Aplicada - IPEA, (42), 2017.

SCORVO FILHO, J. D. Panorama da Aquicultura Nacional. htto://ftp.sp.gov.br/ftppesca/panorama_aquicultura.pdf (Acessado em Nov. 2019).

SUTHERLAND, W. J.; SPIEGELHALTER, D.; BURGMAN, M. A. Policy: twenty tips for interpreting scientific claims. Nature, (503) 335-337, 2013.

STRAND, D. A.; JUSSILA, J.; JOHNSEN, S. I.; VILIJAMAA-DIRKS, S. Detection of crayfish plague spores in large freshwater systems. Journal of Applied Ecology, (51) 544-553, 2014.

TABERLET P.; COISSAC, E.; POMPSNON, F.; BROCHMANN, C.; WILLERSLEV, E. Towards next-generation biodiversity assessment using DNA metabarcoding. Molecular Ecology, (21) 2045-2050, 2012.

TURNER, C.; BARNES, M. A.; XU, C.Y.; JONES, S. E.; JERDE, C. L.; LODGE, D. M. Particle size distribution and optimal capture of aqueous macrobial eDNA. Thomsen PF, Willerslev E Environmental DNA-an emerging tool. Methods in Ecology and Evolution, (7), 2015.

THOMSEN, P.F; WILLERSLEV, E. Environmental DNA an emerging tool in conservation for monitoring past and presente biodiversity. Biological Conservation, (183) 4-18, 2015.

WHIPPS, C. M.; MURRAY, K. N.; KENT, M. L. Occurrence of a Myxozoan parasite Myxidium streisingeri n. sp. in Laboratory Zebrafish Danio rerio. Journal of Parasitology, (101) 86-90, 2015. 
WOLF, K.; MARKIW, M. E. Biology con travenes taxonomy in the Myxozoa: new dis coveries show alternation of invertebrate and vertebrate hosts. Science, (225) 1449-1452, 1984.

YOKOYAMA, H. Transmission of Thelohanellus hovorkai Achmerov, 1960 (Myxosporea: Myxozoa) to common carp Cyprinus carpio through the alternate oligochaete host. Systematic Parasitology, (36)79-84, 1997.

ZATTI, S. A.; ATKINSOM, S. D.; MAIA, A. M.; BARTHOLOMEW, J. L; ADRIANO, E. A. Ceratomyxa gracillima n. sp. (Cnidaria: Myxosporea) provides evidence of panmixia and ceratomyxid radiation in the Amazon basin. Parasitology, 1-10, $2018 \mathrm{a}$.

ZATTI, S. A.; ATKINSOM, S. D.; MAIA, A. M.; BARTHOLOMEW, J. L.; ADRIANO, E. A. Novel Henneguya spp. (Cnidaria: Myxozoa) from cichilid sish in the Amazon basin cluster by geographic origin. Parasitology Research, 1-11, 2018b.

ZATTI, S. A.; ATKINSON, S. D.; BARTHOLOMEW, J. L.; MAIA, A. A. M.; ADRIANO, E. A. Ceratomyxa gracillima n. sp. (Cnidaria: Myxosporea) provides evidence of panmixia and ceratomyxid radiation in the Amazon basin. Parasitology, 2017a.

ZATTI, S. A.; ATKINSON, S. D.; BARTHOLOMEW, J. L.; MAIA, A. A. M.; ADRIANO, E. A. Amazonian waters harbour an ancient freshwater Ceratomyxa lineage (Cnidaria: Myxosporea). Acta Tropica, (169) 100- 106, $2017 \mathrm{~b}$.

ZATTI, S. A.; ARANA, S.; MAIA, A. A.; ADRIANO, E. A. Ultrastructural, ssrDNA sequencing of Myxobolus prochilodus and Myxobolus porofilus and details of the interaction with the host Prochilodus lineatus.Parasitology Research, (115) 4573-4585, 2016. 